\title{
A Method for Documenting the Goals and KPIs of Accelerators and Startups
}

\section{by}

André Cavalcanti

A thesis submitted to the Faculty of Graduate and Postdoctoral Affairs in partial fulfillment of the requirements for the degree of Master of Applied Science in Technology Innovation Management

Carleton University

Ottawa, Ontario

(C) 2018 Andre Cavalcanti 


\begin{abstract}
Decision makers in accelerators and startups need to understand how their businesses are currently performing. A comparison between business goals, performance indicators and market benchmarks are a problem for both sides. The central question that accelerators and their associated startups face is what Key Performance Indicators (KPI) they should measure to know whether they achieved their business goals?
\end{abstract}

This thesis proposes the use of goal-oriented modelling as a technique to identify the goals that accelerators and startups pursue and the corresponding KPIs. Its contribution is threefold: it introduces a method for documenting the goals and KPIs of accelerators and their associated startups, conducts an empirical demonstration of the method, and documents an initial goal model that provides a basis for further research. The results are relevant to managers of accelerators and startups as well as entrepreneurship researchers. 


\section{Acknowledgements}

I wish to thank my supervisor Dr. Michael Weiss for his valuable inputs, counselling, time, and the encouragement that pushed me further to the end line of this thesis.

I would also like to express my gratitude to Mr. Ludovico Prattico, who guiding me to define the strategy of my field research, and the professors of the TIM program, specially Prof. Steven Muegge, who provided their time and knowledge to improve the quality of this research. Furthermore, I am grateful to all companies' leaders that open its doors for this research.

Finally, and the most important, I would like to express my most profound gratitude to my parents and my son Vitor Hugo who is the inspiration that motivates me to wake up and fight every day, in order to give him a better future.

Therefore, it is to them that I dedicate this work. 


\section{Table of Contents}

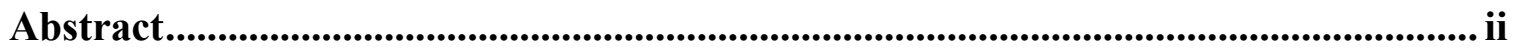



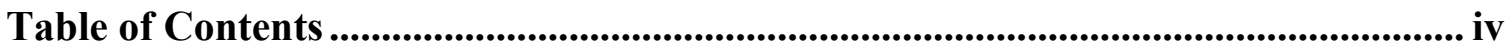



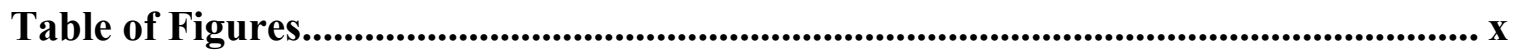



1 Chapter: Introduction ........................................................................................... 1



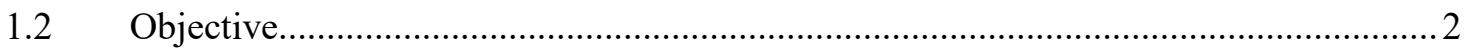



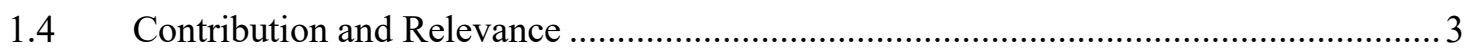

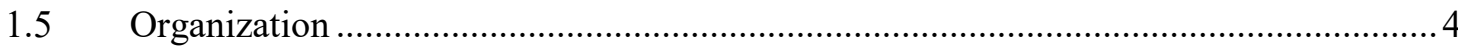

2 Chapter: Literature Review....................................................................................................... 6

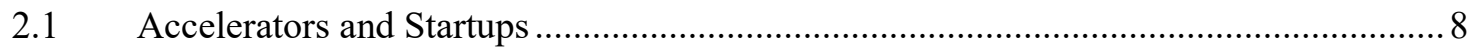

2.1.1 Synergy Between Accelerators and Associated Startups ...................................... 10

2.1.2 Adoption of Metrics in Accelerators and Startups .............................................. 13

2.2 Key Performance Indicators and the Balanced Scorecard....................................... 18

2.2.1 Application of Balanced Scorecard to Startups......................................................20

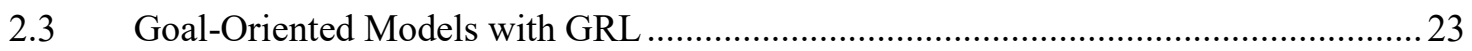


2.3.1 The Goal-Oriented Requirement Language (GRL).

2.3.2 Goal-Oriented Notation and jUCMNav .26

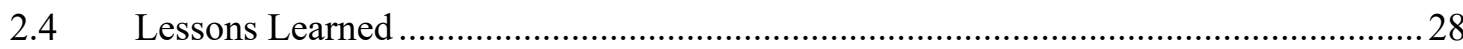

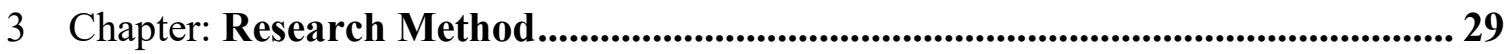

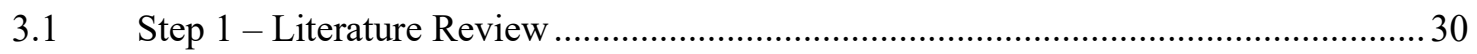

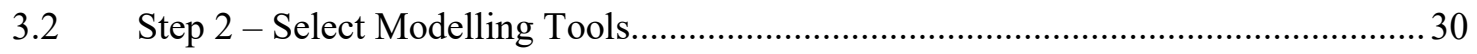

3.3 Step 3 - Select Sample and Design Interview Guidelines .......................................... 33

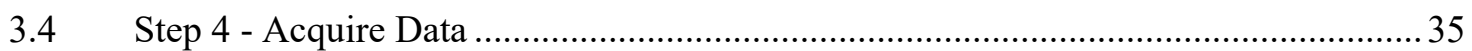

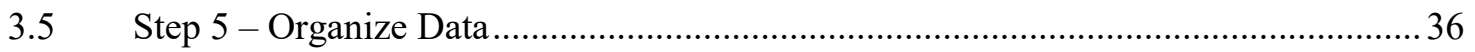

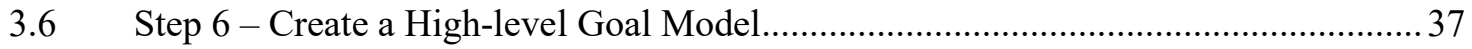

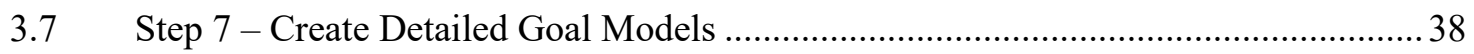

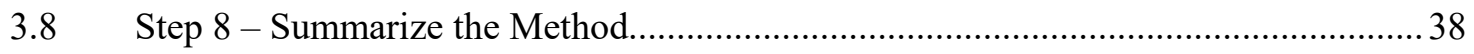

4 Chapter: Results ............................................................................................................... 40

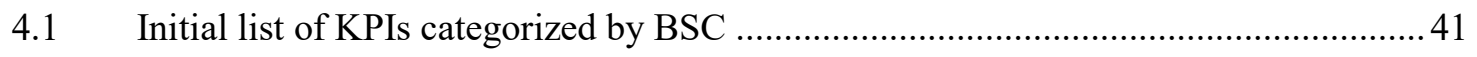



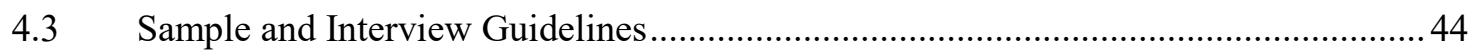





4.5.1 Importance Ratings for the Accelerator ............................................................... 48 
4.5.2 Importance Ratings for the Startup in the Commercialization Stage

4.5.3 Importance Ratings for the Startup in the Growth Stage .50

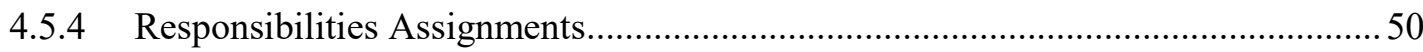

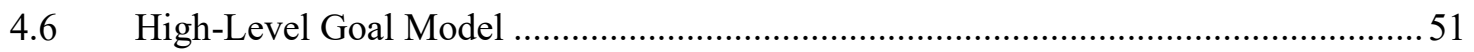



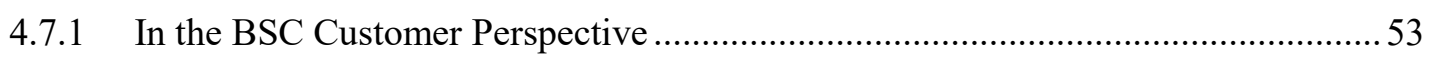

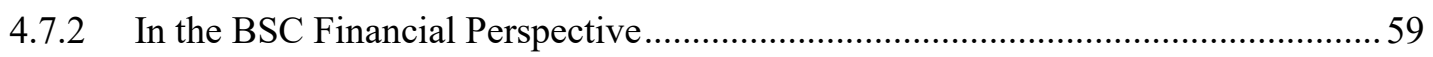

4.7.3 In the BSC Internal Business Process Perspective ................................................63

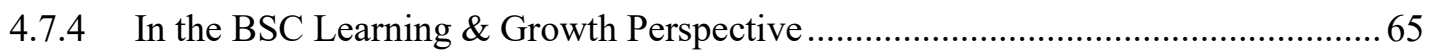

5 Chapter: Discussion ............................................................................................................ 70

6 Chapter: Conclusion, Limitation and Future Research ...................................... 77



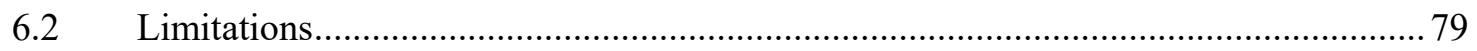





Appendices..................................................................................................................................... 90

Appendix A - Performance Indicators Description......................................................... 90

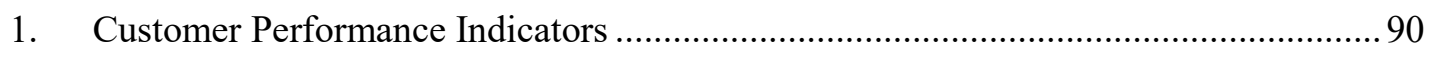

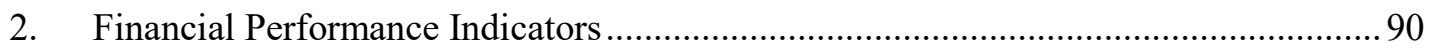

3. Internal Business Process Performance Indicators ................................................ 91 
4. Learning \& Growth Performance Indicators

Appendix B - Data .94

1. Soft Goals - Importance.

a. Accelerator Point of View .95

b. Startup 1 (Commercialization) Point of View .96

c. Startup 2 (Growth) Point of View

d. Accelerator + Startup 1 (Commercialization) Point of View .98

e. Accelerator + Startup 2 (Growth) Point of View .99

f. Accelerator + Startup 1 (Commercialization) + Startup 2 (Growth) Point of View... 100

2. Soft Goals - Responsibility. 101

a. Accelerator Point of View.... 102

b. Startup 1 (Commercialization) Point of View ......

c. Startup 2 (Growth) Point of View 103

d. Accelerator + Startup 1 (Commercialization) Point of View 104

e. Accelerator + Startup 2 (Commercialization) Point of View 105

Appendix C - Interview design ..... 107

1. Interview Design 107 


\section{List of Tables}

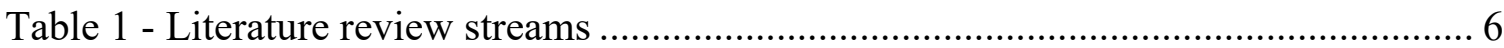

Table 2 - Small Companies in Canada (2016) ............................................................... 8

Table 3 - Distinctions between incubators and accelerators ........................................ 10

Table 4 - Short and Long-term Metrics for Accelerators and their Startup Firms .......... 15

Table 5 - Accelerators KPIs suggested by Vinaixa Vergés (2017) ............................... 16

Table 6 - The 75 KPIs Every Manager Needs to Know (Marr, 2012)........................... 17

Table 7 - Number of Metrics, Frequency and Report Designation ................................ 19

Table 8 - Trends of performance measurements throughout the startup stages of



Table 9 - Requirements Engineering and Business Jargons ........................................ 23

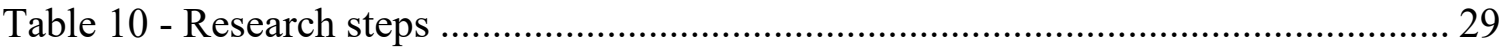

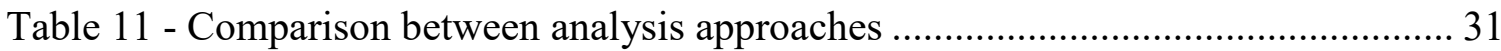

Table 12 - RACI Roles and Responsibilities Definitions (Smith \& Erwin, 2005) ........... 33

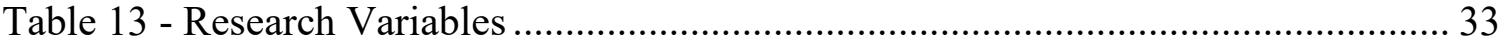

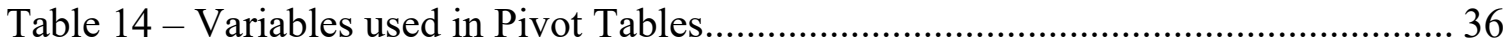

Table 15 - Qualitative Importance of GRL Elements ................................................. 38

Table 16 - List of important KPIs according to Marr (2012), Camacho (2015) and 
Vinaixa Vergés (2017), categorized by Balanced Scorecard perspectives.

Table 17 - Selected Tools

Table 18 - Summary of the interview's attendees

Table 19 - Overall Importance Ratings by BSC Perspectives 46

Table 20 - Goals 53

Table 21 - Adapted RACI Matrix 50

Table 22 - Totals of Soft goals and Performance Indicators per Organization 70

Table 23 - Performance Indicators per Organization 71

Table 24 - Dependencies Between the Accelerator and Associated Startups.................. 74 


\section{Table of Figures}

Figure 1 - Accelerator's Services

Figure 2 - Investment instruments 12

Figure 3 - Types of Performance Indicators ...................................................... 18

Figure 4 - Balanced Scorecard Perspectives ........................................................... 21

Figure 5 - Example of GRL for a Startup in Research and Product Development Stage. 23

Figure 6 - Basic Elements of GRL Notation in jUCMNav ......................................... 26

Figure 7 - Accelerator and Startups Relationship .................................................... 35

Figure 8 - Overall importance of Soft Goals by BSC Perspectives .............................. 52

Figure 9 - Goals: Increase the Customer Satisfaction, Engagement, and Develop a

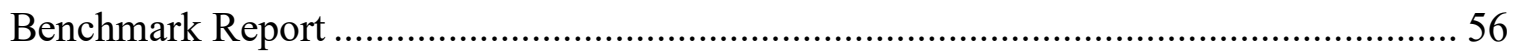

Figure 10 - Goal: Increase Customer Profitability .................................................... 57

Figure 11 - Goal: Increase Revenue Through Partner........................................... 58

Figure 12 - Goal: Increase Revenue, Profit, Margin, and Financial Control ................... 60

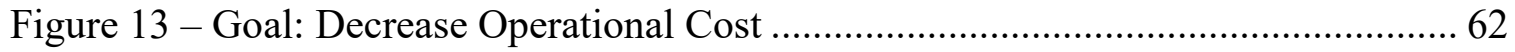

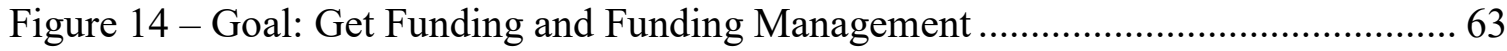

Figure 15 - Goals: Increase Product and Services Performance ................................. 65

Figure 16 - Goal: Innovation enhancement - Accelerator + Startup $1+$ Startup 2 ....... 67 
Figure 17 - Goal: Education and training - Accelerator + Startup 1

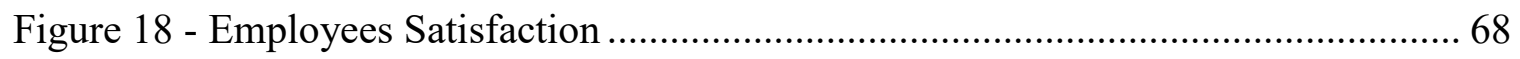

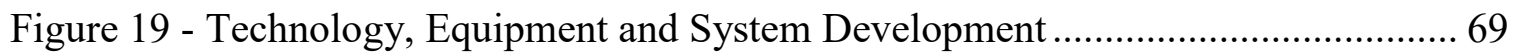




\section{List of Acronyms}

$\begin{array}{ll}\text { Acronym } & \text { Definition } \\ \text { BAI } & \text { Business Accelerators and Incubators } \\ \text { BPM } & \text { Business Process Management } \\ \text { BPMN } & \text { Business Process Modelling Notation } \\ \text { BPMS } & \text { Business Process Management System } \\ \text { BSC } & \text { Balanced Scorecard } \\ \text { EMF } & \text { Eclipse Modelling Framework } \\ \text { EVA } & \text { Earned Value Analysis } \\ \text { GDP } & \text { Gross Domestic Product } \\ \text { GRL } & \text { Goal-oriented Requirement Language } \\ \text { HGF } & \text { High Growth Firms } \\ \text { jUCMNav } & \text { Java Use Case Models Navigator } \\ \text { KPIs } & \text { Key Performance Indicators } \\ \text { KRIs } & \text { Key Result Indicators } \\ \text { OSS } & \text { Open Source Software } \\ \text { PI } & \text { Performance Indicators } \\ \text { S.M.A.R.T. } & \text { Specific, Measurable, Attainable, Realistic, and Timely } \\ \text { SME } & \text { Small and Medium Enterprises } \\ \text { UCM } & \text { Use Case Map } \\ \text { URN } & \text { User Requirements Notation } \\ & \end{array}$




\section{Chapter: Introduction}

\subsection{Overview}

Decision makers in accelerators and startups need to understand how their businesses are currently performing. A comparison between business goals, performance indicators, market benchmarks and official government statistics is a problem for both sides. The central question that accelerators and their associated startups face is what Key Performance Indicators (KPI) they should measure to know whether they achieved their business goals. There is no clear alignment between the metrics that accelerators and startups measure, and to fill this gap, the thesis proposes a method for documenting the goals and KPIs of accelerators and their associated startups.

It is exciting when a goal is achieved, isn't it? However, there is a journey to go from a business goal accomplishment to its KPI measurement. Define relevant performance management measurements have been challenging companies (Ates, Garengo, Cocca, \& Bititci, 2013), and use of the Balanced Scorecard can help organization's leaders to translate their strategy into goals and objectives that consequently can improve the firm's performance (Andersen, Cobbold, \& Lawrie, 2009).

The method combines ideas from goal-oriented modelling, in the form of the GoalOriented Requirement Language (GRL), and the Balanced Scorecard approach. The Goal-Oriented Requirement Language (GRL) allows a researcher to model actors, their goals and the relationships between them (Weiss \& Amyot, 2005a). It can also model KPIs and how they measure the achievement of goals (Pourshahid, 2013). The classification adopted for this research is based on The Balanced Scorecard (BSC) which 
has been used by companies to measure performance and to help process improvements. According to its creators (Kaplan \& Norton, 1993), BSC has the Customer, Financial, Internal Business Process and Learning \& Growth perspective, and to better understand the importance of each one of the four BSC perspectives, 26 soft goals were created, connecting 90 of the most important KPIs according to Marr (2012), Carvalho (2016) and Vinaixa Vergés (2017).

In summary, it is suggested a method supported by a GRL modelling tool, combining goals and key performance indicators classified according to the Balanced Scorecard perspectives.

\subsection{Objective}

The main objective of this thesis is to identify the KPIs that accelerators and startups must measure. A secondary goal is to examine the interdependencies for collecting KPIs between accelerators and startups.

\subsection{Deliverables}

From the objective, we developed two research questions:

- RQ1: What Goals and Performance indicators are essential for accelerators' and startups' strategies?

- RQ2: What are the interdependencies between goals and performance indicators on accelerators and their associated startups?

This thesis has three deliverables:

(1) A method, detailing the data acquisition, the process to organize the collected 
information, modelling Goals and KPIs and apply the model.

(2) A set of goal-oriented models, describing the correlation of goals and KPIs between accelerators and startups.

(3) Answers to two research questions

\subsection{Contribution and Relevance}

The research contributes to the management knowledge in accelerators and startups, providing a process to design their strategic objectives.

The contributions of this thesis are:

- Align KPIs of Accelerators and startups

- Mapping interdependencies and responsibilities in accelerators and startups to achieve goals

- A method for doing so.

The research intends to be relevant for accelerators and startup's managers, and academia.

Contributions for accelerators and startups' managers:

- A method designed to permits an easy way to identify goals and KPIs in accelerators and startups

- A Goal-oriented approach to identify goals and KPIs.

- A method for documenting the goals and KPIs of accelerators and their associated startups 
- An empirical demonstration of the method

- Initial observations of startups in idea, commercialization and growth maturity stage.

- A general list of performance indicators

Contributions for academia:

- Balanced Scorecard and KPI adoption by startups

- A literature contribution with the knowledge of Goals and KPIs application in startups and accelerators.

- An application of goal-oriented modelling to accelerators and startups at different growth stages

- An initial goal model that provides a basis for further research

- A contribution for researches who want to compare business' goals of two or more companies

\subsection{Organization}

This thesis is organized into five chapters as described below:

The chapter two reviews the literature, providing pieces of evidence regarding the synergy between accelerators and startups, the use of Goal Requirement Language (GRL), and its notations to support a Goal-oriented model. Furthermore, an explanation about the variables and the classification used to categorize KPIs, based on Balanced Scorecard has been done in this chapter.

Chapter three describes the research method steps, clarifying it for this study and 
summarizing the method to be applied in accelerators and startups.

Chapter four shows the results of this research. After identifying the Goals and KPIs, goal-oriented models were designed in jUCMNav. Based on that, the theory has been constructed, and the GOAL to KPI method was described.

Chapter five answers the research questions.

The chapter six, "Conclusion, Limitations and Future Research," synthesizes the main points of the study, edging the limitations and make recommendations for further researches in the same study field. 


\section{Chapter: Literature Review}

Chapter 2 is organized into four sections. Section 2.1 provides evidences of the importance of accelerators and startups in the actual business scenario and introduces the accelerators and startups synergy. Section 2.2 addresses the motivation factors for the adoption of Balanced Scorecard and KPIs in Accelerators and Startups. The section 2.3 explains what Goal-oriented requirement language is, its notation and why use it to model goals and KPIs. Section 2.4 summarizes the lessons learned.

\begin{tabular}{|c|c|c|c|}
\hline No. & Stream & Rationale & Literature \\
\hline 1 & $\begin{array}{l}\text { Accelerators } \\
\text { and Startups }\end{array}$ & $\begin{array}{l}\text { - Evidence of the importance of } \\
\text { accelerators and startups in the } \\
\text { actual business scenario } \\
\text { - Introduces the business synergy of } \\
\text { accelerators and startups } \\
\text { - The adoption of performance } \\
\text { indicators by accelerators and } \\
\text { startups }\end{array}$ & $\begin{array}{l}\text { Camacho (2015) } \\
\text { Cohen (2013) } \\
\text { Government of Canada } \\
(2016) \\
\text { Hogg, }(2016) \\
\text { Isabelle (2013) } \\
\text { Keogh, Mulvie, \& Cooper } \\
(2005) \\
\text { Kohler (2016) } \\
\text { Torun (2016) } \\
\text { Von Bueren (2016) }\end{array}$ \\
\hline 2 & $\begin{array}{l}\text { Balanced Scorecard } \\
\text { and Key Performance } \\
\text { Indicators Theory }\end{array}$ & $\begin{array}{l}\text { - Key performance indicators theory } \\
\text { at a glance } \\
\text { - The adoption of Balanced Scorecard } \\
\text { in Startups }\end{array}$ & $\begin{array}{l}\text { Kaplan \& Norton (1993) } \\
\text { Llorach \& Ottosson (2016) } \\
\text { Marr (2012) } \\
\text { Parmenter (2015) }\end{array}$ \\
\hline 3 & $\begin{array}{l}\text { Goal-Oriented } \\
\text { models with GRL }\end{array}$ & $\begin{array}{l}\text { - Modelling business goals with a } \\
\text { GRL approach. } \\
\text { - The Goal-oriented requirement } \\
\text { language (GRL) }\end{array}$ & $\begin{array}{l}\text { Amyot et al. (2013) } \\
\text { Bochman (2010) } \\
\text { Van Lamsweerde (2000) } \\
\text { Weiss \& Amyot (2005) }\end{array}$ \\
\hline
\end{tabular}

To clarify their objectives and achieve business goals, accelerators and startups should work in synchronicity. Thus, the first stream of the literature review intends to contextualize the relationship between accelerators and startups and the issues they are facing. Camacho (2015) and Isabelle (2013) provides evidences of the economic 
importance of accelerators and startups in the actual business scenario. Furthermore, Official statistics of the Government of Canada (2016) were studied to understand the SMEs's scenario in the country. Cohen (2013), Kohler (2016), Von Bueren (2016) and Torun (2016) listed the differences of accelerators and incubators, in terms of services and startups' support, introducing the concept of accelerators and startups' synergy. Hogg (2016) defends that accelerators should identify KPIs in early-stage, highlighting the needs of governance and finally, Keogh, Mulvie, \& Cooper (2005) explored the lack of resources faced by startups, intensifying the perception that startups need financial support to growth and the necessity of low-cost solutions in its management.

In the Balanced Scorecards and Key Performance Indicators Theory stream, a theory of performance indicators and the most important KPIs were described by Parmenter (2007) and Marr (2012). Moreover, Kaplan \& Norton (1996) the creators of the Balanced Scorecard were cited in this thesis as a pillar for future adoption of BSC in small companies, reinforced by Llorach \& Ottosson (2016) opinion.

In the Goal-Oriented models with GRL stream, Amyot et al. (2013) was cited to explain the use of jUCMNav, software": as co-author of the GRL standard and creator of the jUCMNav software used in the method proposed in this thesis. The modelling process is a must to understand the importance of soft goals, goals and KPIs (Weiss \& Amyot, 2005a). Additionally, Bochman (2010) and van Lamsweerde (2000) provided definitions that clarifies requirement engineering jargons and business jargon, transposing the jUCMNav's terms to common business language.

The following sections briefly review each research stream, and the final section is a summary and synthesis of the lessons salient to this research. 


\subsection{Accelerators and Startups}

Technology entrepreneurship has a conjunction of factors, actors, partnerships, and business networks (Camacho, 2015), evolving to an ecosystem where might be almost impossible for a new venture to succeed with its resources, isolated from the stakeholders around the company (Isabelle, 2013). Fortunately, the number of accelerators' programs has been growing dramatically, supporting new ventures to access resources and partners which they do not have access to itself (Camacho, 2015),

Camacho (2015) and Isabelle (2013) also believes that technology entrepreneurship is an essential factor in economic development, bringing disruptive technologies, creating new jobs and improving markets in competitiveness.

Official statistics in Canada (Government of Canada, 2016) reports that $97.9 \%$ of the companies in the country are small and medium enterprises (SME). More than 581,000 are classified as micro-business, with one to four employees. The Table 2 - Small Companies in Canada (2016) is showing the percentage of employees in small companies, reinforcing the importance of SMEs in the Canadian economy.

\begin{tabular}{l|l|r}
$\begin{array}{l}\text { Table 2 - Small Companies in Canada (2016) } \\
\text { Companies Size }\end{array}$ & Number of Employees & \% \\
\hline \multirow{4}{*}{ Small } & 1 to 4 employees & 54.1 \\
\cline { 2 - 3 } & 5 to 9 employees & 19.4 \\
\cline { 2 - 3 } & 10 to 19 employees & 12.7 \\
\cline { 2 - 3 } & 20 to 49 employees & 8.9 \\
\cline { 2 - 3 } & 50 to 99 employees & 2.8 \\
\hline Total & & 97.9 \\
\hline
\end{tabular}

Furthermore, micro-businesses are responsible for an average of $30 \%$ of Provincials 
Gross Domestic Product (GDP) and employ 632,000 professionals.

The same report shows that the maximum growth rate based on small company's incomes between 2010 and 2013 was 11.7\% with an average rate of 7.4\% in HGF - High Growth Firms (Government of Canada, 2016). In summary, a low percentage of small companies achieve the goal to be an HGF.

A lack of credit history in startups to fund operations (Government of Canada, 2016) or training employees (Keogh et al., 2005) is a critical negative root factor. The majority of startups' entrepreneurs used personal savings to finance their business ( $80 \%$ ), a percentage of them got credit from financial institutions (45\%), and 19\% of entrepreneurs also received trade credit from suppliers (Government of Canada, 2016). Fortunately, the Canadian government's incentives and support for new ventures' creation, coupled with the growing number of accelerator programs, are struggling with the lack of access to resources by entrepreneurs, and need low-cost solutions to implement the company goals.

In the academia, studies have been done to distinguish accelerators from business incubators (Bøllingtoft \& Ulhøi, 2005); (Hoffman \& Radojevich-Kelley, 2012); (Isabelle, 2013). They affirm that both incubators and accelerators are companies formed with highly experienced professionals that provide mentoring, coaching, office space and sometimes financial support for projects, to improve the chances of success in startups. Main differences between Accelerators and Incubators were described by several authors (Carvalho, 2016; Cohen, 2013; Dempwolf, Auer, \& D'Ippolito, 2014; Isabelle, 2013; Torun, 2016). Accelerators usually are profit-oriented companies, funding startups in exchange of equity stake in the company, usually provides meeting rooms instead of an office to install the startup company, and do not have the geographical range to act, 
working in global, national or regional investment opportunities. The Table 3

distinguishes the approach of incubators and accelerators regarding their governance (Isabelle, 2013; Kohler, 2016; Von Bueren, 2016).

Table 3 - Distinctions between incubators and accelerators

\begin{tabular}{l|l}
\multicolumn{1}{c|}{ Incubator } & \multicolumn{1}{c}{ Accelerator } \\
\hline For an idea to an early-stage company & For startups and early stage \\
\hline Focus on founders & A focus on small teams \\
\hline Long-term process & Short term process \\
\hline Long time to market & Short time to market \\
\hline An institution & A program within an institution \\
\hline Building sustainability firms & Short-term horizon, cohort-based \\
\hline More focus on economic development & More focused on growth and ROI \\
\hline Generally not-for-profit & Generally for-profit \\
\hline Older establishments & Newer establishments or programs \\
\hline
\end{tabular}

\subsubsection{Synergy Between Accelerators and Associated Startups}

For-profit business owners usually think about the sales and profit margins. The primary objectives of startups are literally the same: sell and develop their products/services, increase the operational efficiency, generate a reasonable profit, get returns on their investments, and avoid risks (Seens, 2015). Besides that, time is a crucial factor to achieve the company financial objectives because businesses depend on their revenue to survive, pay employees' salaries and expand and grow the business. Intrinsically related to profitability is a high-productively operation (Seens, 2015). 
From the business accelerator perspective, as a for-profit company and venture partner, the return of investment is a relevant factor to invest in a startup. However, to achieve this state, the accelerator must provide a pathway that startups grow fast, speeding up its

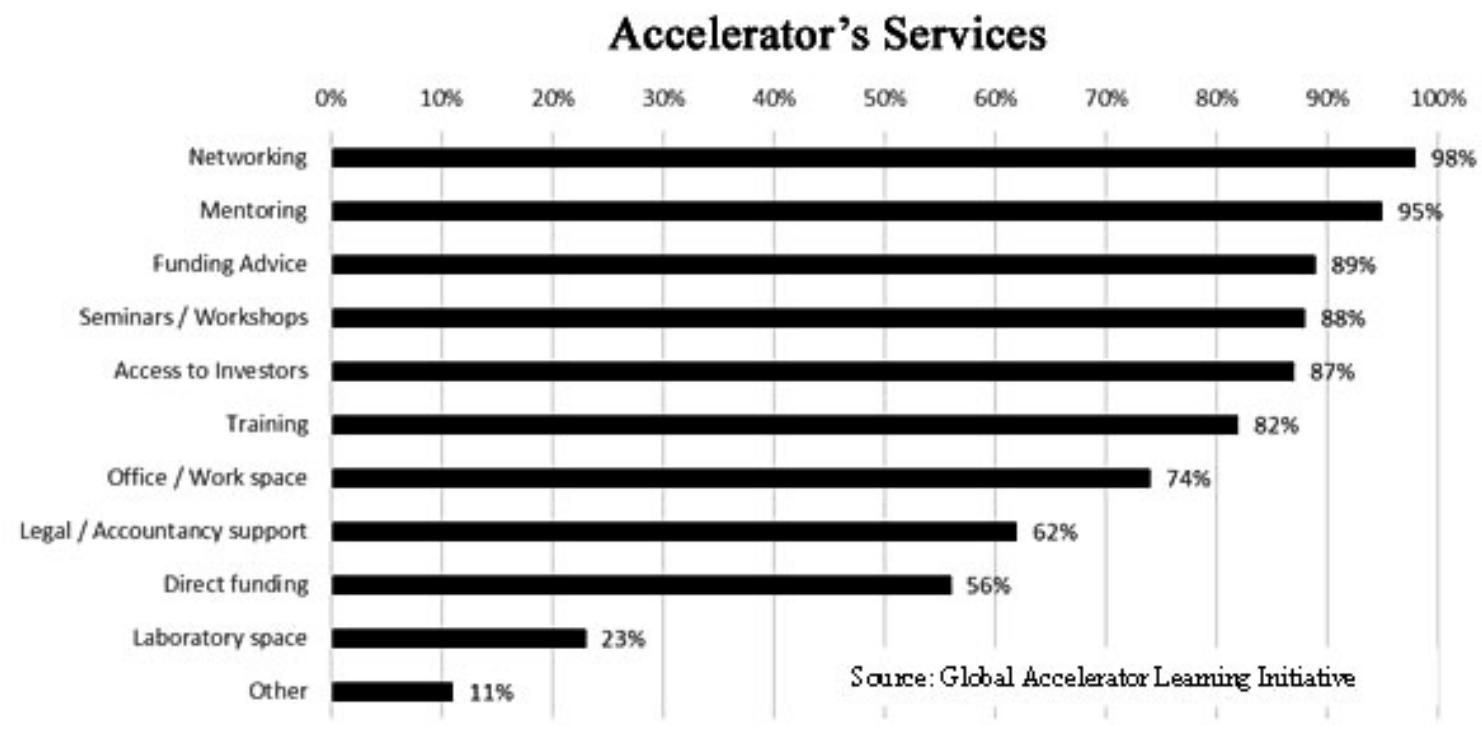

Figure 1 - Accelerator's Services

network, and supporting them with intensive mentorship and advice during the accelerator program (Cohen, 2013). Roberts and Kempner (Roberts \& Kempner, 2017) also agree that accelerators still have an essential role to play that can help position entrepreneurs for success. Accelerators would prefer early-stage or startup companies in their portfolio, according to GALI reports (https:/www.galidata.org/accelerators/). Von Bueren (2016) said, and I quote: “As an aspiring entrepreneur, I find it difficult to compare the value-added and performance of accelerator programs, not to mention which accelerator to choose for my potential startup", reinforcing the doubts of entrepreneurs to attend an acceleration program. The figure 1 is reporting the most common services provided by accelerators in their cohort programs. 
On the business side, a startup owner might understand the company momentum, and based on that define the best approach, deciding to incubate or accelerate the company. At a glance, the entrepreneur should define if an accelerating program is fitted to their company improvement and if the company has an appetite to concede an equity stake to an investor. For further information about accelerator programs, NESTA developed a complete guide that explains how an accelerator operates (NESTA Innovation Skills Team, 2014). Common investment instruments were identified in the relationship

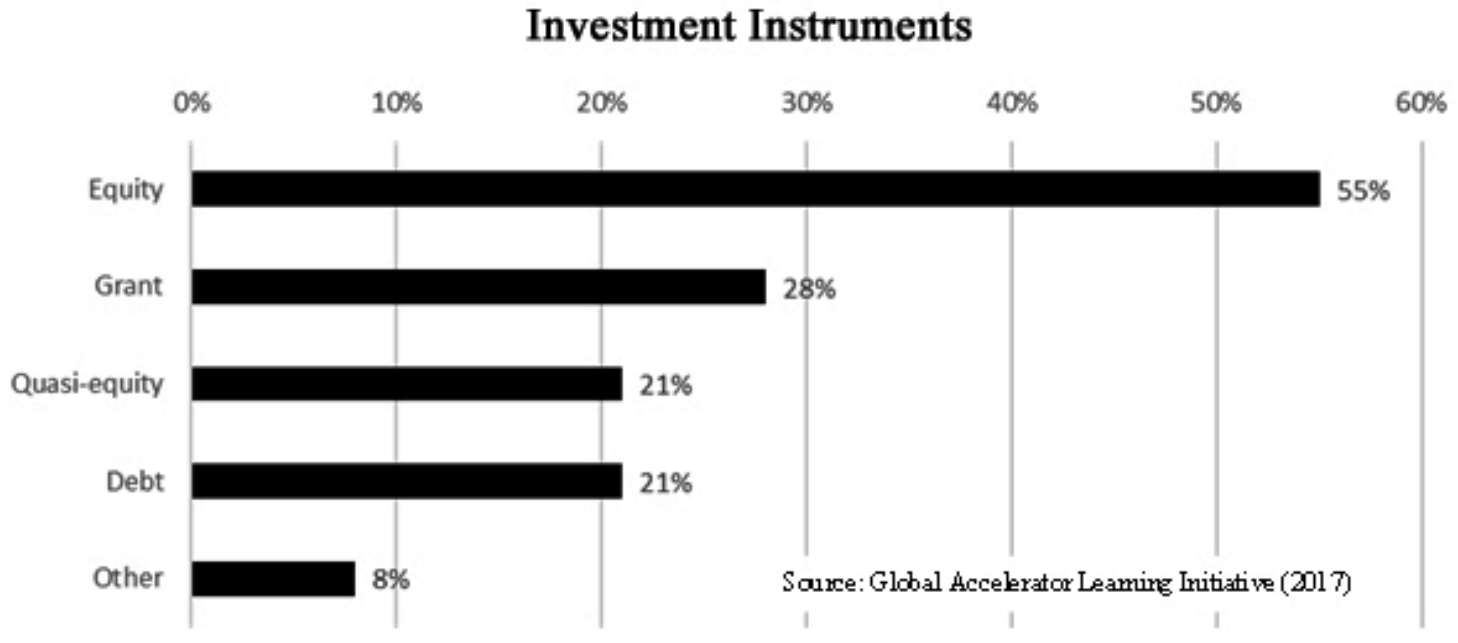

Figure 2 - Investment instruments between accelerators and associated startups. They have been described in the figure 2 .

On the top of that, the Government of Canada recurrently evaluates the SME's scenario as an essential participant in economic growth and job creation needs (Seens, 2015). The Canadian Government must support new ventures in their financial and operational, and in counterpart, accelerators should follow official statistics as a benchmark, comparing those official results with their performance indicators. Moreover, collect and compare the right KPIs from their fellow startups can be a mechanism to improve the processes and drive their business goals to the right path. 


\subsubsection{Adoption of Metrics in Accelerators and Startups}

An essential part of governance and management in accelerators is to follow specific metrics, evaluating internal and external results. It is necessary to improve processes, correct issues and measure performance over time. For that reason, it is recommended that accelerators use performance indicators to track the measurements that companies aim to follow (Carvalho, 2016).

A measurement must be attached to a goal, otherwise is going to be a waste of time (Croll \& Yoskovitz, 2013). They also affirm that a good metric changes the way you behave. Accountancy metrics might facilitate predictions and customer metrics can change the startup's business drive. However, early-stage startups typically rely on production and sales revenues (Maurya, 2016). Accounting metrics, as revenue, profit, and ROI, aren't helpful at the early stages (Maurya, 2016).

On the other hand, a Forbes article (Ehrenberg, 2014) defends the use of few KPIs for startups in early stages: Sales Metrics, to understand how sales are developing over time, to preview and make forecast, picks up seasonality and other patterns, and also define the pricing strategy. Furthermore, Custom Acquisition Cost (CAC) indicator should be a good way to monitor sales performance. (Ehrenberg, 2014).

Under a venture capitalist point of view, the most important metrics to evaluate an earlystage startup might be financial, user, acquisition, sales, and marketing (DorantesGonzalez, 2017).

To summarize, the main issue is how to define the right performance indicators for the stakeholders, accelerators and if it is fitted or not to affiliated startups. More than twenty- 
one thousands of KPIs were identified (KPI Institute, n.d.) and it is technically impossible to define a pattern to be used in all market segments, company sizes, with diverse objectives and business goals. A KPI set might be done as a tailor-made task, in order to identify a specific set for each company. This study is providing a method to address it, serving as a starter set of KPIs that can be used as a benchmark.

It was undoubtedly noticed that companies are focused on financial and customer KPIs. Nevertheless, other categories of KPIs should be evaluated, especially in a long-term business relationship between accelerators and startups. To facilitate the adoption of performance measurement in companies, Parmenter (2007) encourage the use of a KPI / balanced scorecard approach. Hogg (2016) believes that accelerators should identify KPIs with their early-stage, helping founders to focus on a few core metrics that matter in their industry. It should be a starting point to develop a process that would be useful to manage and monitor KPIs.

A committee to discuss a pattern of KPIs to be used in accelerators and incubators is working in Ottawa region, and this thesis can contribute with this effort, creating a framework to be used in further experiments. The Business Accelerators and Incubators (BAI) are discussing how the government, entrepreneurs, investors and industry how to be able to establish a national performance measurement framework, in order to standardize the BAIs reports. According to the BAI committee (Government of Canada, 2017), the main benefits to get a KPI standard are to increase transparency in reports, improve the analysis of economic impacts and collaboration between stakeholders, reduce the learning curve to measure and implement KPIs in companies and administrative efforts, and reinforcing the marketing appeal of Canada as a country that 
seriously invests in entrepreneurship (Government of Canada, 2017). Additionally, a standard set of KPIs might be useful to identify the performance of accelerators and startups, getting a better understanding of the progress and the business movements.

Carvalho (2016) suggested that accelerators and startups might develop two distinct KPI set. The first one to be applied in short-term, after the cohort program duration, and the second for a long-term, in order to keep the records to follow the companies' improvements. The metrics for accelerators and startups described by him (Carvalho, 2016) are summarized in the Table 4 - Short and Long-term Metrics for Accelerators and their Startup Firms.

Table 4 - Short and Long-term Metrics for Accelerators and their Startup Firms

\begin{tabular}{|c|c|c|}
\hline Time Horizon & Accelerator metrics & Startup metrics \\
\hline $\begin{array}{l}\text { Short-term (program } \\
\text { duration plus } 6 \text { months) }\end{array}$ & $\begin{array}{l}\text { - Number of applicants } \\
\text { - Number of participants (cohort } \\
\text { size) } \\
\text { - Number of investors at Demo Day } \\
\text { - Percentage receiving next-stage } \\
\text { funding } \\
\text { - Percentage acquired } \\
\text { - Percentage failed }\end{array}$ & $\begin{array}{l}\text { - Operational status (operating, } \\
\text { closed, acquired) } \\
\text { - Number of financial investments or } \\
\text { number of investors } \\
\text { - Size of financial investments } \\
\text { - Number of customers gained }\end{array}$ \\
\hline $\begin{array}{l}\text { Long-term } \\
\text { (expected cash out } \\
\text { in } 3 \text { to } 7 \text { years) }\end{array}$ & $\begin{array}{l}\text { - } \quad \text { Sources of funding } \\
\text { - } \quad \text { Performance distribution } \\
\text { - The internal rate of return } \\
\text { - Network metrics (partnerships } \\
\text { created and others) }\end{array}$ & $\begin{array}{l}\text { - Sales or revenue } \\
\text { - Number of employees } \\
\text { - The rate of return to investors } \\
\text { - Stock prices (if applicable) }\end{array}$ \\
\hline
\end{tabular}

Other authors believe in a standard set of KPIs commonly used in accelerators previously researched by them. As an example, Vinaixa Vergés (2017) compiled other authors and made a list of KPIs to be applied in accelerators management, as you can see in the Table 5: 
Table 5 - Accelerators KPIs suggested by Vinaixa Vergés (2017)

\begin{tabular}{|c|c|}
\hline KPI & Description \\
\hline Burn rate & $\begin{array}{l}\text { This KPI is the negative cash flow of a company. It determines } \\
\text { how much money startups need to operate and grow. }\end{array}$ \\
\hline Runway & $\begin{array}{l}\text { Linked to the burn rate, this measures how much time the } \\
\text { company has until it runs out of cash }\end{array}$ \\
\hline Activation rate & $\begin{array}{l}\text { This metric measured the first experience of any potential } \\
\text { customer. It can be measured in several forms, such as through } \\
\text { returning visitors and time on websites, among others. }\end{array}$ \\
\hline $\begin{array}{l}\text { Ratio of daily active users (DAU) } \\
\text { to monthly active users (MAU): }\end{array}$ & $\begin{array}{l}\text { Ratio of daily active users (DAU) to monthly active users (MAU): } \\
\text { This ratio measures how many different users or customers there } \\
\text { may be within a given time window. }\end{array}$ \\
\hline Customer churn rate & This is the percentage of customers lost in a given time \\
\hline Revenue growth rate & It marks the percentage increase in revenue on a monthly basis \\
\hline Customer acquisition cost (CAC) & $\begin{array}{l}\text { It is the amount spent on marketing, sales, or anything else to } \\
\text { acquire one new customer. }\end{array}$ \\
\hline Customer retention rate & $\begin{array}{l}\text { This is the number of customers that repeated their experience } \\
\text { during a given period. }\end{array}$ \\
\hline Lifetime value (LTV) & $\begin{array}{l}\text { It measures how much net value the average customer will bring } \\
\text { to the company during the relationship }\end{array}$ \\
\hline Ratio of CAC to LTV & $\begin{array}{l}\text { Considered one of the most important metrics, this measures the } \\
\text { sustainability of a company. It is measured based on the extent to } \\
\text { which the percentage of the total value brought by a client is spent } \\
\text { in acquiring another client. }\end{array}$ \\
\hline CAC recovery time & $\begin{array}{l}\text { This measure how much time one may need to break even the } \\
\text { investment in acquiring one new customer. }\end{array}$ \\
\hline Overhead & This is a measure of the fixed expenses of the company. \\
\hline Profit margin & $\begin{array}{l}\text { It is the difference between the sale price of one product and its } \\
\text { costs. }\end{array}$ \\
\hline Conversion rate & $\begin{array}{l}\text { This measures the ability of companies to sell products to its } \\
\text { customers and their desire to acquire the company's products. }\end{array}$ \\
\hline $\begin{array}{l}\text { Gross merchandise volume } \\
\text { (GMV): }\end{array}$ & $\begin{array}{l}\text { It is the overall value of the goods or services sold and purchased } \\
\text { through a marketplace. }\end{array}$ \\
\hline
\end{tabular}

.

A set of 75 performance indicators was created by Marr (2012), encompassing customer, financial, marketing, operational, human resources and environmental and social sustainability, with a non-specific industry approach. Marr (2012), detailed the 
most important KPIs for managers, and they are listed and categorized in the Table 6.

Table 6 - The 75 KPIs Every Manager Needs to Know (Marr, 2012)

\begin{tabular}{|c|c|c|}
\hline $\begin{array}{l}\text { To measure financial } \\
\text { performance }\end{array}$ & To understand your customers & $\begin{array}{l}\text { To gauge your market and } \\
\text { marketing efforts }\end{array}$ \\
\hline $\begin{array}{l}\text { 1. Net Profit } \\
\text { 2. Net Profit Margin } \\
\text { 3. Gross Profit Margin } \\
\text { 4. Operating Profit Margin } \\
\text { 5. EBITDA } \\
\text { 6. Revenue Growth Rate } \\
\text { 7. Total Shareholder Return (TSR) } \\
\text { 8. Economic Value Added (EVA) } \\
\text { 9. Return on Investment (ROI) } \\
\text { 10. Return on Capital Employed } \\
\text { (ROCE) } \\
\text { 11. Return on Assets (ROA) } \\
\text { 12. Return on Equity (ROE) } \\
\text { 13. Debt-to-Equity (D/E) Ratio } \\
\text { 14. Cash Conversion Cycle (CCC) } \\
\text { 15. Working Capital Ratio } \\
\text { 16. Operating Expense Ratio (OER) } \\
\text { 17. CAPEX to Sales Ratio } \\
\text { 18. Price Earnings Ratio (P/E } \\
\text { Ratio) }\end{array}$ & $\begin{array}{l}\text { 19. Net Promoter Score (NPS) } \\
\text { 20. Customer Retention Rate } \\
\text { 21. Customer Satisfaction Index } \\
\text { 22. Customer Profitability Score } \\
\text { 23. Customer Lifetime Value } \\
\text { 24. Customer Turnover Rate } \\
\text { 25. Customer Engagement } \\
\text { 26. Customer Complaints }\end{array}$ & $\begin{array}{l}\text { 27. Market Growth Rate } \\
\text { 28. Market Share } \\
\text { 29. Brand Equity } \\
\text { 30. Cost per Lead } \\
\text { 31. Conversion Rate } \\
\text { 32. Search Engine Rankings (by } \\
\text { keyword) and click-through } \\
\text { rate } \\
\text { 33. Page Views and Bounce } \\
\text { Rate } \\
\text { 34. Customer Online } \\
\text { Engagement Level } \\
\text { 35. Online Share of Voice } \\
\text { (OSOV) } \\
\text { 36. Social Networking } \\
\text { Footprint } \\
\text { 37. Klout Score }\end{array}$ \\
\hline $\begin{array}{l}\text { To measure your operational } \\
\text { performance }\end{array}$ & $\begin{array}{l}\text { To understand your employees } \\
\text { and their performance }\end{array}$ & $\begin{array}{l}\text { To measure your } \\
\text { environmental and social } \\
\text { sustainability performance }\end{array}$ \\
\hline $\begin{array}{l}\text { 38. Six Sigma Level } \\
\text { 39. Capacity Utilization Rate } \\
\text { (CUR) } \\
\text { 40. Process Waste Level } \\
\text { 41. Order Fulfilment Cycle Time } \\
\text { 42. Delivery in Full, On Time } \\
\text { (DIFOT) Rate } \\
\text { 43. Inventory Shrinkage Rate (ISR) } \\
\text { 44. Project Schedule Variance } \\
\text { (PSV) } \\
\text { 45. Project Cost Variance (PCV) } \\
\text { 46. Earned Value Analysis (EVA) } \\
\text { 47. Innovation Pipeline Strength } \\
\text { (IPS) } \\
\text { 48. Return on Innovation } \\
\text { Investment (ROI2) } \\
\text { 49. Time to Market } \\
\text { 50. First Pass Yield (FPY) } \\
\text { 51. Rework Level } \\
\text { 52. Quality Index } \\
\text { 53. Overall Equipment } \\
\text { Effectiveness (OEE) } \\
\text { 54. Process or Machine Downtime } \\
\text { Level } \\
\text { 55. First Contact Resolution (FCR) }\end{array}$ & $\begin{array}{l}\text { 56. Human Capital Value Added } \\
\text { (HCVA) } \\
\text { 57. Revenue Per Employee } \\
\text { 58. Employee Satisfaction Index } \\
\text { 59. Employee Engagement Level } \\
\text { 60. Staff Advocacy Score } \\
\text { 61. Employee Churn Rate } \\
\text { 62. Average Employee Tenure } \\
\text { 63. Absenteeism Bradford Factor } \\
\text { 64. 360-Degree Feedback Score } \\
\text { 65. Salary Competitiveness Ratio } \\
\text { (SCR) } \\
\text { 66. Time to Hire } \\
\text { 67. Training Return on } \\
\text { Investment }\end{array}$ & $\begin{array}{l}\text { 68. Carbon Footprint } \\
\text { 69. Water Footprint } \\
\text { 70. Energy Consumption } \\
\text { 71. Saving Levels Due to } \\
\text { Conservation and } \\
\text { Improvement Efforts } \\
\text { 72. Supply Chain Miles } \\
\text { 73. Waste Reduction Rate } \\
\text { 74. Waste Recycling Rate } \\
\text { 75. Product Recycling Rate }\end{array}$ \\
\hline
\end{tabular}




\subsection{Key Performance Indicators and the Balanced Scorecard}

"KPIs represent a set of measures focusing on those aspects of organizational performance that are the most critical for the current and future success of the organization," says Parmenter (2015). Furthermore, he had clarified that KPIs are not financial measures, not necessarily to be frequently measured, and it might be acted by the company's team, not by the CEO or senior management executives (Parmenter, 2015). In the startups most common scenario, some of KPIs will be measured end followed by the business owners, especially in a micro-business, where the tasks are concentrated in up to four employees (Government of Canada, 2016).

To better understand the types of performance indicators, Parmenter (2015) explains that Key Results Indicators (KRIs) are recurrently treated as KPIs. The measurements in KRIs are essential for the company board, but not necessarily to understand the core of the business. Technically, KRI is supposed to be applied in accelerators more than in startups. Pointing out the company direction is useful. Commonly, financial and customer metrics are classified as KRIs. To exemplify, profitability, return on capital employed,

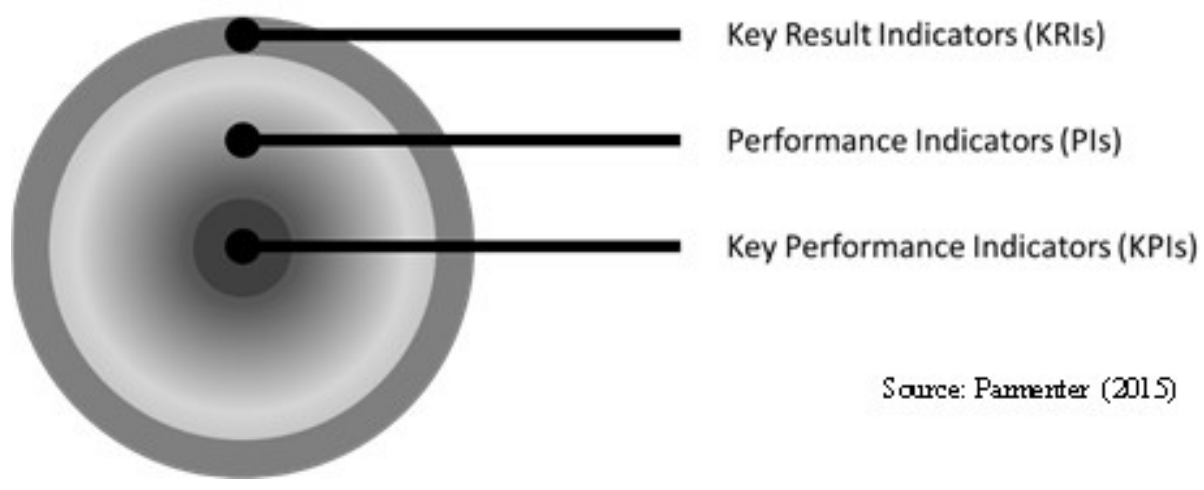

Figure 3 - Types of Performance Indicators 
customer or employee satisfaction, in other words, metrics that are not measured in a daily/weekly basis as KPIs are but in monthly or quarterly periods. To be clear, KRIs are metrics that impact governance, not management. Parmenter (2015) recommends the company has two separated reports, one with KRIs and other with PIs and KPIs. The second report is addressing management performance, with a Balanced Scorecard comprising up to twenty indicators. In the intersection between KRIs and KPIs are the Performance Indicators (PIs). They are complementary to KPIs and can be reported clustered by department, team or business divisions in small companies. The Figure 3 illustrates the 3 types of performance indicators described above.

Related to the quantity to be collected and report frequency, Kaplan and Norton recommend a maximum of 20 KPIs (Kaplan \& Norton, 1993). Hope \& Fraser (2003) suggest fewer than 10 KPIs. In 2013, Parmenter (2015) created the 10/80/10 rule, incorporating $10 \mathrm{KRIs}$, and up to 80 PIs in an organization. The Table 7 summarized authors believes.

Table 7 - Number of Metrics, Frequency and Report Designation

\begin{tabular}{|c|c|c|c|c|c|}
\hline \multirow[b]{2}{*}{ Metrics } & \multirow{2}{*}{ Frequency } & \multirow{2}{*}{$\begin{array}{c}\text { Report } \\
\text { Designation }\end{array}$} & \multicolumn{3}{|c|}{ Number of Metrics } \\
\hline & & & $\begin{array}{c}\text { (Kaplan \& } \\
\text { Norton, 1998) }\end{array}$ & $\begin{array}{c}\text { (Hope \& Fraser, } \\
2003)\end{array}$ & $\begin{array}{c}\text { (Parmenter, } \\
\text { 2015) }\end{array}$ \\
\hline KRI & Monthly / Quarterly & Governance & - & - & 10 \\
\hline PI & \multirow{2}{*}{ Daily / Weekly } & \multirow{2}{*}{ Management } & - & - & 80 \\
\hline KPI & & & Up to 20 & 10 & 10 \\
\hline
\end{tabular}

Following these rules, this thesis is focused on the most important KPIs and KRIs for accelerators and startups, restricting to 20 the maximum number of indicators to be measured per company. 


\subsubsection{Application of Balanced Scorecard to Startups}

Following the literature suggests, the author created a categorization for KPIs based on the Balanced Scorecards perspectives. It has been done to facilitate the data collection and analysis, creating scenarios easily identifiable to interviewees.

This thesis does not intend to evangelize the reader to adopt the Balanced Scorecard as a management tool for startups. However, considerable literature explores this theme and demystifying beliefs that BSC is only successfully adopted in large companies.

SMEs whose adopt BSC gain short and long-term strategic vision (Gomes \& Lírio, 2014; Gumbus \& Lussier, 2006), improves the performance management gaining focus and contributing for the company goals, translating the vision and strategy across the organization (Gumbus \& Lussier, 2006; de Boer, Vandecasteele, \& Rau, 2001). Also, organize their metrics, improving the accountability for results. BSC helps SMEs to avoid uncertainties since young and small companies commonly are in rapid change environments and have a small budget to mitigate risks (Lonbani, Sofian, \& Baroto, 2016; Rickards, 2007).

Kaplan and Norton (1993) developed the BSC to help managers to understand their business environment in an interconnected way, creating a relationship between the perspectives.

The BSC framework has 4 perspectives: (1) Customer, (2) Financial, (3) Internal Business Processes and (4) Learning and Growth (Kaplan \& Norton, 1993), illustrated in the Figure 4. Kaplan and Norton (1996) also suggested four categories for each 
perspective, decomposed as Objectives, Measures, Target and Initiatives.
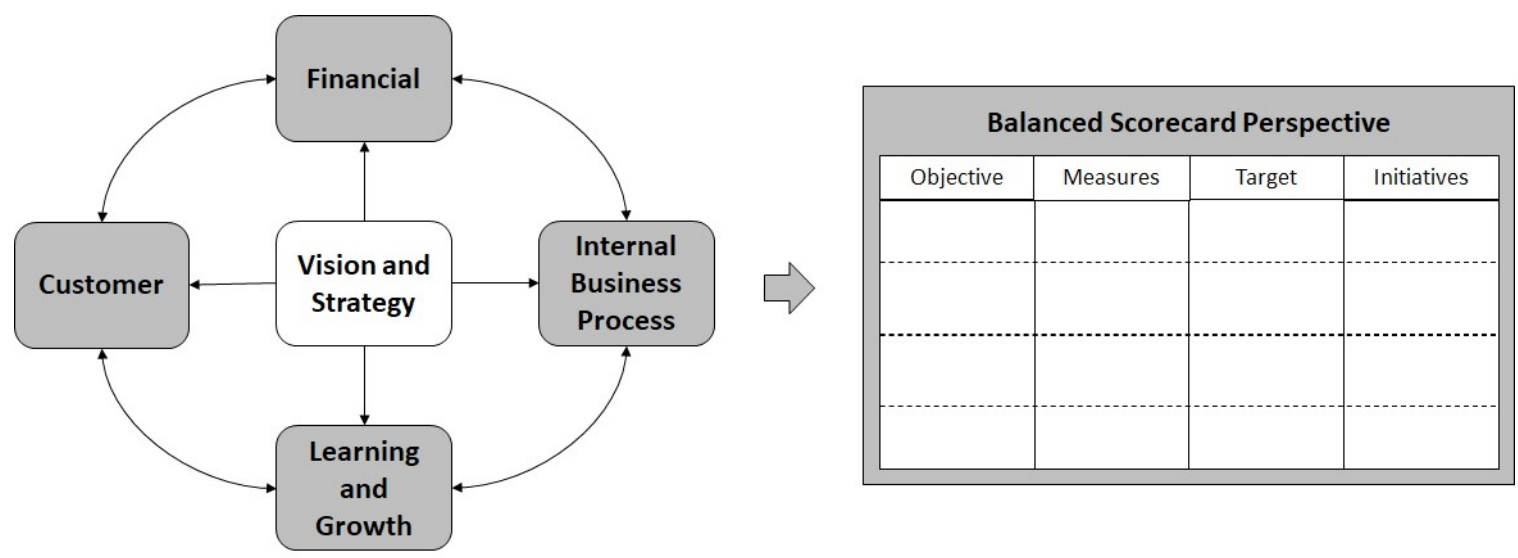

Figure 4 - Balanced Scorecard Perspectives

The Customer Perspective infers about the relationship with customers, explaining how to attract and retain them. The Financial perspective contains objectives and financial performance measures, including operational expenses, incomes, other expenditures and investment measurements. This BSC perspective is crucial to evaluate how the strategy is performing. The Internal Business Processes perspective identifies the management's objectives of operations and general processes in the company. It is focused to improve customers value and productivity. Finally, the Learning \& Growth Perspective is focused to identifies the objectives and necessities of human resources know-how, skills, organizational culture and the company's IT systems (Llorach \& Ottosson, 2016).

Tech startups in various maturity stages can implement the Balanced Scorecard (Llorach \& Ottosson, 2016). They identified patterns by stage in startups regarding objectives and KPIs, and it is summarized in the Table 8.

Table 8 - Trends of performance measurements throughout the startup stages of development 


\begin{tabular}{|c|c|c|c|c|}
\hline \multicolumn{2}{|c|}{ BSC perspectives } & \multirow{2}{*}{\begin{tabular}{|l|}
$\begin{array}{c}\text { Research and Product } \\
\text { Development }\end{array}$ \\
- Assess market \\
demands \\
- $\begin{array}{l}\text { Build a customer } \\
\text { base }\end{array}$ \\
\end{tabular}} & \multirow{2}{*}{\begin{tabular}{|l} 
Commercialization \\
$\begin{array}{l}\text { High interaction with } \\
\text { the market segment }\end{array}$
\end{tabular}} & \multirow{2}{*}{\begin{tabular}{|l|}
\multicolumn{1}{|c|}{ Growth } \\
- Increase Market \\
share and expand to \\
other markets
\end{tabular}} \\
\hline Customer & Objective & & & \\
\hline & KPI & $\begin{array}{l}\text { - Product experience } \\
\text { - Market activities }\end{array}$ & $\begin{array}{l}\text { - Customer outcome } \\
\text { - Measures } \\
\text { - Market activities }\end{array}$ & $\begin{array}{l}\text { - Market activities, } \\
\text { customer } \\
\text { satisfaction }\end{array}$ \\
\hline \multirow{2}{*}{ Financial } & Objective & - Seek funding & $\begin{array}{l}\text { - Monetize R\&D } \\
\text { efforts }\end{array}$ & $\begin{array}{l}\text { - Sustainable } \\
\text { business model, } \\
\text { scale-up }\end{array}$ \\
\hline & KPI & $\bullet--$ & $\begin{array}{l}\text { - Operational } \\
\text { revenues, costs }\end{array}$ & - Profitability, ROI \\
\hline \multirow{2}{*}{$\begin{array}{l}\text { Internal } \\
\text { Business } \\
\text { Processes }\end{array}$} & Objective & $\begin{array}{l}\text { - } \mathrm{R} \& \mathrm{D} \text { according to } \\
\text { market demands }\end{array}$ & $\begin{array}{l}\text { - Enhance achieving } \\
\text { customer \& critical } \\
\text { processes for } \\
\text { shareholders }\end{array}$ & --- \\
\hline & KPI & $\begin{array}{l}\text { - Product attributes } \\
\text { such as price, } \\
\text { quality, delivery time }\end{array}$ & $\begin{array}{l}\text { - Commercial capacity } \\
\text { and internal work } \\
\text { processes }\end{array}$ & $\begin{array}{l}\text { - The efficiency of } \\
\text { the organizational } \\
\text { operations }\end{array}$ \\
\hline \multirow{2}{*}{$\begin{array}{l}\text { Learning \& } \\
\text { Growth }\end{array}$} & Objective & --- & - Recruitment & $\begin{array}{l}\text { - Keep \& attract } \\
\text { competent talent }\end{array}$ \\
\hline & KPI & --- & - Recruitment process & $\begin{array}{l}\text { - Staff satisfaction } \\
\text { - Career development }\end{array}$ \\
\hline
\end{tabular}

The table 9 can be graphically represented in a GRL modelling approach, providing extra details to specify priorities, alternative solutions and analysis to decision-makers. A graphical approach as in Figure 5 - Example of GRL for a Startup in Research and Product Development Stage, can attribute the importance rating, the contributions between intentional elements and may identify the responsible actors of soft goals, goals, or KPIs. 
Financial

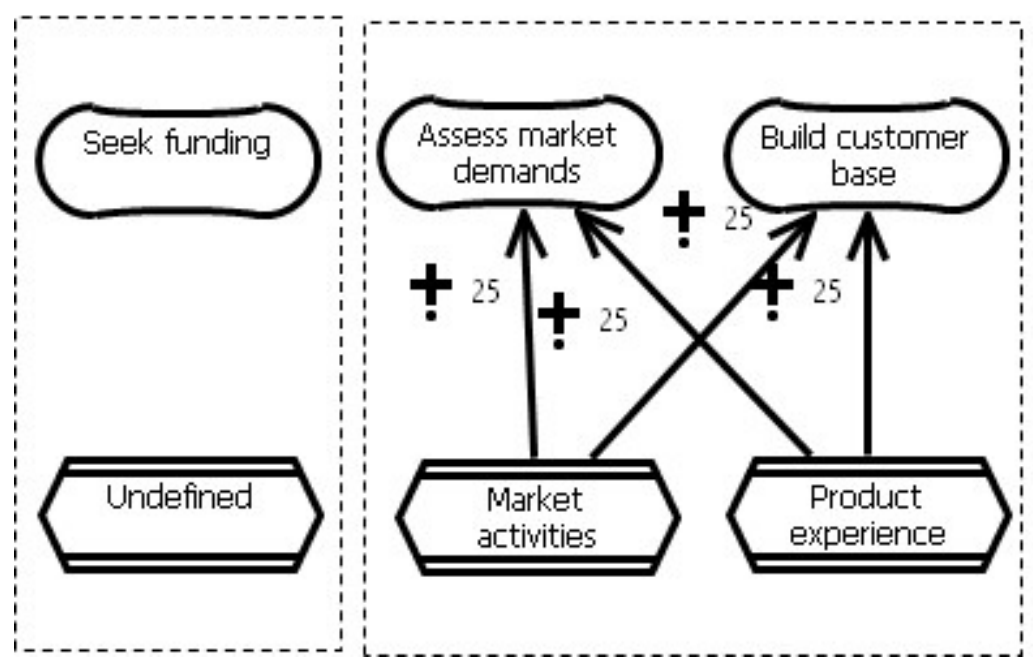

Internal Business

Process

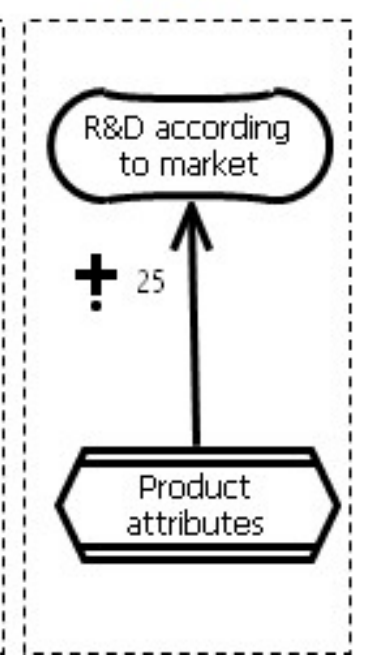

Figure 5 - Example of GRL for a Startup in Research and Product Development Stage

\subsection{Goal-Oriented Models with GRL}

According to Bochman (2010), under a requirement engineering point of view, goals are a way to align a system with the strategic objectives in a company, provide management traceability, and it might be a foundation for risk analysis. Van Lamsweerde (2000) defined Soft Goals as "a High-level objective of the business, organization or system." Other jargons used in the literature might be translated to business jargon as exemplified in the Table 9.

Table 9 - Requirements Engineering and Business Jargons

\begin{tabular}{l|l} 
Requirements Engineering Jargon & Business Jargon \\
\hline Soft Goal / High-Level Goal & High-Level Objective \\
\hline Goal & Goal / S.M.A.R.T. Objective \\
\hline Actor & Agent / Stakeholder \\
\hline Obstacles & Obstacles / Barriers \\
\hline
\end{tabular}




\subsubsection{The Goal-Oriented Requirement Language (GRL)}

GRL was used as the basis for the proposed method, because it allows the analyst to model business goals and their relationships in a visual format, comparing alternative scenarios driven by different priorities (Bochman, 2010). It is designed to decompose Soft Goals in tasks and understand their interconnectivity, and GRL has been designed to model the decomposition of high-level goals into lowest-level goals and KPIs. High-level goals are represented as soft goals (intangibles like performance or profit). Tangible hard Goals are mentioned only as Goals. Soffer \& Wand (2005) presented a formal approach to analyzing the dependency of soft-goals on processes. They explained that processes should help to accomplish specific goals or a combination of soft-goals. However, a softgoal does not depend of processes, and their proposed method to identify soft-goals goes through decomposing them to minimize the processes dependencies. Soft goals are goals without clear-cut criteria for satisfaction (Horkoff, Yu, \& Ghose, 2010), often difficult to quantify, imprecise (Horkoff \& Yu, 2011) and may alternatively take place of the Goal (Bochman, 2010). Furthermore, that Goals can provide a procedure for complex business specifications, allowing cooperation between stakeholders, providing a rationale to identify requirements, acting as a basis for organization's strategic objectives, and a criterion for requirements completeness, risk analysis, scope limits, dependencies among actors, supporting traceability management, said Bochman (2010). GRL also allows modelers to represent KPIs explicitly. In a GRL model, KPIs can be linked to the goals they measure (Pourshahid, 2013).

In advanced mode, Pourshahid, Johari, Richards, Amyot, \& Akhigbe (2014) describe a methodology for modelling business intelligence systems that enables the aggregation of 
Key Performance Indicators and their integration into goal models.

Goal modelling is extensively used in technical and business activities, as requirements engineering, business management, and compliance assessment, and GRL, a mature goal modelling language is supported by the jUCMNav tool (Amyot et al., 2012). Also, the tool supports User Requirements Notation (URN) (Mussbacher \& Amyot, 2009). Other goal-oriented modelling languages such as KAOS (van Lamsweerde \& Letier, 2004) have been proposed, but they are not as extensively supported by tools. GRL is widely used in requirements engineering and has also been successfully used to describe business models (Weiss \& Amyot, 2005a). Additionally, GRL is part of the User Requirements Notation, which has been adopted as an international standard. For more information on the User Requirements Notation please consult the project's website (http://jucmnav.softwareengineering.ca/foswiki/UCM/WebHome).

jUCMNav supports qualitative indicators (bad, average, good, excellent) and quantitative GRL values (-100 to 100) or qualitative labels, WeaklySatisfied and Satisfied for example (Amyot et al., 2013), enabling analysts to design models in several scenarios. Strategy inclusion and contribution changes are available, and advanced analysis features such as strategy differences between two GRL strategies and sensitivity (Amyot et al., 2013). However, to simplify the use of the tool, few parameters were used to develop the proposed method. 


\subsubsection{Goal-Oriented Notation and jUCMNav}
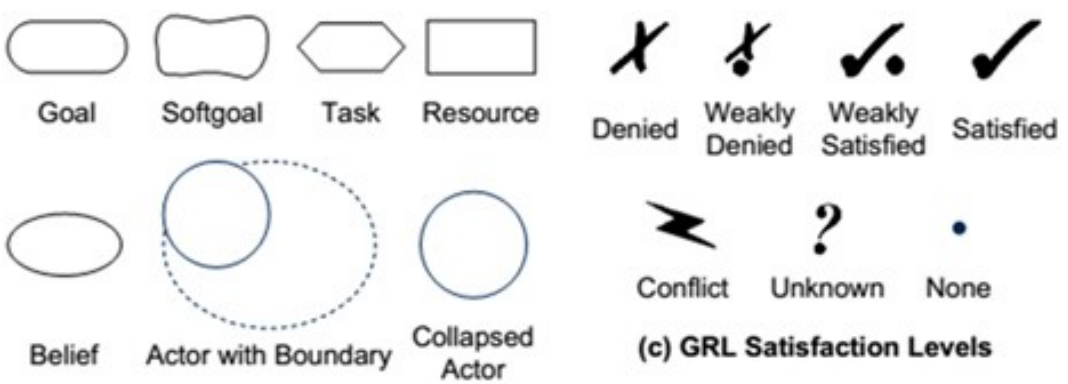

(a) GRL Elements



(b) GRL Links

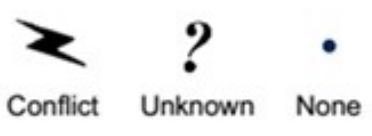

(c) GRL Satisfaction Levels

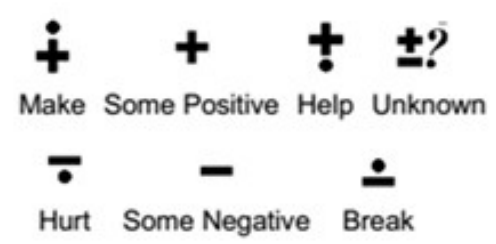

(d) GRL Contributions Types

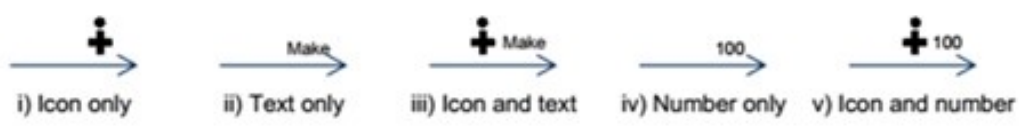

(e) Representations of Qualitative and Quantitative Contributions

Figure 6 - Basic Elements of GRL Notation in jUCMNav

GRL models have been designed using the open-source jUCMNav tool, an Eclipse-based editor for URN models (Amyot et al., 2013). The basic notations of jUCMNav can be found in the Figure 6.

According to a specialized blog, some important features of jUCMNav (I*Wiki, n.d.) are:

- UCM and GRL editing.

- User-defined traceability links between GRL elements and UCM elements

- Many navigation features (based on links, and on definitions/references)

- On-demand expansion of related intentional elements / actors in GRL diagrams

- GRL analysis based on GRL strategies 
- Six GRL analysis algorithms: quantitative, qualitative, two hybrid ones, quantitative with KPI functions/aggregation, and constraint-oriented.

- Integrated UCM/GRL analysis (GRL evaluations affect scenario traversal, and vice-versa)

- Visualization of model differences

- Visualization of differences between the impacts of two given acenarios

- Visualization of trends based on groups of strategies

- Support for sensitivity analysis based on ranges for contribution values and satisfaction values

- Support Goal satisfaction scales from -100 to +100 and from 0 to 100 ranges

- Structuring of related GRL and UCM diagrams in "concerns"

- Support of (qualitative and quantitative) Key Performance Indicators combined with GRL for business process modelling and monitoring

- Web service interface to read external data sources and feed them to KPI/GRL models, for monitoring

- Report generation in PDF, RTF and HTML

- Multilingual interface

Some concepts and features have not been used in this study. However, the list of features is presented to motivate the audience to takes advantage of jUCMNav as a tool to create your GRL models, improving the analysis with the algorithms provided by the tool. 


\subsection{Lessons Learned}

A list of lessons learned was developed to drive the field research, bringing to surface some findings in the literature and issues that can be investigated.

- Canada is supporting their accelerators and startups and intends to be recognized as a safe harbor to new ventures.

- An early-stage movement of authorities and accelerators is trying to standardize KPIs to tie the measurement chain in this industry (BAI).

- Startups' objectives, measurements and KPIs vary according to the company's development phase.

- A lack of synergy between accelerators and startups management and objectives was detected.

- Balanced Scorecard might be used to standardize the management of accelerators and fellow startups

- The use of a goal-oriented approach to collect and analyze data is trustable and cost-efficient for accelerators and startups 


\section{Chapter: Research Method}

This chapter describes the method used to produce the deliverables of this research. The chapter is organized into nine sections. Section 3.1 describes the streams in the Literature Review. The available modelling tools are addressed in section 3.2. The sample and the interview guidelines have been explicated in the section 3.3 and the interviews data collection in 3.4. The section 3.5 explains how to organize the collected data. Section 3.6 demonstrated the importance of a high-level goal model in the process, and the development of detailed GRL models are explained in section 3.7.

Differently of other methods in the literature, the proposed process has an straight approach to find the best performance indicators, to understand the goals and identify the synergy points between two companies.

The Table 10 summarizes the steps carried out in this research. The subsections detail the steps taken to generate the results and deliverables.

Table 10 - Research steps

\begin{tabular}{|c|c|c|c|}
\hline Step & Description & Activities & Outcomes \\
\hline 1 & Literature review & $\begin{array}{l}\text { Identify KPIs for measuring the } \\
\text { performance of accelerators and startups }\end{array}$ & $\begin{array}{l}\text { - Initial list of KPIs } \\
\text { - Categorization of KPIs by BSC } \\
\text { perspectives }\end{array}$ \\
\hline 2 & $\begin{array}{l}\text { Select modelling } \\
\text { tools }\end{array}$ & $\begin{array}{l}\text { Identify and compare tools for modelling } \\
\text { KPIs }\end{array}$ & - Tools for modelling KPIs \\
\hline 3 & $\begin{array}{l}\text { Select sample and } \\
\text { design interview } \\
\text { guidelines }\end{array}$ & $\begin{array}{l}\text { Select accelerators and startups to } \\
\text { interview and develop interview } \\
\text { guidelines }\end{array}$ & $\begin{array}{l}\text { - List of accelerators and startups } \\
\text { to interview } \\
\text { - Interview guidelines }\end{array}$ \\
\hline 4 & Acquire data & $\begin{array}{l}\text { Conduct interviews and collect } \\
\text { information about the importance of KPI } \\
\text { categories, KPIs, soft goals, goals and } \\
\text { responsibilities }\end{array}$ & $\begin{array}{l}\text { - Record of the interviews with } \\
\text { accelerator and startups. }\end{array}$ \\
\hline 5 & Organize data & $\begin{array}{l}\text { Organize the data into tables, identifying } \\
\text { the attributed importance ratings of soft } \\
\text { goals for each studied company. }\end{array}$ & $\begin{array}{l}\text { - Soft goals classified by their } \\
\text { importance, prioritizing the goals } \\
\text { to be achieved and the KPIs } \\
\text { related to them. } \\
\text { - Responsibility assignments for }\end{array}$ \\
\hline
\end{tabular}




\begin{tabular}{c|l|l|l}
\hline & & each KPI \\
\hline 6 & $\begin{array}{l}\text { Create a high-level } \\
\text { goal model }\end{array}$ & $\begin{array}{l}\text { Create a high-level goal model that links } \\
\text { soft goals to hard goals and is organized } \\
\text { by BSC perspectives }\end{array}$ & $\bullet$ High-level goal model \\
\hline 7 & $\begin{array}{l}\text { Create detailed } \\
\text { goal models }\end{array}$ & $\begin{array}{l}\text { Create detailed goal models for high- } \\
\text { importance goals } \\
\text { Attribute responsibilities to actors using } \\
\text { RACI }\end{array}$ & $\begin{array}{l}\bullet \text { Detailed goal models that } \\
\text { include actors, soft goals, goals, } \\
\text { contribution links, KPIs, and } \\
\text { interdependencies } \\
\text { - Responsibilities attributed in a } \\
\text { RACI matrix }\end{array}$ \\
\hline 8 & $\begin{array}{l}\text { Summarize the } \\
\text { process }\end{array}$ & $\begin{array}{l}\text { Summarize the steps of the process for } \\
\text { modelling KPIs }\end{array}$ & • Steps of the method \\
\hline
\end{tabular}

The unit of analysis of this research is a Key Performance indicator used by an accelerator or startup. The data was collected and iteratively analyzed in July and August 2018. The date of Carleton's Ethics Board clearance was June 26, 2018 and the Ethics Protocol Clearance ID number is 109019. Its expiration due date is June 30, 2019.

\subsection{Step 1 - Literature Review}

The data collected intended to identify the most important and used KPIs in the literature. Three key sources were consulted as explained in the section 2. Marr (2012) describes the most important and used KPIs in general, classified in six categories. Vinaixa Vergés (2017) aggregated KPIs from other authors to be applied in accelerators and Carvalho (2016) suggested metrics to be applied in startups. The outcome of the step 1 is a classified KPI list (See Table 16 - List of important KPIs according to Marr (2012), Camacho (2015) and Vinaixa Vergés (2017), categorized by Balanced Scorecard perspectives.).

\subsection{Step 2 - Select Modelling Tools}

\section{Spreadsheet}


General analysis tasks can be supported by spreadsheet software. However, KPI modelling requires a tailored tool that can represent KPIs. Microsoft Excel was used to aggregate data and analyze it. However, open source spreadsheet tools should be considered to execute the same tasks. As an option, Calc (Apache Open Office) or Gnumeric (GNOME Free Software Desktop Project) can perform the same tasks with no cost in license fees.

\section{GRL Modelling Tool}

The jUCMNav tool was selected because of its support to analyze KPIs and Goals (Amyot et al., 2013). The decision comes with a comparison of other OSS in the market and a comparison between them in the literature. Besides jUCMNav, GR-Tool, OME and OpenOME are good examples (Amyot et al., 2010).

Also, there are several goal languages closest to GRL. To exemplify, Amyot (Amyot et al., 2010) compared KAOS, $i^{*}$, NFR, and TROPOS. According to Weiss and Amyot (Weiss \& Amyot, 2005b), the advantage of GRL against other goal languages is its integration with the Use Case Map (UCM), which is part of User Requirements Notation (URN), in business process modelling, allowing versatility to the models.

The Table 11 makes a comparison of analysis and tools supported by them (Amyot et al., 2010).

Table 11 - Comparison between analysis approaches

\begin{tabular}{l|c|c|c}
\multicolumn{2}{c}{ Qualitative Analysis } & Quantitative Analysis & Hybrid Analysis \\
\hline \multirow{3}{*}{ Modelling Language } & TROPOS & TROPOS & \\
& GRL & I* Framework & GRL \\
& KAOS & NFR & \\
\hline
\end{tabular}




\begin{tabular}{c|c|c|c} 
& & GR-Tool & \\
Tool Support & GR-Tool & OME \\
OpenOME & jUCMNav \\
& jUCMNav & \\
\hline
\end{tabular}

Goal modelling is an important part of various types of activities such as requirements engineering, business management, and compliance assessment (Castano \& ER, 2012). The Goal-oriented Requirement Language was chosen to this research as being a standard and a mature goal modelling language supported by the jUCMNav tool (Amyot et al., 2012).

Amyot et al. (2012) also explain that jUCMNav is an open-source Eclipse plug-in that supports the definition, analysis, transformation, and management of requirements engineering models. jUCMNav has been instrumental in validating key concepts for the current standard as well as prototyping new concepts (Mussbacher \& Amyot, 2009), combining modelling concepts and notations for goals, intentions, and scenarios. An extensive literature can be found regarding jUCMNav and GRL modelling and several business cases are published, confirming the adoption of the tool in the academia and business' environments (Group I-Star, 2012).

\section{RACI Matrix}

A Responsibility Assignment Matrix, adapted as a RACI chart, was used as an auxiliary tool to describe the responsibilities across the accelerator, startups and stakeholders. RACI matrix is used to report the involvement of actors in activities (Project Management Institute, 2017). Furthermore, it has been used to describe responsibilities in project management frameworks (Hartman \& Ashrafi, 2004), promote improvements in 
IT frameworks (Feltus, Petit, \& Dubois, 2009) and business processes requirements

(Feltus, Petit, \& Dubois, 2011). The RACI chart also have been utilized as a tool to define responsibilities in several industries and scenarios, and has been used to build and improve business process models (Cabanillas, Resinas, \& Ruiz-Cortes, 2011).

Organizations increasingly use modelling notations to represent their processes.

However, a limitation between responsibility management and modelling notations were identified by Cabanillas (Cabanillas, Resinas, \& Ruiz-Cortés, 2012), its study expected to point out the responsibility of undertaking the activities.

The RACI matrix has four classifications, that are responsible, accountable, consult, and inform statuses as described in Table 12:

Table 12 - RACI Roles and Responsibilities Definitions (Smith \& Erwin, 2005)

\begin{tabular}{|c|c|c|c|c|}
\hline & Responsible & Accountable & Consulted & Informed \\
\hline RACI Chart & $\begin{array}{l}\text { Actor } \\
\text { responsible } \\
\text { for the } \\
\text { activity or } \\
\text { objective } \\
\text { tasks. }\end{array}$ & $\begin{array}{l}\text { Actor who is } \\
\text { ultimately } \\
\text { answerable } \\
\text { for the } \\
\text { activity or } \\
\text { decision }\end{array}$ & $\begin{array}{l}\text { Actor to be } \\
\text { consulted } \\
\text { prior to a final } \\
\text { decision or } \\
\text { action. }\end{array}$ & $\begin{array}{l}\text { Actor who } \\
\text { needs to be } \\
\text { informed after } \\
\text { a decision or } \\
\text { action is } \\
\text { taken. }\end{array}$ \\
\hline
\end{tabular}

\subsection{Step 3 - Select Sample and Design Interview Guidelines}

General information was collected about each accelerator and startup using the variables in Table 13.

Table 13 - Research Variables

$\begin{array}{llll}\text { Organization } & \begin{array}{c}\text { Number of } \\ \text { employees }\end{array} \quad \text { Interviewee role } \quad \text { Industry } \quad \text { Maturity stage }\end{array}$




\begin{tabular}{|c|c|c|c|c|}
\hline Accelerator & --- & Identifies the & --- & --- \\
\hline Startup & $\begin{array}{c}\text { Identifies the size } \\
\text { of the } \\
\text { organization }\end{array}$ & $\begin{array}{l}\text { respondent, } \\
\text { highlighting the } \\
\text { collected KPIs } \\
\text { into strategic or } \\
\text { management } \\
\text { clusters. }\end{array}$ & $\begin{array}{l}\text { Identifies the } \\
\text { industry of the } \\
\text { startup }\end{array}$ & $\begin{array}{c}\text { Identifies the } \\
\text { startup's maturity } \\
\text { state: (1) Product } \\
\text { Development, (2) } \\
\text { Commercializatio } \\
\text { n or (3) Growth }\end{array}$ \\
\hline
\end{tabular}

The variable "role" is only considered for the accelerator interviewees because of the importance of the senior manager and the c-level participation. Those ones are directly benefitted with the adoption of the proposed method and can contribute with experience and business knowledge for the research. In startups, only c-level professionals were considered because of the small number of employees in the selected organizations. The number of employees was considered to guarantee the startups are classified in small size, according to the official parameter in Canada (see Table 2). The maturity stage is essential to identify if the organization is not in the idea stage. Startups in a very early stage are not the focus of this research, assuming that companies in this stage are working to accomplish the infrastructural needs to their operations, and for this reason, the performance analysis is not prioritized, and the firm may be not yet able to apply the proposed method.

The sample includes a business accelerator company and two fellow accelerated startups. The organizations met the following criteria for inclusion:

a. The accelerator must have at least 2 startup companies in its portfolio at the time of the research, which is also going to be invited to participate. b. The interviewees must be a C-Level, a Director or a Manager in their 
organization.

c. Startups must be in the commercialization or growth maturity's stages and associated with one of the business accelerator organization studied.

d. Startup companies which has less than 100 employees

A small sample was necessary to develop the research, to design the framework and the GRL models. To provide a consistent method to compare the results between organizations, a profound and informative sample shown be better than a largest sample of vague responses. For that reason, several variables were applied in this research, creating different scenarios and allowing cross-data between organizations, enriching the results. Thus, to test the suggested method, the data was homogenized to permit a comparison between the actors: the accelerator, a startup in the commercialization stage, and another one in the growth stage.

The accelerator studied is connected to startups according to the diagram in the Figure 7.

To protect the identity of the

participants, no company or interviewee will be identified. Only the researcher, his supervisor and the Carleton's Ethics

Board can have access of this

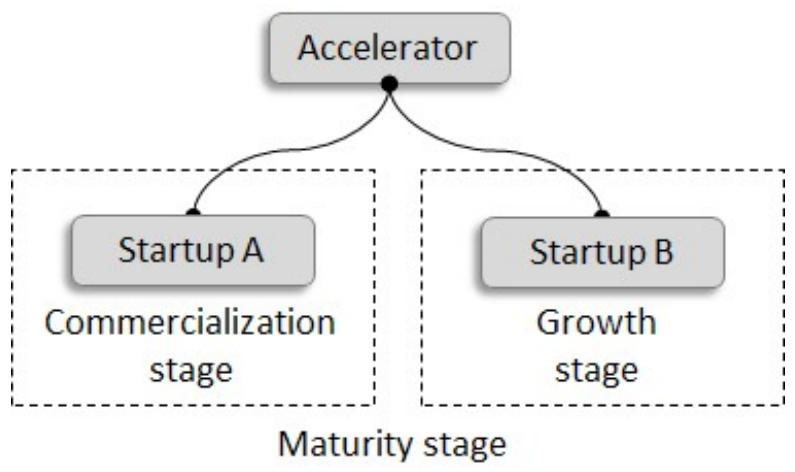

confidential information.

Figure 7 - Accelerator and Startups Relationship

\subsection{Step 4 - Acquire Data}

The interviews were applied with managers of the accelerators and startups to collect their first impression about goals and soft goals. A questionnaire was elaborated to 
support the interviews (See Appendix C). It was filled by the interviewer as the interviewee answered the questions, discussing the subject in-depth to understand the importance level, and the responsibility of the actors under the interviewee point of view. The qualitative data provided by the audience was transcribed into a spreadsheet to be organized, classified and analyzed further.

The list of performance indicators previously elaborated was presented to interviewees to help them to figure out goals and KPIs for each high importance soft goal rated. The respondents were motivated by the interviewer to find out the KPIs that are fitted to achieve the company Goals, and not only choose one of them in a reference list.

\subsection{Step 5 - Organize Data}

The collected new data from interviews was transcribed into a spreadsheet and analyzed in pivot tables to understand the companies' responses, identifying and attributing importance and responsibilities for soft goals, goals and KPIs.

First, cross tables have been used to organize the data and then, the pivot tables were created. It permits to generates a variety of scenarios, views in several perspectives. It should be used to analyze the importance and responsibility ratings.

The variables to develop the pivot tables are described in the Table 14.

Table 14 - Variables used in Pivot Tables

\begin{tabular}{l|l}
\hline \multicolumn{1}{c}{ Variable } & \multicolumn{1}{c}{ Description } \\
\hline BSC Perspective & Denotes the balanced scorecard perspective. E.g.: Financial \\
\hline Subject & Reference of the type of the subject. E.g.: Importance; Responsibility \\
\hline Organization & Organization respondent. E.g.: Accelerator; Startup 1; Startup 2. \\
\hline Soft Goal & E.g.: Revenue, profit and margin \\
\hline
\end{tabular}




\begin{tabular}{l|l} 
High & Sum of High importance ratings \\
\hline Medium & Sum of Medium importance ratings \\
\hline Low & Sum of Low importance ratings \\
\hline Responsibility & Who is the responsible for? E.g.: Startup 1 \\
\hline Responsible & Sum of Responsible \\
\hline Accountable & Sum of Accountable \\
\hline Consulted & Sum of Consulted \\
\hline Informed & Sum of Informed \\
\hline
\end{tabular}

\subsection{Step 6 - Create a High-level Goal Model}

After the data organization step, the findings were used as a foundation to construct the High-Level Goal model. The researcher developed these models based on Goal-oriented Requirement Language (GRL) with jUCMNav, an open source software (OSS) to design the models and support its analysis. At first, the soft goals were interconnected in an overall GRL model. The general GRL model had been developed with the inputs of the interviewees, serving as a template to insert further details as goals, KPIs and actors.

The GRL notation elements used in this method were categorized into three groups:

1) GRL elements: Soft Goal, Goal, KPI and Actor

2) GRL qualitative importance: High, Medium, Low and None

3) GRL links: Contributions, Decomposition and Dependencies

The generated the High-Level GRL model, every soft goal received a rating. The values were attributed according to the importance, or the contribution of the element. Thus, the values can be used to measure each element separately, to calculate the contribution relevance to achieve a goal, or measure a KPI importance. 
Table 15 - Qualitative Importance of GRL Elements

\begin{tabular}{l|c|c|c|c} 
& High & Medium & Low & None \\
\hline Value & 100 & 50 & 25 & 0 \\
\hline
\end{tabular}

\subsection{Step 7 - Create Detailed Goal Models}

An iterative approach was used to create, increment and improve the GRL models. It would be necessary revisit the created pivot tables to extract information and design the detailed goal models. As a result, only soft goals rated as high-importance should be detailed, including goals to be achieved, actors, contributions and responsibilities.

The responsibilities to measure indicators and achieve goals should be shared and be part of the goal modelling. However, to explicit denote the responsibilities between the companies, a RACI matrix could be helpful to detail the role of companies to achieve their goals (See Table 12). It is an important step to create collaboration and synergy between the firms.

As a complement, in order to finish the analysis and get a refined information in place, the performance indicators should be classified as KRI, KPI and PI (See Table 7). The classification of the indicators will represent if the performance indicator is fitted for high-level executives or for management, and also the periodicity to be measured.

\subsection{Step 8-Summarize the Method}

A summary of the steps has been done to elucidate the process in chapter 4 Chapter:. The setup stage is not part first two stages and consist of a literature review and the selection of a tool to model KPIs steps. 
The method is described in the Results Chapter, as the same time the results are presented. 


\section{Chapter: Results}

The research intends to identify the KPIs that accelerators and startups must measure, and the interdependencies between accelerators and startups to achieve their goals. A method was created based on the steps of the research, as seen in the Table 10 - Research steps.

Step 1 and 2 are part of the setup of this research, which means they are not part of the method to identify accelerators and startups' KPIs. The results of these steps are briefly explained in this chapter to contextualize the findings in the setup phase of the research.

The method is described below:

\section{Interview and Analysis Stage:}

- Select Sample and Design Interviews Guidelines (Step 3): Define the audience to be interviewed and design a questionnaire to support the interviews. The outcomes of the Step 3 have been detailed in Section 4.3

- Acquire Data (Step 4): In section 4.4, the data was collected during interviews and the outcomes are reported. The interview guideline is detailed in Appendix $\mathrm{C}-$ Interview design.

- Organize Data (Step 5): Section 4.5 is addressing the results of the data collection, and provides insights, highlighting the importance of goals for each studied organization. The data has been organized in spreadsheets, cross tables, and pivot tables, and it will attribute the importance ratings to elements in the high-level goal model. It has been necessary to analyze the responses of each company. and the findings should appear after modelling the GRL diagrams 


\section{Goal Modelling Stage:}

- Create a High-Level Goal Model (Step 6): The section 4.6 presents the Highlevel GRL model which was designed in jUCMNav. It creates a scenario to compare soft goals between the companies and serves as a base for the detailed GRL models, unfolding the interconnections between soft-goals cited on the interviews.

- Create Detailed Goal Models (Step 7): Detailed goal models are presented in section 4.7. The detailed goal models would emphasize the most important goals and KPIs for accelerator, startups and stakeholders in each BSC perspective. The analyst can use the list of KPIs provided by this study as a reference, suggesting the KPIs to the high importance goals. Additionally, the section shows the results related to responsibility and dependencies, that should complement the findings on GRL models. To refine the models, the analysts should iteratively return to the models and make a visual analysis, based on the importance ratings identified in the spreadsheets, and the responsibilities defined in the RACI matrix.

\subsection{Initial list of KPIs categorized by BSC}

The researcher collected an extensive list of KPIs and categorized it in few soft goals. Each soft goal should represent a collection of hundreds of possible performance indicators, but only the suggested in the literature were included in the list for this study, as you can see in the Table 16. Aggregating all KPIs mentioned in the literature review, we developed a list of KPIs classified in soft goals according to the Balanced Scorecard perspectives. 
Table 16 - List of important KPIs according to Marr (2012), Camacho (2015) and Vinaixa Vergés (2017), categorized by Balanced Scorecard perspectives.

\begin{tabular}{|c|c|c|}
\hline $\begin{array}{l}\text { BSC } \\
\text { Perspective }\end{array}$ & Soft goal & Lit of the Most important Indicators \\
\hline \multirow{6}{*}{ Customers } & Customer retention & $\begin{array}{l}\text { - Customer Retention Rate } \\
\text { - Customer Turnover Rate } \\
\text { - Customer churn rate }\end{array}$ \\
\hline & Customer satisfaction & $\begin{array}{l}\text { - Customer Satisfaction Index } \\
\text { - Customer Complaints }\end{array}$ \\
\hline & Customer profitability & - Customer Profitability Score \\
\hline & Customer lifetime value & $\begin{array}{ll}\text { - } & \text { Customer Lifetime Value (LTV) } \\
\text { - } & \text { Ratio of daily active users (DAU) to } \\
\text { monthly active users (MAU) } \\
\text { - } \\
\text { - } & \text { CAtio of CAC to LTV } \\
\text { - } & \text { CAvery time }\end{array}$ \\
\hline & Customer engagement & $\begin{array}{l}\text { - Customer Engagement Level } \\
\text { - Net Promoter Score (NPS) }\end{array}$ \\
\hline & $\begin{array}{l}\text { Partnerships and external } \\
\text { relationships }\end{array}$ & - Revenue through partners \\
\hline \multirow{7}{*}{ Financial } & Revenue, profit and margin & $\begin{array}{ll}\text { - } & \text { Net Profit } \\
\text { - } & \text { Net Profit Margin } \\
\text { - } & \text { Gross Profit Margin } \\
\text { - } & \text { EBITDA } \\
\text { - } & \text { Cash Conversion Cycle (CCC) } \\
\text { - } & \text { Revenue Growth Rate }\end{array}$ \\
\hline & $\begin{array}{l}\text { Return on investment, capital, } \\
\text { equity or assets }\end{array}$ & $\begin{array}{ll}\text { - } & \text { Return on Investment (ROI) } \\
\text { - } & \text { Return on Assets (ROA) } \\
\text { - } & \text { Return on Equity (ROE) }\end{array}$ \\
\hline & CAPEX - Capital Expenditure & - CAPEX to Sales Ratio \\
\hline & OPEX - Operational Expenditure & $\begin{array}{l}\text { - } \text { Working Capital Ratio } \\
\text { - Operating Profit Margin } \\
\text { - } \quad \text { Return on Capital Employed (ROCE) } \\
\text { - Operating Expense Ratio (OER) } \\
\text { - Economic Value Added (EVA) } \\
\text { - Overhead }\end{array}$ \\
\hline & Funding & $\begin{array}{l}\text { - } \text { Funding Received } \\
\text { - Price Earnings Ratio (P/E Ratio) } \\
\text { - } \text { Debt-to-Equity (D/E) Ratio }\end{array}$ \\
\hline & Company valuation & - Total Shareholder Return (TSR) \\
\hline & Portfolio evaluation & $\begin{array}{l}\text { - Burn Rate } \\
\text { - Runaway }\end{array}$ \\
\hline \multirow{2}{*}{$\begin{array}{l}\text { Internal } \\
\text { Process } \\
\text { Performance }\end{array}$} & Quality level (e.g., Six Sigma) & $\begin{array}{l}\text { - Six Sigma level } \\
\text { - } \text { Quality Index }\end{array}$ \\
\hline & Supply chain/fulfillment & $\begin{array}{l}\text { - } \text { Capacity Utilization rate (CUR) } \\
\text { - Process Waste Level } \\
\text { - Order Fulfillment Cycle Time }\end{array}$ \\
\hline
\end{tabular}




\begin{tabular}{|c|c|c|}
\hline & & $\begin{array}{l}\text { - Delivery in Full, On Time (DIFOT) Rate } \\
\text { - Inventory Shrinkage Rate (ISR) } \\
\text { - Supply Chain Miles }\end{array}$ \\
\hline & Project control and monitoring & $\begin{array}{l}\text { - } \quad \text { Project Schedule Variance (PSV) } \\
\text { - } \quad \text { Project Cost Variance (PCV) } \\
\text { - } \quad \text { Earned Value Analysis (EVA) }\end{array}$ \\
\hline & Marketing and Online metrics & $\begin{array}{l}\text { - Activation Rate } \\
\text { - Customer Acquisition Cost } \\
\text { - Conversion Rate } \\
\text { - Time to Market Index } \\
\text { - Market growth rate } \\
\text { - Market Share } \\
\text { - Brand Equity } \\
\text { - Online Metrics } \\
\quad \text { Search Engine Rankings (SEO) and } \\
\quad \text { Click-through rate (SEM) } \\
\text { Page Views and Bounce Rate } \\
\circ \quad \text { Online Share of Voice (OSOV) } \\
\circ \quad \text { Social Networking Fotprint } \\
\circ \quad \text { Klout score } \\
\end{array}$ \\
\hline & Operational setup and process & $\begin{array}{l}\text { - } \text { Capacity Utilization rate (CUR) } \\
\text { - First Pass Yield (FPY) } \\
\text { - Rework Level } \\
\text { - } \text { Operational Equipment Effectiveness } \\
\text { - } \text { (OEE) } \\
\text { - } \text { Process or Machine Downtime Level } \\
\text { - First Call Resolution (FCR) }\end{array}$ \\
\hline & Products and services performance & $\begin{array}{l}\text { - Gross merchandise volume (GMV) } \\
\text { - Capacity Utilization Rate (CUR) } \\
\text { - Cost per Lead }\end{array}$ \\
\hline & Consumables or recyclables & $\begin{array}{l}\text { - Carbon Footprint } \\
\text { - Water Footprint } \\
\text { - Energy Consumption } \\
\text { - Saving Levels Due to Conservation and } \\
\text { Improvement Efforts } \\
\text { - Waste Reduction Rate } \\
\text { - Waste Recycling Rate } \\
\text { - Product Recycling Rate }\end{array}$ \\
\hline & Education and training & - Training Return on Investment \\
\hline & $\begin{array}{l}\text { Technology, equipment and } \\
\text { systems development }\end{array}$ & - IT Costs as Percentage of Revenue \\
\hline $\begin{array}{l}\text { Learning \& } \\
\text { Growth }\end{array}$ & Innovation enhancement & $\begin{array}{l}\text { - Innovation Pipeline Strenght (IPS) } \\
\text { - Return on Innovation Investment (ROI2) } \\
\text { - IP Quality of Assets (Juetten, 2016) }\end{array}$ \\
\hline & $\begin{array}{l}\text { Actual jobs, new jobs and } \\
\text { positions retained. }\end{array}$ & $\begin{array}{l}\text { - Employee Churn Rate } \\
\text { - Average Employee Tenure } \\
\text { - Time to Hire } \\
\text { - Absenteeism Bradford Factor } \\
\text { - Salary Competitiveness Ratio (SCR) }\end{array}$ \\
\hline
\end{tabular}




\section{Human capital value}

Employee satisfaction and engagement
- Human Capital Value Added (HCVA)

- Revenue Per Employee

- 360-Degree Feedback Score

- Employee Satisfaction Index

- Employee Engagement Level

- Staff Advocacy Score

\subsection{Tools for Modelling KPIs}

After made an evaluation of the available tools in the literature, we decided to use the tools in the table below.

Table 17 - Selected Tools

$\begin{array}{ll}\text { Objective } & \text { Selected Tools }\end{array}$

\begin{tabular}{l|l}
\hline Spreadsheets, Cross Tables and Pivot Tables & Microsoft Excel \\
\hline GRL Modelling Tool & jUCMNav \\
\hline Matrix of Responsibility & RACI \\
\hline
\end{tabular}

\subsection{Sample and Interview Guidelines}

The instructions were detailed in the Research Method, Step 3 - Select Sample and Design Interview Guidelines.

This research was attended by 2 accelerator's professionals, and 2 founder / entrepreneurs from the associated startups. A summary of attendees is reported in Table 18.

Table 18 - Summary of the interview's attendees

\begin{tabular}{|c|c|c|c|c|c|}
\hline Organization & $\begin{array}{l}\text { Number of } \\
\text { employees }\end{array}$ & $\begin{array}{l}\text { Company } \\
\text { Lifetime }\end{array}$ & $\begin{array}{c}\text { Interviewee } \\
\text { role }\end{array}$ & Industry & $\begin{array}{c}\text { Maturity } \\
\text { stage }\end{array}$ \\
\hline \multirow{2}{*}{ Accelerator A } & \multirow{2}{*}{$\begin{array}{l}\text { 1-9 persons } \\
\text { employed }\end{array}$} & \multirow{2}{*}{$\begin{array}{c}\text { More than } 5 \\
\text { years }\end{array}$} & Manager & \multirow{2}{*}{---} & \multirow[b]{2}{*}{--- } \\
\hline & & & C-Level & & \\
\hline Startup 1 & $\begin{array}{l}\text { 1-9 persons } \\
\text { employed }\end{array}$ & $\begin{array}{c}\text { Less than } 1 \\
\text { year }\end{array}$ & $\begin{array}{c}\text { Founder / } \\
\text { Entrepreneur }\end{array}$ & $\begin{array}{c}\text { Professional, } \\
\text { Scientific and } \\
\text { Technical } \\
\text { Services }\end{array}$ & $\begin{array}{l}\text { Commercia- } \\
\text { lization }\end{array}$ \\
\hline
\end{tabular}




\begin{tabular}{l|c|c|c|c|c} 
Startup 2 & $\begin{array}{c}20-49 \text { persons } \\
\text { employed }\end{array}$ & 3 to 5 years & $\begin{array}{c}\text { Founder } / \\
\text { Entrepreneur }\end{array}$ & $\begin{array}{c}\text { Professional, } \\
\text { Scientific and } \\
\text { Technical } \\
\text { Services }\end{array}$ & Growth \\
\hline
\end{tabular}

\subsection{Acquire Data - Results of Interviews}

The interviews were applied with managers of the accelerators and startups to collect their first impression about goals and soft goals. A form was elaborated to support the interviews and it can be found in Appendix C - Interview design. It was filled by the interviewer as the interviewee answered the questions, discussing the subject in-depth to understand the importance level, and the responsibility of the actors under the interviewee point of view. The qualitative data provided by the audience was transcribed into a spreadsheet to be organized, classified and analyzed further.

The list of performance indicators previously elaborated was presented to interviewees to help them to figure out goals and KPIs for each high importance soft goal rated. The respondents were motivated by the interviewer to find out the KPIs that are fitted to achieve the company Goals, and not only choose one of them in a reference list.

\subsection{Organize Data - Soft goals classified by importance}

Accelerators and startups in the commercialization or growth stages have distinctives goals to accomplish. The Table 19 synthesizes the overall importance ratings for the accelerator and startups. 
Table 19 - Overall Importance Ratings by BSC Perspectives

\begin{tabular}{c|c|c|c|}
\multirow{2}{*}{ BSC Perspective } & \multirow{2}{*}{ Accelerator } & \multicolumn{2}{|c|}{ Startups Stages } \\
\cline { 3 - 4 } & & Commercialization & Growth \\
\hline Customer & High & High & Medium \\
\hline Financial & Medium & Low & Medium \\
\hline Internal Business Processes & Medium & Medium & Medium \\
\hline Learning \& Growth & High & High & Medium \\
\hline
\end{tabular}

Accelerators vary in their governance model, number of employees and number or graduated startups under their umbrella. According to the literature (Llorach \& Ottosson, 2016), startups in the commercialization stage are more focused on the early relationship with the market and customers, and the attention of startups in growth stage is focused on increase their market share and surpass the customer expectations.

The overall importance of the balanced scorecard perspectives differs in each researched firm. The tendency of the accelerator is to prioritize the relationship with its customer, which means associated startups, internal consultants, and the stakeholders in their ecosystem. The startup in commercialization stage felt the same perspectives as most the important ones. However, the objective is launch innovative products in the market and acquire clients as fast as they can. The company in growth stage has a balanced scenario, but some specific soft goals will gain force in this maturity stage.

Therefore, this study is discarding startups in the Idea stage, when the company usually does not have structured their business model, enter in the market, has sales, or it is still developing their product. To implement the suggested method, it is going to be necessary that the company has been fully operational, and for that reason, it does not make sense for ventures in the idea stage. 
In the Balanced Scorecard's Customer perspective, Customer Satisfaction soft goal was decomposed in two other goals by the executive of Startup 2, which are the Customer Retention and Customer Engagement. Also, Customer Profitability was highlighted as an essential goal to be considered.

In the Financial perspective, all soft goals converged to increase the Revenue, Profit and Margin. The margin and profit are impacted by the operational costs, which is into the Internal Business Process perspective.

Marketing and Online metrics are still important for startups. Another critical soft goal in the Internal Business Process perspective is Product and Services Performance, which has the mission to improve the startup's sales.

In the Learning and Growth perspective, the Employee Satisfaction and the Innovation Enhancement were considered critical for the companies' success, and the Technology Equipment and System Development might need attention to be crucial regarding monthly costs and to improve the company valuation.

The Table 20 - Soft Goals Importance Ratings - highlights the soft goals identified as high importance ratings by the interviewed companies. The overall rating was calculated based on the cross tables results. The collected data is available in Appendix B - Data.

\begin{tabular}{|c|c|c|c|c|c|}
\hline $\begin{array}{l}\text { BSC } \\
\text { Perspective }\end{array}$ & Soft Goals High Ratings & Overall & $\begin{array}{l}\text { Accelerator } \\
\text { (A) }\end{array}$ & $\begin{array}{l}\text { Startup } 1 \\
\text { (S1) }\end{array}$ & $\begin{array}{c}\text { Startup } 2 \\
\text { (S2) }\end{array}$ \\
\hline \multirow{5}{*}{ CUSTOMER } & Customer engagement & $\checkmark$ & $\checkmark$ & $\checkmark$ & $\checkmark$ \\
\hline & Customer lifetime value & & $\checkmark$ & & \\
\hline & Customer profitability & $\checkmark$ & $\checkmark$ & $\checkmark$ & \\
\hline & Customer retention & $\checkmark$ & $\checkmark$ & $\checkmark$ & \\
\hline & Customer satisfaction & $\checkmark$ & $\checkmark$ & $\checkmark$ & $\checkmark$ \\
\hline
\end{tabular}




\begin{tabular}{|c|c|c|c|c|c|}
\hline & Partnerships and external relationships & & & $\checkmark$ & \\
\hline \multirow{7}{*}{ FINANCIAL } & CAPEX and Capital Expenditure & & & & \\
\hline & Company valuation & & & & \\
\hline & Funding & & $\checkmark$ & & $\checkmark$ \\
\hline & OPEX and Operational Expenditure & & & & $\checkmark$ \\
\hline & Portfolio evaluation & & & & \\
\hline & Return on investment, capital, equity or assets & & & & \\
\hline & Revenue, profit and margin & $\checkmark$ & $\checkmark$ & $\checkmark$ & $\checkmark$ \\
\hline \multirow{8}{*}{$\begin{array}{l}\text { INTERNAL } \\
\text { BUSINESS } \\
\text { PROCESS }\end{array}$} & Consumables or recyclable & & & & \\
\hline & Marketing and Online metrics & $\checkmark$ & & $\checkmark$ & $\checkmark$ \\
\hline & Operational setup and process & & & $\checkmark$ & \\
\hline & Patents & & & & \\
\hline & Products and services performance & $\checkmark$ & $\checkmark$ & $\checkmark$ & $\checkmark$ \\
\hline & Project control and monitoring & & $\checkmark$ & & \\
\hline & Quality level (e.g.: Six Sigma) & & $\checkmark$ & & \\
\hline & Supply chain/fulfillment & & & & \\
\hline \multirow{6}{*}{$\begin{array}{l}\text { LEARNING } \\
\text { AND } \\
\text { GROWTH }\end{array}$} & Actual jobs, new jobs and positions retained & & & & \\
\hline & Education and training & $\checkmark$ & $\checkmark$ & $\checkmark$ & \\
\hline & Employee satisfaction and engagement & $\checkmark$ & $\checkmark$ & $\checkmark$ & \\
\hline & Human capital value & & & & \\
\hline & Innovation enhancement & $\checkmark$ & $\checkmark$ & $\checkmark$ & $\checkmark$ \\
\hline & Technology, equipment and systems development & $\checkmark$ & $\checkmark$ & $\checkmark$ & \\
\hline
\end{tabular}

\subsubsection{Importance Ratings for the Accelerator}

On the Customer perspective, when the accelerator understands the needs of associated startups, it might provide better services, and consequently, raise the startups performance and improve the partnership between them. The accelerator might understand the customer journey of the companies in its portfolio. Additionally, new potential business ventures might be a constant procurement on the accelerators side. On the Internal Business Process perspective, the maturity of the accelerators and its members is perceived. Usually, accelerator's programs have restricted rules and processes 
are well defined. In this case, it would only be necessary a periodical refinement and not spend time in process development. Basically, the Learning and Growth perspective has focus in staff. For improvements in the accelerator mentoring programs or perhaps for design a new management project or process, accelerator's professionals shall support startups in technology, science, marketing, business, law, and a variety of other subjects to cover the needs of internal processes and their accelerated companies. A special attention with the organization employee's satisfaction is key for the relationship between accelerators and startups.

\subsubsection{Importance Ratings for the Startup in the Commercialization Stage}

The startup in the Commercialization stage clearly turn its attention to Customer perspectives. The customer profitability, satisfaction, retention and engagement indicators are the focus of the company in this maturity stage. Furthermore, some attention might be done to partnership and suppliers' development. Surprisingly, it was identified as a high-level importance in the Learning \& Growth perspective.

Moreover, startups in the commercialization stage understanding that training employees and engage them in the company's objectives are a critical factor of success. Incentive innovation in the workplace is another point that was cited.

In the Internal Business Process perspective, marketing, online metrics, operational processes, products and services performance were pointed out as the highest importance metrics to be followed. Also, project management measurement appears with a medium importance level.

The Financial perspective does not seem as a big concern for the company in the 
commercialization stage. However, according to the founder of the Startup 1,

management is mandatory in the Financial Perspective because cost and income's control might reduce financial risks. The interviews shown that the highest importance level in the startups' financial aspect was to follow the revenue, profit and margin metrics, which is common for both researched startups, independently of the maturity stage they are.

\subsubsection{Importance Ratings for the Startup in the Growth Stage}

In the Growth stage, the four perspectives had similar ratings, but when the results had been matched with the accelerator data, Customer and Learning \& Growth perspectives gained importance. To illustrate it, the results of Customer Profitability, Customer retention, Quality Level, Education and Training and Employee Satisfaction soft goals increased to high importance when associated with the accelerator's objectives.

On the other hand, soft goals rated with major importance for the Startup 2 dropped when matched with the accelerator objectives. In this case, Marketing and Online Metrics soft goals decreased its rating.

\subsubsection{Responsibilities Assignments}

The Table 21 addresses the responsibilities of companies regarding the accomplishment of goals and the measurement of performance indicators.

Table 21 - Adapted RACI Matrix

\begin{tabular}{|c|c|c|c|c|c|c|}
\hline \multirow{2}{*}{$\begin{array}{l}\text { BSC } \\
\text { Perspective }\end{array}$} & \multirow{2}{*}{ Goal } & \multirow{2}{*}{ Performance Indicators (PI) } & \multicolumn{4}{|c|}{ Organizations Responsibility } \\
\hline & & & (A) & (S1) & (S2) & $(\mathrm{SH})$ \\
\hline \multirow{5}{*}{ Customers } & \multirow{3}{*}{ Increase Customer Satisfaction } & Customer Retention Rate & $\mathrm{C}$ & A & --- & --- \\
\hline & & Customer Satisfaction Index & I & A & A & --- \\
\hline & & Customer Engagement Level & I & $\mathrm{A}$ & $\mathrm{A}$ & --- \\
\hline & $\begin{array}{l}\text { Increase the Customer } \\
\text { Profitability }\end{array}$ & Customer Profitability Score & I & A & --- & --- \\
\hline & $\begin{array}{l}\text { Increase Revenue Through } \\
\text { Partners }\end{array}$ & Revenue through partners & $\mathrm{C}$ & $\mathrm{R}$ & --- & A \\
\hline
\end{tabular}




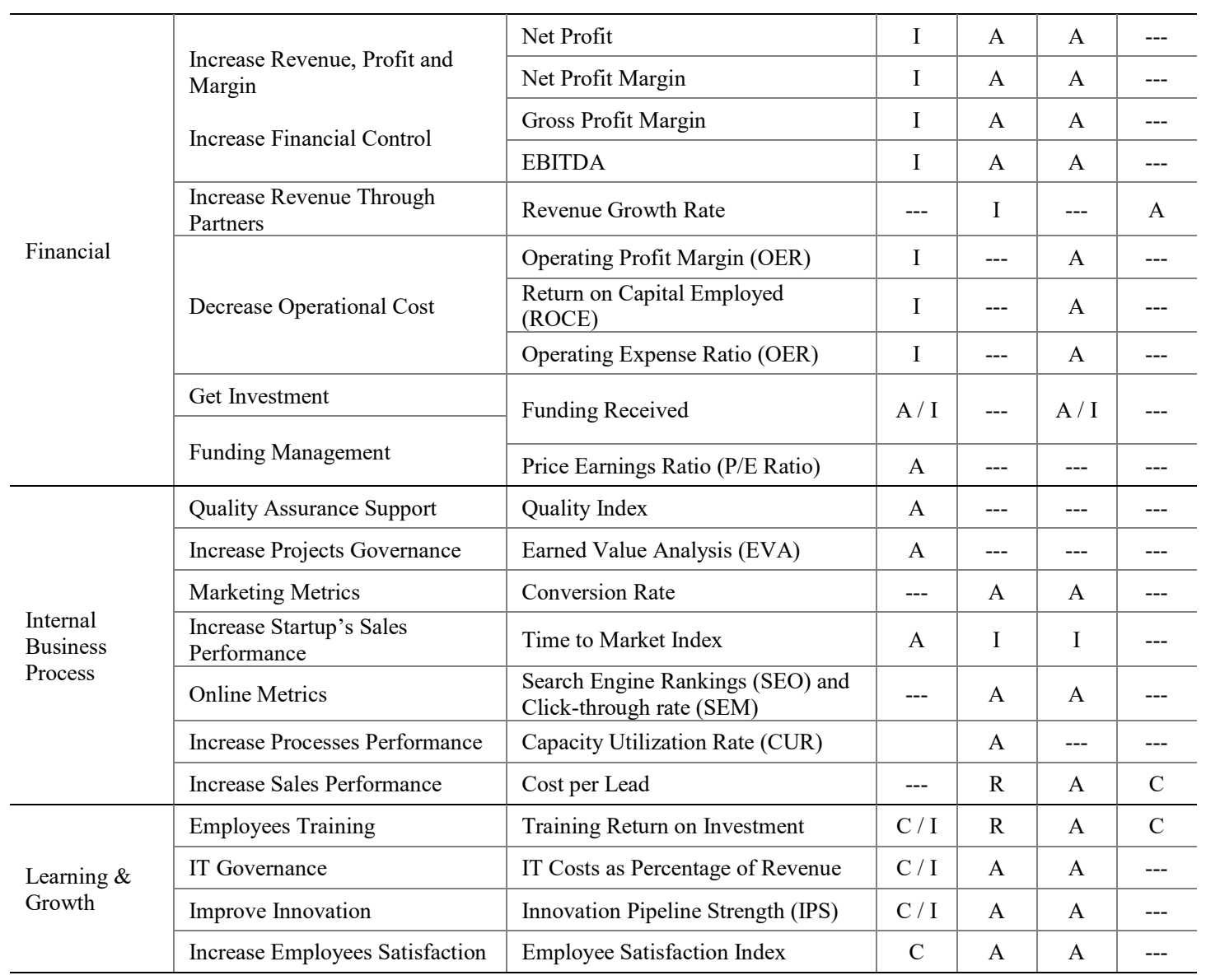

Legend:

(A) Accelerator; (S1) Startup 1 - Commercialization stage; (S2) Startup 2 - Growth stage.

R- Responsible; A- Accountable; C - Consulted; I - Informed.

\subsection{High-Level Goal Model}

An organization might have clear objectives before starting to measure their performance indicators. To represent these objectives and the relationship between them, a High-Level GRL model was designed, including Soft Goals categorized according to each BSC perspectives. Some soft goals pointed out as high importance by the interviewees naturally received specific goals related to them, and then, these goals have been connected to KPIs that can monitoring their accomplishment. 




Figure 8 - Overall importance of Soft Goals by BSC Perspectives 


\subsection{Detailed Goal Models}

A total of 20 goals were identified in the interviews, as seen in the Table 22, and they are detailed in further goal models.

Table 22 - Goals

\begin{tabular}{|c|c|c|c|c|}
\hline BSC Perspective & Goal & $\begin{array}{c}\text { Accelerator } \\
\text { (A) }\end{array}$ & $\begin{array}{l}\text { Startup } 1 \\
\text { (S1) }\end{array}$ & $\begin{array}{l}\text { Startup } 2 \\
\text { (S2) }\end{array}$ \\
\hline \multirow{3}{*}{ Customers } & Increase Customer Satisfaction & & $\checkmark$ & $\vee$ \\
\hline & Increase the Customer Profitability & & $\checkmark$ & \\
\hline & Increase Revenue Through Partners & & $\checkmark$ & \\
\hline \multirow{6}{*}{ Financial } & Increase Revenue, Profit and Margin & & $\checkmark$ & $\checkmark$ \\
\hline & Increase Financial Control & $\checkmark$ & & \\
\hline & Increase Revenue Through Partners & & $\vee$ & \\
\hline & Decrease Operational Cost & $\checkmark$ & & $\checkmark$ \\
\hline & Get Investment & & & $\checkmark$ \\
\hline & Funding Management & $\checkmark$ & & \\
\hline \multirow{7}{*}{ Internal Business Process } & Quality Assurance Support & $\checkmark$ & & \\
\hline & Increase Projects Governance & $\checkmark$ & & \\
\hline & Marketing Metrics & & $\checkmark$ & $\checkmark$ \\
\hline & Increase Startup's Sales Performance & $\checkmark$ & & \\
\hline & Online Metrics & & $\checkmark$ & $\checkmark$ \\
\hline & Increase Processes Performance & & $\checkmark$ & \\
\hline & Increase Sales Performance & & $\checkmark$ & $\checkmark$ \\
\hline \multirow{4}{*}{ Learning \& Growth } & Employees Training & $\checkmark$ & $\checkmark$ & $\checkmark$ \\
\hline & IT Governance & $\checkmark$ & $\checkmark$ & \\
\hline & Improve Innovation & $\checkmark$ & $\checkmark$ & $\checkmark$ \\
\hline & Increase Employees Satisfaction & $\checkmark$ & $\checkmark$ & $\checkmark$ \\
\hline
\end{tabular}

\subsubsection{In the BSC Customer Perspective}

The Customer perspective has six soft goals that were analyzed: (1) Customer engagement; (2) Customer lifetime value; (3) Customer profitability; (4) Customer retention; (5) Customer satisfaction and (6) Partnerships and external relationships. 
Researched startups were emphatic in say that the Customer perspective is the most important. They believe that the customer is the primary target and the profitability is only a consequence of their satisfaction level. It is a unanimous feeling, and engage the customers is the second attention -point for the organizations. Additionally, accelerators are focused on the customer profitability aspects of their associated startups. Thus, they can act as consultants and information providers for associated startups.

Technically, startups are responsible for managing their objectives, goals and metrics in the Customer perspective. A distinctive situation was described by the Startup 1 about the Internal Partnership and External Relationship soft goal. The Startup 1 has a key external stakeholder which has been developed to perform pre-sales tasks and should be critical to increase the revenue of the company. Thus, the startup should manage the stakeholder to increase this partner's performance.

The accelerator's customer are their fellow startups, and for that reason, the accelerator should drive its efforts to positively interfere in the startups' results. Looking from the accelerator point of view, the customer satisfaction comes with the startup clients' relationship improvements, helping them to attract new customers, engage and retain the actual ones, and improves the customer profitability to increase the startup's revenue and margin. The objectives are shared between the accelerator and the startup in commercialization stage, but to be supported by the accelerator. The startup 1 might share the Customer Satisfaction Index with the accelerator to get back indicators to be used as a benchmark. Informed by the startup, the accelerator should be able to understand the momentum of the company and act as a consultant to help the associated startup in retention, and the third-party stakeholders management. 
The indicators identified in the interview are Customer Satisfaction Index, Customer Engagement Rating and Customer Profitability. The Customer Lifetime Value is not recognized as an important performance indicator for the startup 1. However, in a highest level, it is primordial to evaluate the customer journey and this information is valuable for the accelerator. Accelerator's advisors should get better comprehension of potential improvements to help the startup to perform better.

Looking from the startup in growth stage point of view, the importance rating is highly focused on the satisfaction and engagement of their customers. The accelerator's customer support should be in also focused in these performance indicators.

The accelerator is responsible for its customer success factors, and part of this is supporting their associated startups in some soft goals of the BSC Customer perspective. Information about the customer profitability and customer satisfaction should be reported by startups to accelerators with some frequency, and the Startup 2 suggested the report about the Customer Engagement soft goal as well. Also, the same startup beliefs that the company might consult the accelerator regarding customer retention and customer lifetime value. It seems that the accelerator shall aggregate their startups' portfolio data to create a report to be shared with fellow startups as a benchmark.

\section{Goals: Increase the Customer Satisfaction, Engagement, and Develop a Benchmark Report}

Apparently, the customer satisfaction rating feels like an intangible measurement, it means, it is difficult to get accurate information. However, if some tangible measurements clear up the scenario, the uncertainties about the customers' satisfaction 
may decrease.

The GRL model shows the contribution of performance indicators between actors, in this case the accelerator and both associated startups. The indicators to measure the performance of the goal achievement were defined based on the list developed for this study (see Table 16)Table 16 - List of important KPIs according to Marr (2012), Camacho (2015) and Vinaixa Vergés (2017), categorized by Balanced Scorecard perspectives.. The selected ones were Customer Satisfaction Index, Customer Engagement Rating and Customer Retention Rating to support the goal accomplishment. The responsibility to improve the customer satisfaction is exclusively handle on the startups' shoulders. On the other hand, startups should recurrently inform the accelerator about the collected indicators and in retribution, the accelerator might divulge a report to be used as a benchmark.

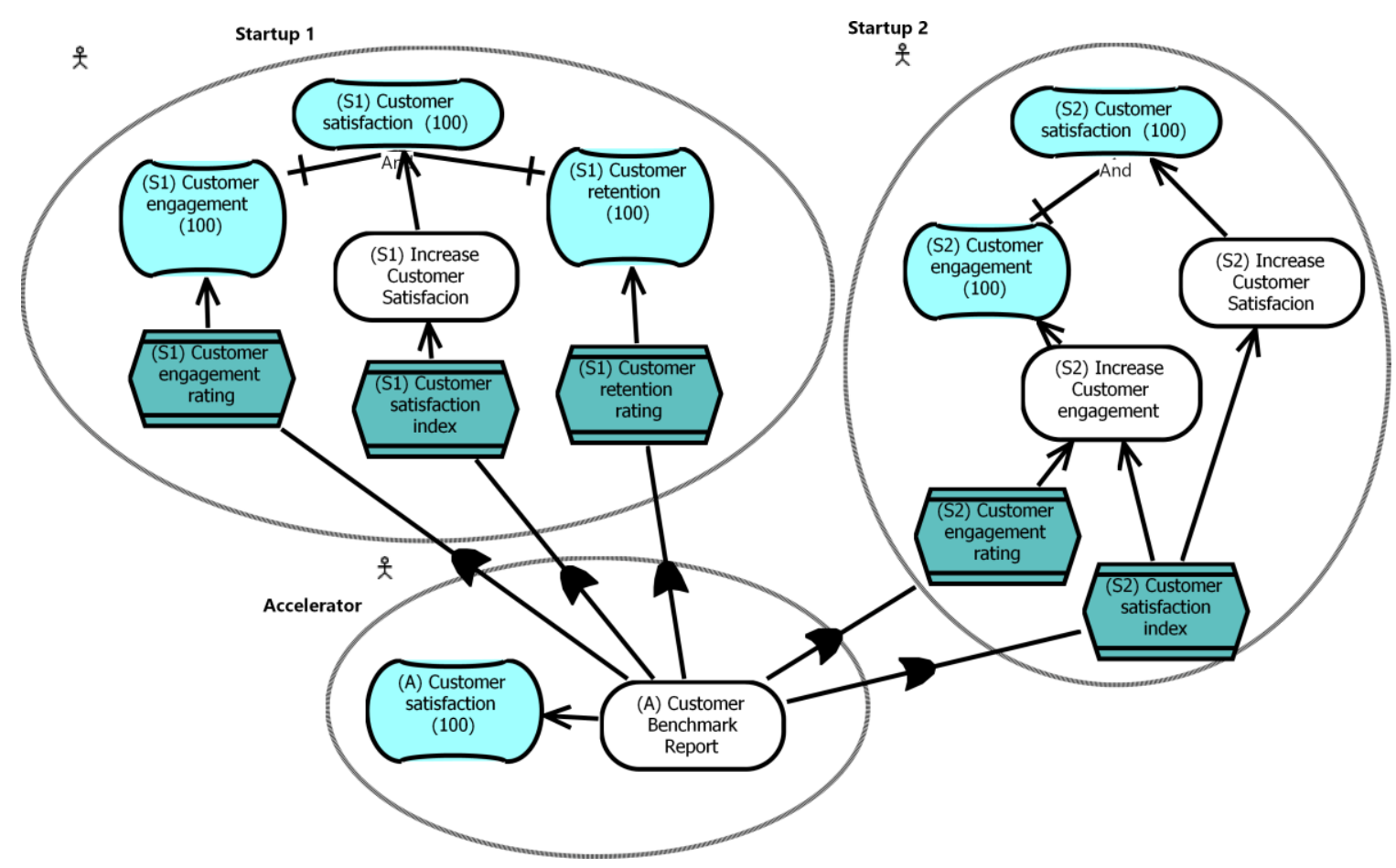

Figure 9 - Goals: Increase the Customer Satisfaction, Engagement, and Develop a Benchmark Report

The Startup 2 gave less importance to the Customer Profitability soft goal, rating it as 
Medium importance, and opted to control the Customer Satisfaction and Customer

Engagement goals. Differently of startup 1, the startup in growth stage highlighted the engage ratings than the retained customers ratings.

\section{Goal: Increase the Customer Profitability}

The Customer Profitability soft goal received the second highest importance rate in the Customer perspective. It is crucial to achieve the financial objectives and directly impacts in the Revenue, Profit and Margin goal, identified as the most critical one in this study.

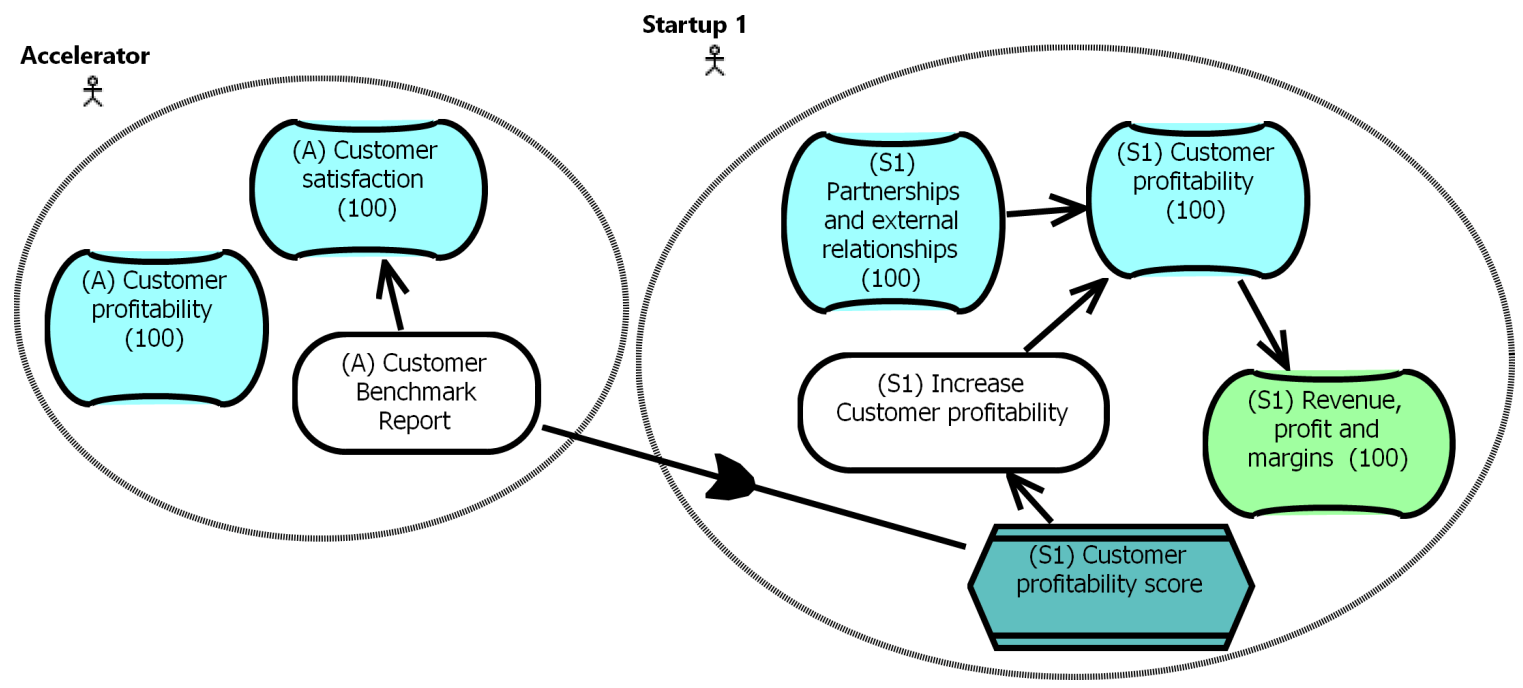

Figure 10 - Goal: Increase Customer Profitability

Indeed, increase the customer profitability is a necessary goal that must be followed by startups in commercialization and growth stages. The GRL diagram (Figure 10 - Goal: Increase Customer Profitability) shows that other objectives impact in this goal. Performance indicators as Customer Lifetime Value (CLV), Customer Acquisition Cost (CAC) and Customer Churn Rate should drive the company to comprise the consumer behavior, and so, should be auxiliary in determinations to raise the profitability per 
customer.

The accelerator's customers are their fellow startups, and for that reason, the focus of the Customer perspective analysis converges to the startup's flank. The accelerator should be the knowledge base and a safe harbor for the companies under its umbrella, providing consulting services and sharing information that adds value to their fellow startups and stakeholders. Taking it into account, the accelerator might foment the use of a lifetime value metric in startups, helping the startup in commercialization stage to develop and measure their performance indicators.

\section{Goal: Increase Partners Profitability}

Only in the Startup 1 scenery, the partnership with pre-sales vendors is critical to improve the company's revenue. In this case, the accelerator's support is not necessary since the management responsibility is exclusively on the startup, providing technical and business support to the partners.

The startup should ask for the external partner to provide evidences and metrics to manage the business performance.

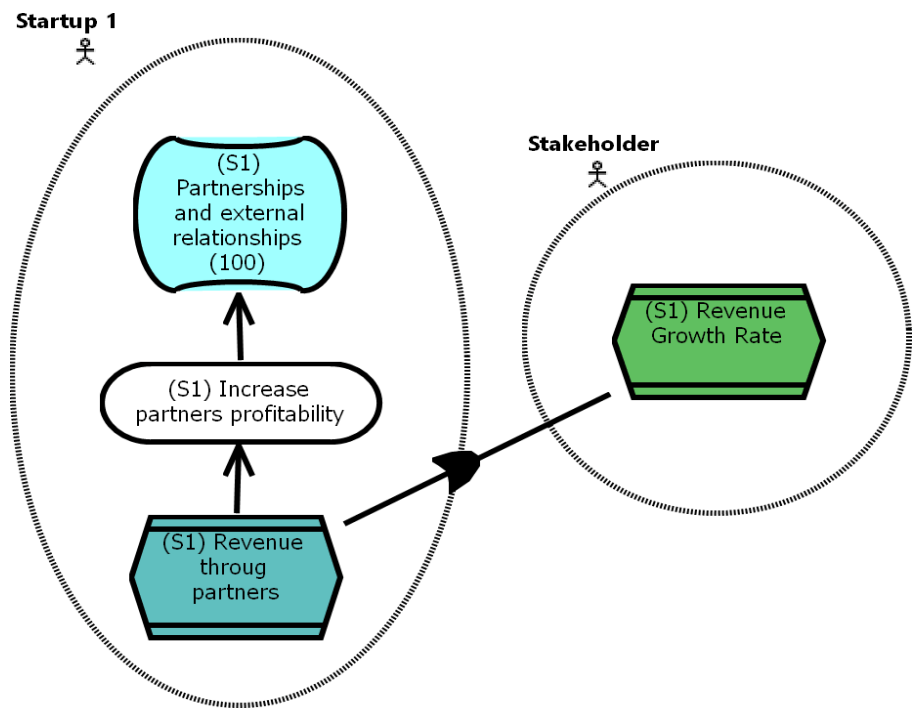

Figure 11 - Goal: Increase Revenue Through Partner 


\subsubsection{In the BSC Financial Perspective}

The Financial perspective has seven soft goals that were analyzed: (1) CAPEX - Capital Expenditure; (2) Company valuation; (3) Funding; (4) OPEX - Operational Expenditure; (5) Portfolio evaluation; (6) Return on investment, capital, equity or assets and (7) Revenue, profit and margin.

In accelerators' perspective, financial objectives have considerable importance, especially regarding the return on investment, assets expenses and funding.

A lack of financial management was detected in the researched startups. Only Revenue, Profit and Margin Soft Goals were classified with high importance rate in the interviews, suggesting that operational costs, project financial analysis and external investments metrics are not taking account in the commercialization stage's startup. It makes sense since the company is ready to be launched in the market and financial measurements are not so necessary at this time. Dissimilar, the Startup 2 which is in the growth stage, rated OPEX control with high value. It also valued Funding soft goal as entirely necessary as well as the Accelerator. To put the financial management in practice, startups might share information with accelerators about revenue, profit and margin, and receive back a benchmark report about the performance of the accelerator's fellow startups.

In general terms, the financial indicators should be managed by each organization, excepted in the Portfolio Evaluation soft goal, when the Accelerator has the responsibility and act as a consultant for the associated startups. Specifically, in the Portfolio Evaluation soft goal, the startup in commercialization stage understood that an external consultant might be contracted. 
Instead of the medium rating, Return on Investment, Capital, Equity or Assets soft goal has two different perspectives. First, the startup in the commercialization stage has a feeling of total responsibility, and the accelerator should be informed, while the startup in growth stage shares the responsibility with the accelerator. It believes the accelerator is responsible and the startup should be accountable to achieve the soft goal. The startups are responsible for managing external funding, and in the growth stage, inform the accelerator as well.

\section{Goals: Increase Revenue, Profit, Margin and Financial Control}

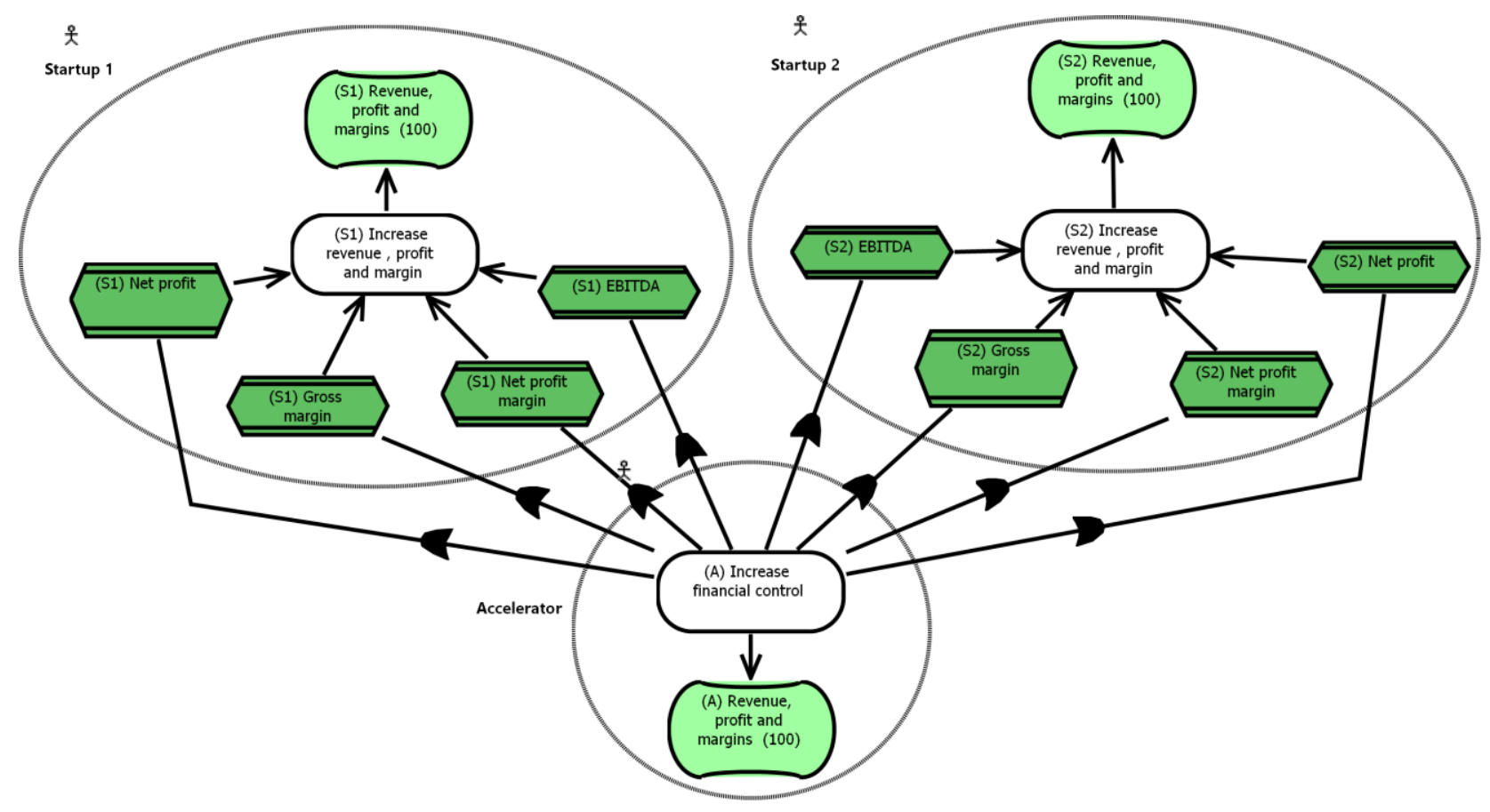

Figure 12 - Goal: Increase Revenue, Profit, Margin, and Financial Control

Other soft goals in the BSC Financial perspective should be under startups' responsibility and the accelerator might be informed or consulted. Developing the management in the financial perspective would be helpful for all actors. 
In the BSC Financial perspective, Revenue, Profit and Margin soft goal was highlighted as the most important by accelerators and startups because of its full impact in the organization performance.

Several soft goals are interconnected when the objective is to increase Revenue, Profit and Margin. To achieve this goal, startups should evaluate other perspectives in BSC, as Customer and Internal Business Process perspectives, in order to cognize the nonfinancial influencers and how to improve the chances to achieve this goal.

The startups should provide financial information to the accelerator in order to be helped in their management. Accelerator's consultants should evaluate the financial KPIs of the startups since they get part of the accelerator program and have a close relationship with the entrepreneurs. A lack of financial control was detected with this study.

Several soft goals impact in the Revenue, Profit and Margin soft goal, including Customer Retention and Profitability, Marketing and Online Metrics, Products and Services Performance, and another financial metrics as CAPEX, OPEX and Funding.

The soft goal Funding impacts in profit and margin since that investors should be paid back on their capital contribution. The customer retention is another relevant expenditure in a company. Generally, the cost to retain clients is a significant part of the expenses, and the company must recurrently try new formulas to reduce it. Online and off-line marketing is at the same time the villain and the hero in companies. If the marketing result is positive, it means more revenue, but if not, it will be observed as expenses. And for that reason, managing marketing costs in synergy with the sales of products and services is always a good deal. 


\section{Goal: Decrease Operational Cost}

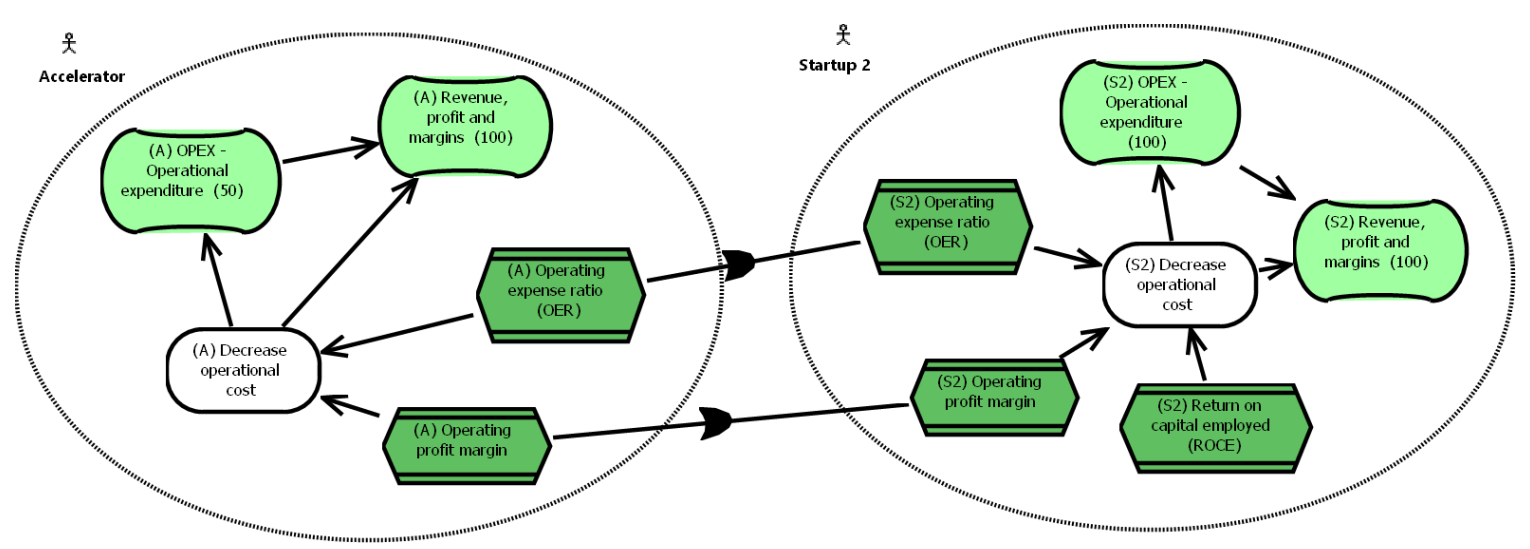

Figure 13 - Goal: Decrease Operational Cost

Costs also might be considered as an essential factor to improve the financial health of the company, but it was not reflected in this research, where the respondents classified OPEX as medium importance and CAPEX as low importance. CAPEX, which means investments, and OPEX, monthly expenses, impacting on the financial results positively or negatively. It depends not exclusively on the revenue, but if the costs are still optimized or not.

Reduce OPEX has the center of attention in this analysis. Decrease the operational expenditure is required for better financial performance, but some factors should influence it. Not rarely, jobs are the most expensive costs for a company. Add it to massive use of technology, operational features, funding chargebacks and extra costs in projects, and then you are going to have a large slice of your incomes compromised in payments. Manage it is important to not affect the organization's profit.

\section{Goal: Get Funding and Funding Management}

The soft goal Funding does not have a direct impact on the goal achievement but should 
be sporadically being evaluated by the startups to have their accounting updated.

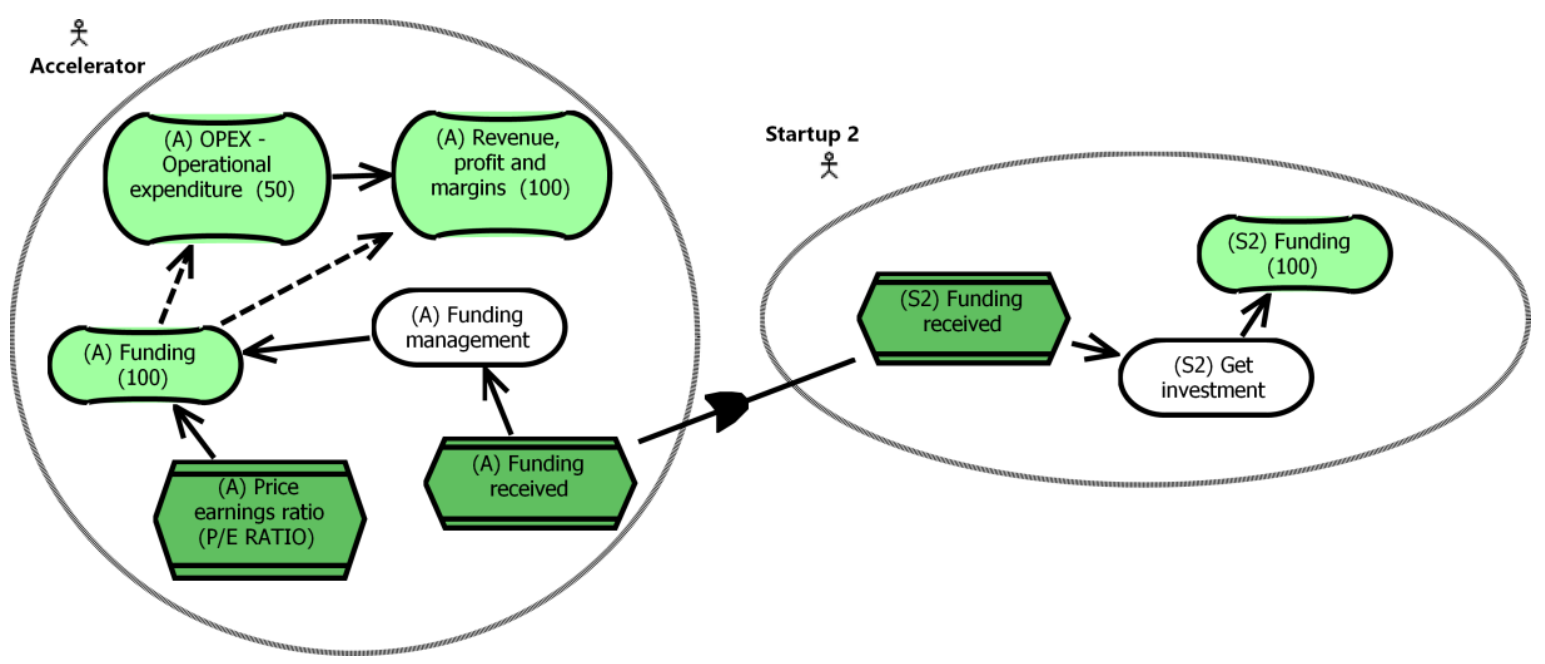

Figure 14 - Goal: Get Funding and Funding Management

The accelerator and the startup in growth stage rated the Funding soft goal has high importance, and it should be necessary to report to venture partners. On the accelerator side, the adoption of the Price earnings ratio (P/E RATIO) indicator should help to identify investment opportunities.

\subsubsection{In the BSC Internal Business Process Perspective}

The Internal Business Processes perspective has eight soft goals that were analyzed: (1) Consumables or recyclable; (2) Marketing and Online metrics; (3) Operational setup and process; (4) Patents; (5) Products and services performance; (6) Project control and monitoring; (7) Quality level and (8) Supply chain/fulfillment.

The overall rating of the Internal Business Process perspective is medium. However, the high importance of soft goals denotes the different organizations' goals. All companies rated Products and Services Performance as high importance rating. The acceptance of their products or services in the market is the focus because it will increment sales, 
income and potential growth of the startup's market share. Accelerator's projects might have extra control, and the quality of startups' offerings should be attractive to investors. The online presence is essential for startups, to divulge their products and promote sales. The startup in the commercialization stage has more work to do. In this maturity stage, the product is ready to be launched on the market, so its operational processes are passive of adjustments.

Organizations are responsible for their internal processes, but the interdependencies between the actors are higher than others BSC perspectives. The accelerator expected to be informed about Patents and Products and services performance. Additionally, consulting services should be provided in quality, marketing and intellectual property fields to Startup 2.

\section{Goals: Increase Product and Services Performance}

To increase the Product and Services Performance in sales and quality, the startup might consider the factors that impact on the client side. Aspects as marketing and project governance are directly associated with the sales performance and consequently impacting in the company's Revenue, Profit and Margin soft goal.

Startups might control the online customer's journey. Hundreds of performance indicators can be used in the Marketing and online metrics soft goal. They are accessible in online analytics tools for free and are reasonably precise to collect data of the startup website, its campaigns and to monitor the client's online behavior. The cost per lead is a critical KPI for accelerator and associated startups. It will be useful to improve the process to acquire new clients. 


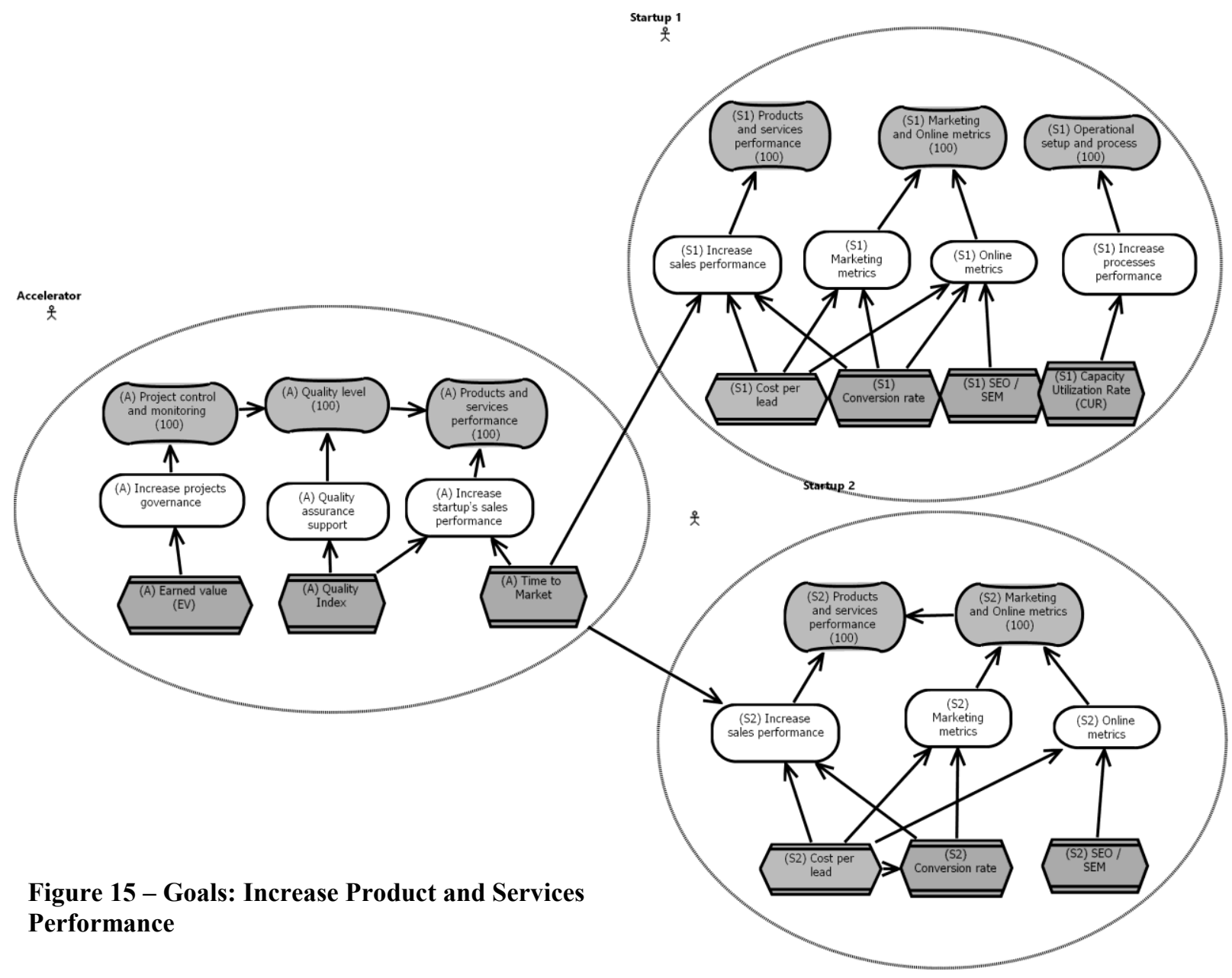

\subsubsection{In the BSC Learning \& Growth Perspective}

The Learning \& Growth perspective has six soft goals that were analyzed: (1) Actual jobs, new jobs and positions retained; (2) Education and training; (3) Employee satisfaction and engagement; (4) Human capital value; (5) Innovation enhancement and (6) Technology, equipment and systems development.

According to the interviewees' responses, the Learning and Growth BSC perspective received the second highest importance rating, confirming the value of the human factor in the all business researched.

The Learning and Growth BSC perspective is regarding capabilities that motives 
employees to accomplish the company objectives. The synergy between startups and the accelerator has a high importance level in the Innovation Enhancement subject. It seems the symbiosis to develop new ideas cooperatively. The relationship between the Startup 1 and the accelerator is more intensive in the Education and Training soft goal, regarding Employees' Satisfaction and Engagement, and subjects related to Technology, Equipment and Systems Development. Thus, the accelerator might spend more time and attention with the startup in commercialization stage than the one in growth stage.

The relationship between Accelerators and associated startups should be intense in several aspects. On the accelerator side of the relationship with startups, the consulting tasks are indispensable. Accelerator's consultants should be prepared to support startups in training, human resource metrics and technology. Moreover, startups also claim support for innovation enhancement.

The accelerator believes that Startup 1 should inform it in all soft goals of the Learning and Growth perspective. In the same page, Startup 2 also should inform the accelerator in the same soft goals, except in Education and Training which they believe that accelerator should consulted.

In return, it is suggested the accelerator to analyze the data provided by startups and distribute an internal benchmark report.

\section{Goals: Innovation Enhancement Program}

This soft goal was highlighted as the most important in the Learning \& Growth perspective. As a goal to be achieved, an in-house Innovation enhancement program was suggested, which will support all organizations involved. 


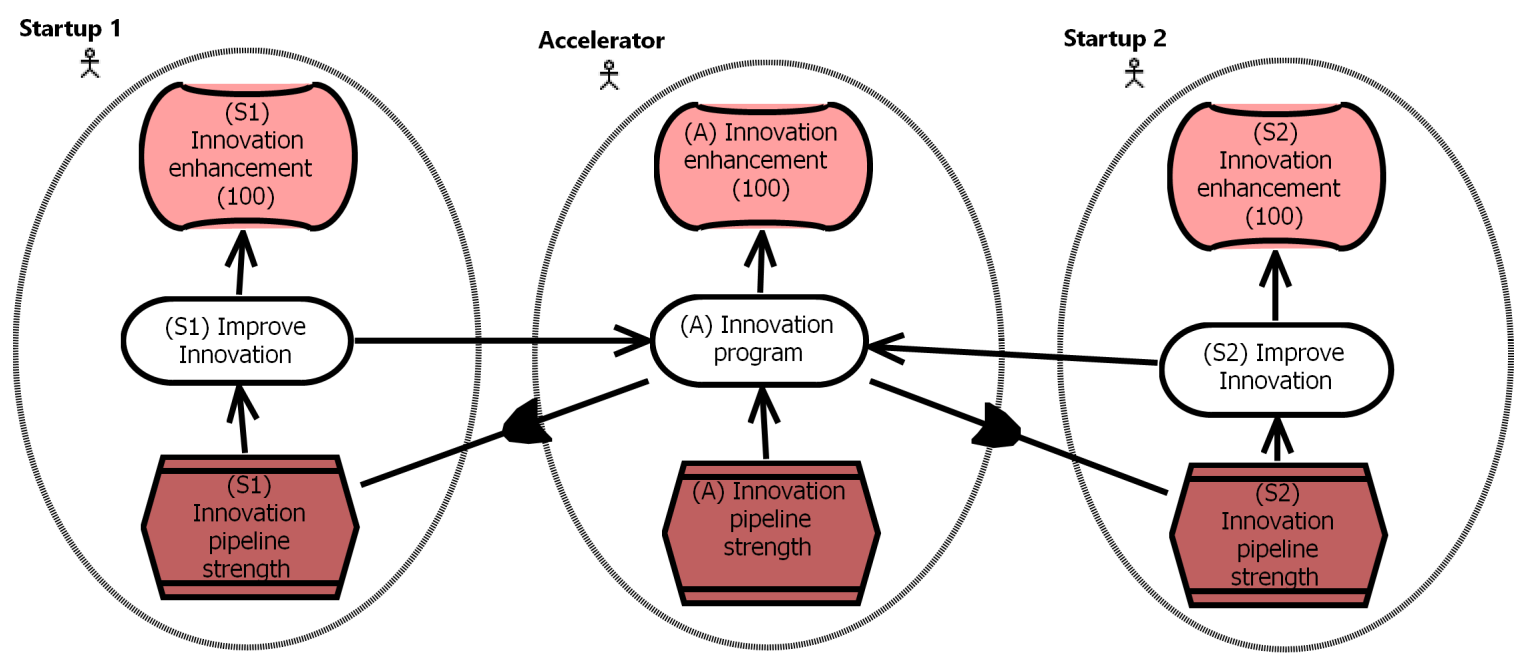

Figure 16 - Goal: Innovation enhancement - Accelerator + Startup $1+$ Startup 2

\section{Goal: Employees Training}



Figure 17 - Goal: Education and training - Accelerator + Startup 1

The Education and Training received high importance score from the accelerator and the

Startup 1, and medium rating from Startup 2, but the average rating is high. Furthermore, 
this soft goal is intrinsically related to the innovation enhancement in an organization, motivating employees with new ideas and professional updating.

In this case, training partners and professional training companies should be contracted to provide lectures and knowledge transference according to the specific needs of each organization.

\section{Goal: Increase Employees' Satisfaction}

Human Capital Value, which has a low rating, is the father of the Employees'

Satisfaction and Engagement soft goal, which received a high rating of accelerator executives and by the Startup 1 interviewee. The importance of this soft goal slightly decreased in the Startup 2 rating.

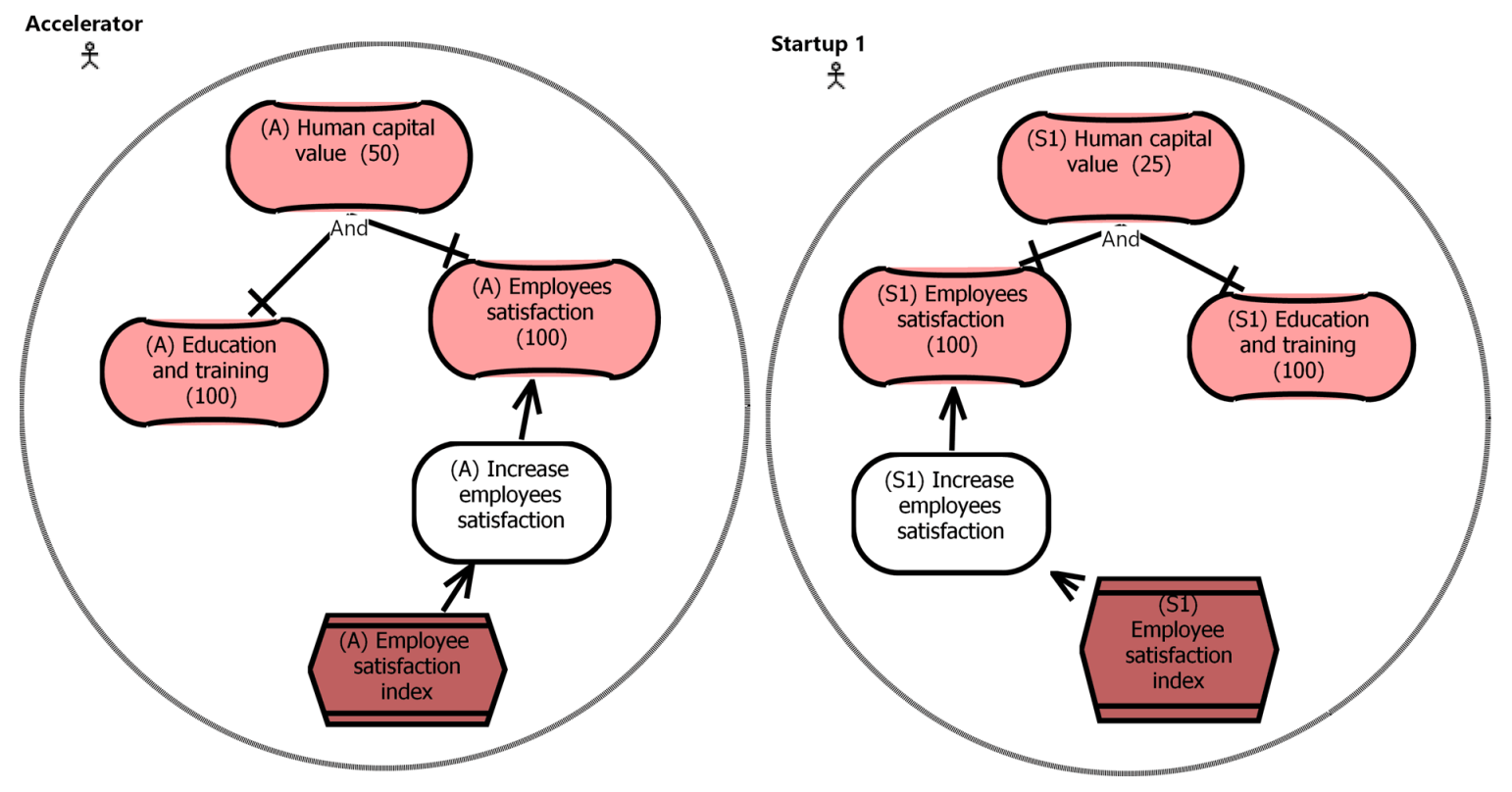

Figure 18 - Employees Satisfaction 


\section{Goal: Technology, Equipment and System Development}

The Technology, Equipment and System Development has its focus in the IT costs, cybersecurity, IT infrastructure and technical aspects to support the company's online presence. It is a standalone soft goal but not less important than the previous ones.

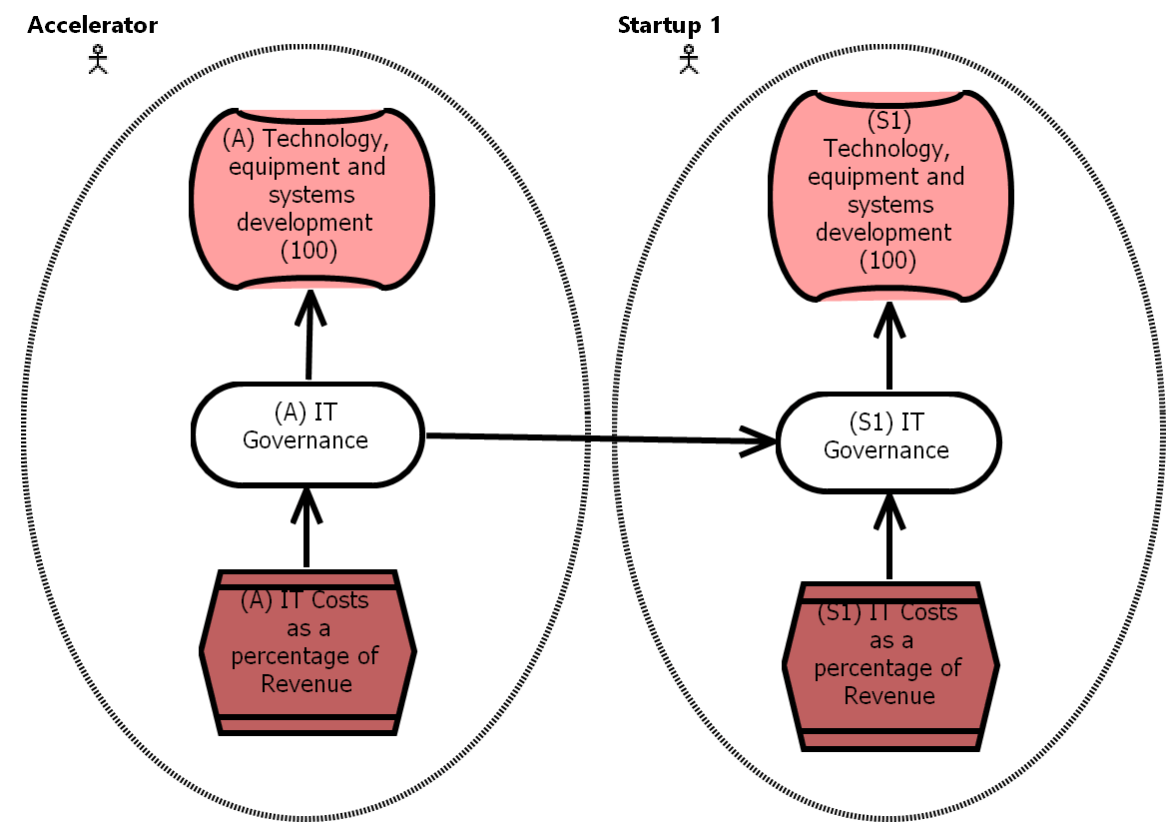

Figure 19 - Technology, Equipment and System Development 


\section{Chapter: Discussion}

This section answers the two research questions

\section{RQ1: What Goals and Performance indicators are essential for accelerators' and startups' objectives?}

A list with 90 performance indicators was created and classified in 26 Balanced Scorecard soft goals, as you can see in Table 16 - List of important KPIs according to Marr (2012), Camacho (2015) and Vinaixa Vergés (2017), categorized by Balanced Scorecard perspectives. Then, we identified 20 goals and 26 performance indicators selected based on the interviews' responses. These goals addressed the organizations' objectives and provided a list of potential performance indicators.

To follow the number of metrics suggested by Kaplan \& Norton (1993) and Parmenter (2015), only KRIs and KPIs were considered (see Table 7), summing less than 20 indicators per company. Although, reminiscent performance indicators in the list should be sporadically measured for specific purposes (see Table 16).

\begin{tabular}{|c|c|c|c|c|}
\hline \multirow{2}{*}{ Performance Indicators } & \multirow{2}{*}{$\begin{array}{c}\text { Goals } \\
\begin{array}{c}\text { High Importance } \\
\text { goals }\end{array} \\
\end{array}$} & \multicolumn{3}{|c|}{$\begin{array}{c}\text { Performance Indicator } \\
\text { Type }\end{array}$} \\
\hline & & KRI & KPI & Total \\
\hline Accelerator & 13 & 13 & 2 & 15 \\
\hline Startup 1 (Commercialization) & 13 & 8 & 9 & 17 \\
\hline Startup 2 (Growth) & 11 & 12 & 5 & 17 \\
\hline
\end{tabular}

The performance indicators were classified according to the concepts of Parmenter (2015) in Table 7 - Number of Metrics, Frequency and Report Designation, and 
summarized in Table 24.

Table 24 - Performance Indicators per Organization

\begin{tabular}{|c|c|c|c|c|c|c|c|}
\hline \multirow{2}{*}{$\begin{array}{l}\text { BSC } \\
\text { Perspective }\end{array}$} & \multirow{2}{*}{ Goal } & \multirow{2}{*}{ Performance Indicators (PI) } & \multirow{2}{*}{$\begin{array}{c}\text { PI } \\
\text { Type }\end{array}$} & \multicolumn{4}{|c|}{ PI per Organization } \\
\hline & & & & (A) & (S1) & $(\mathrm{S} 2)$ & $(\mathrm{SH})$ \\
\hline \multirow{5}{*}{ Customers } & \multirow{3}{*}{ Increase Customer Satisfaction } & Customer Retention Rate & KPI & & $\checkmark$ & & \\
\hline & & Customer Satisfaction Index & KPI & & $\checkmark$ & $\checkmark$ & \\
\hline & & Customer Engagement Level & KRI & & $\checkmark$ & $\checkmark$ & \\
\hline & $\begin{array}{l}\text { Increase the Customer } \\
\text { Profitability }\end{array}$ & Customer Profitability Score & KPI & & $\checkmark$ & & \\
\hline & $\begin{array}{l}\text { Increase Revenue Through } \\
\text { Partners }\end{array}$ & Revenue through partners & KPI & & $\checkmark$ & & \\
\hline \multirow{10}{*}{ Financial } & \multirow{4}{*}{$\begin{array}{l}\text { Increase Revenue, Profit and } \\
\text { Margin } \\
\text { Increase Financial Control }\end{array}$} & Net Profit & KRI & $\checkmark$ & $\checkmark$ & $\checkmark$ & \\
\hline & & Net Profit Margin & KRI & $\checkmark$ & $\checkmark$ & $\checkmark$ & \\
\hline & & Gross Profit Margin & KRI & $\checkmark$ & $\checkmark$ & $\checkmark$ & \\
\hline & & EBITDA & KRI & $\checkmark$ & $\checkmark$ & $\checkmark$ & \\
\hline & $\begin{array}{l}\text { Increase Revenue Through } \\
\text { Partners }\end{array}$ & Revenue Growth Rate & KRI & & & & $\checkmark$ \\
\hline & \multirow{3}{*}{ Decrease Operational Cost } & Operating Profit Margin (OER) & KRI & $\checkmark$ & & $\checkmark$ & \\
\hline & & $\begin{array}{l}\text { Return on Capital Employed } \\
\text { (ROCE) }\end{array}$ & KRI & & & $\checkmark$ & \\
\hline & & Operating Expense Ratio (OER) & KRI & $\checkmark$ & & $\checkmark$ & \\
\hline & Get Investment & Funding Pecoived & KPI &  & & 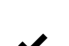 & \\
\hline & Funding Management & Price Earnings Ratio (P/E Ratio) & KRI & $\checkmark$ & & & \\
\hline \multirow{7}{*}{$\begin{array}{l}\text { Internal } \\
\text { Business } \\
\text { Process }\end{array}$} & Quality Assurance Support & Quality Index & KRI & $\checkmark$ & & & \\
\hline & Increase Projects Governance & Earned Value Analysis (EVA) & KPI & $\checkmark$ & & & \\
\hline & Marketing Metrics & Conversion Rate & KPI & & $\checkmark$ & $\checkmark$ & \\
\hline & $\begin{array}{l}\text { Increase Startup's Sales } \\
\text { Performance }\end{array}$ & Time to Market Index & KRI & $\checkmark$ & & & \\
\hline & Online Metrics & $\begin{array}{l}\text { Search Engine Rankings (SEO) and } \\
\text { Click-through rate (SEM) }\end{array}$ & KPI & & $\checkmark$ & $\checkmark$ & \\
\hline & Increase Processes Performance & Capacity Utilization Rate (CUR) & KPI & & $\checkmark$ & & \\
\hline & Increase Sales Performance & Cost per Lead & KPI & & $\checkmark$ & $\checkmark$ & \\
\hline \multirow{4}{*}{$\begin{array}{l}\text { Learning \& } \\
\text { Growth }\end{array}$} & Employees Training & Training Return on Investment & KPI & $\checkmark$ & $\checkmark$ & $\checkmark$ & \\
\hline & IT Governance & IT Costs as Percentage of Revenue & KRI & $\checkmark$ & $\checkmark$ & $\checkmark$ & \\
\hline & Improve Innovation & Innovation Pipeline Strength (IPS) & KRI & $\checkmark$ & $\checkmark$ & $\checkmark$ & \\
\hline & Increase Employees Satisfaction & Employee Satisfaction Index & KRI & $\checkmark$ & $\checkmark$ & $\checkmark$ & \\
\hline
\end{tabular}

Legend:

(A) Accelerator; (S1) Startup 1 - Commercialization stage; (S2) Startup 2 - Growth stage. KPI (Key Performance Indicator); KRI (Key Result Indicator)

Some findings denoted actions that can be taken by companies. These actions were described in detail below. 


\section{In the BSC Customer Perspective:}

- Accelerator: The organization should develop a Customer Benchmark Report, aggregating the KPIs provided by the associated accelerators. No indicators should be measured by the accelerator, since that the startups would provide the reports. As mentioned by Carvalho (2016), the accelerator focus should be in develop the network and partnerships to benefit the associated startups with its customers relationship

- Startup 1 (commercialization stage): The company should follow the metrics to increase the Customer Satisfaction, Customer Profitability, and also to control their partnership profitability ratios. Vinaixa Vergés (2017) emphasizes these customer metrics in the relationship between accelerator and startups.

- Startup 2 (growth stage): It might follow the Customer Satisfaction Index, informing the accelerator regularly. The Customer Engagement Level was considered a secondary performance indicator to be measured because it is a ramification of the Customer Satisfaction goal. Another KPIs shall be measured to increase knowledge of the consumer. As an example, Customer Retention Rate or Customer Acquisition Cost (Dorantes-Gonzalez, 2017; Marr, 2012; Vinaixa Vergés, 2017).

\section{In the BSC Financial Perspective:}

- Accelerator: To increase its financial control, Net Profit, Net Profit Margin, Gross Profit Margin and EBITDA are the KPIs to be measured. To decrease operational cost, the accelerator should use the Return on Capital Employed 
(ROCE) and maintain funding received under control (Marr, 2012).

- Startup 1 (commercialization stage): The same indicators of the accelerator's goal should be measured by the startup 1. However, the goal of the Startup 1 is totally different than the accelerator. The startup is seeking out increase revenue, profit and margin.

- Startup 2 (growth stage): With the same goal and KPIs to be followed by the startup in commercialization stage, the startup 2 also needs to decrease operational cost. For that reason, it was chosen ROCE (Marr, 2012) as a KPI. The funding received (Carvalho, 2016) should be controlled as well.

\section{In the BSC Internal Business Process Perspective:}

- Accelerator: The focus of the company should be in quality assurance and project control. So, the Quality Index and Earned Value Analysis (EVA) were selected to help managers to control the goals (Marr, 2012). Furthermore, the accelerator should help startups to increase their sales performance. The Time to Market Index (Marr, 2012) is the indicator to be shared between the organizations.

- Startup 1 (commercialization stage) and Startup 2 (growth stage): To increase their sales, the startups should measure and control the Cost per Lead (Marr, 2012).

\section{In the BSC Learning \& Growth Perspective:}

- Accelerator: The organization may lead an Innovation program with associated startups. The Innovation Pipeline Strength (IPS) is the indicator to analyze the 
potential of new ideas and so, it is fitted to the goal measurement (Marr, 2012). Training is a need for startups employees, and the accelerator might use a KPI to measure the trainings efficacy and efficiency. It is recommended the Training Return on Investment indicator (Marr, 2012). Highlighted with high importance, the Employee Satisfaction Index (Marr, 2012) should be adopted to measure the accelerator and startups in early-stage. The IT governance cost is usually a concern and the IT Cost as Percentage of Revenue (Marr, 2012) is a way to check the expenditures in IT.

- Startup 1 (commercialization stage): The startup 1 intends to use the same accelerator's metrics, following the same goals.

- Startup 2 (growth stage): Potential participant in the Innovation Program, the startups 2 might use the Innovation Pipeline Strength (Marr, 2012) indicator.

\section{RQ2: What are the interdependencies between goals and performance indicators on accelerators and their associated startups?}

The accelerator should be recurrently informed or consulted by startups, and some performance indicators should be shared across the organizations. The Table 25 summarizes the dependencies of startups information on the accelerator point of view.

Table 25 - Dependencies Between the Accelerator and Associated Startups

\begin{tabular}{|c|c|c|c|c|c|c|}
\hline \multirow{2}{*}{$\begin{array}{l}\text { BSC } \\
\text { Perspective }\end{array}$} & \multirow{2}{*}{ Goal } & \multirow{2}{*}{ Performance Indicators } & \multirow{2}{*}{$\begin{array}{c}\text { Report } \\
\text { frequency }\end{array}$} & \multicolumn{3}{|c|}{ Dependencies } \\
\hline & & & & (S1) & (S2) & (SH) \\
\hline \multirow{3}{*}{ Customer } & \multirow{2}{*}{ Increase Customer Satisfaction } & Customer Satisfaction Index & Weekly & $\checkmark$ & $\checkmark$ & \\
\hline & & Customer Engagement Level & Monthly & $\checkmark$ & $\checkmark$ & \\
\hline & $\begin{array}{l}\text { Increase the Customer } \\
\text { Profitability }\end{array}$ & Customer Profitability Score & Weekly & $\checkmark$ & & \\
\hline \multirow{3}{*}{ Financial } & \multirow{3}{*}{$\begin{array}{l}\text { Increase Financial Control } \\
\text { Increase Revenue, Profit and } \\
\text { Margin }\end{array}$} & Net Profit & Monthly & $\checkmark$ & $\checkmark$ & \\
\hline & & Net Profit Margin & Monthly & $\checkmark$ & $\checkmark$ & \\
\hline & & Gross Profit Margin & Monthly & $\checkmark$ & $\checkmark$ & \\
\hline
\end{tabular}




\begin{tabular}{l|l|l|l|l|l|l} 
& & EBITDA & Monthly & $\checkmark$ & $\checkmark$ & \\
\cline { 3 - 6 } & \multirow{4}{*}{ Decrease Operational Cost } & Operating Profit Margin (OER) & Monthly & & $\checkmark$ & \\
\hline & $\begin{array}{l}\text { Return on Capital Employed } \\
\text { (ROCE) }\end{array}$ & Monthly & & $\checkmark$ & \\
\hline & Operating Expense Ratio (OER) & Monthly & & $\checkmark$ & \\
\cline { 2 - 6 } & Funding Management & Funding Received & Monthly & & $\checkmark$ & \\
\hline \multirow{3}{*}{$\begin{array}{l}\text { Learning \& } \\
\text { Growth }\end{array}$} & Employees Training & Training Return on Investment & AD HOC & $\checkmark$ & $\checkmark$ & \\
\hline & IT Governance & IT Costs as Percentage of Revenue & Monthly & $\checkmark$ & $\checkmark$ & \\
\hline & Innovation Program & Innovation Pipeline Strength (IPS) & Monthly & $\checkmark$ & $\checkmark$ & \\
\hline
\end{tabular}

A total of 14 indicators should be shared with the accelerator by associated startups. Initially it sounds invasive, but the majority of performance indicators are percentages, not values, except in the financial BSC perspective. On the other hand, the accelerator shall be conscious to use that information to prepare reports and share it back to startups. Can be thought as a kind of benchmark report that may be useful to compare the startups' customer satisfaction ratings, the financial healthy, and in the innovation and IT management fields.

\section{Interdependencies between the accelerator and associated startups}

To measure te customer satisfaction, the startups should collect and consolidate the customer data as a Customer Satisfaction Index, sharing the results with the accelerator every week. The accelerator should provide the parameters to measure it. Also, a monthly report of the customers engagement level might be important to be shared between the companies.

Getting the Customer Profitability Score (Marr, 2012) in hands, the accelerator might be able to compare the startups in its companies' portfolio and eventually help startups to increase their profitability per customer. However, the accelerator depends of a weekly report coming from the startup in commercialization stage to be informed. 
To increase the financial control, and help startups to increase revenue, profit and margin, the accelerator may collect financial indicators monthly from startup 1 and 2. The startup 2 should also share some performance indicators monthly with the accelerator, in order to help them to reduce the operational cost.

The funding management is a concern to startup 2 and for that reason, they should share the received venture capital with the accelerator. It is quite important for the accelerator as well, because being aware of facts they can improve their relationship with investors.

A small questionnaire should be prepared and responded after each formal training program by attendees (MaRS, 2015). Also, when the new knowledge is putting in practice, the effectiveness for the job should be measured. That is the purpose of the Training Return of Investment. It is an "ad hoc" indicator and should be measured according to the accelerator's defined parameters.

IT costs are a concern for all businesses and to improve IT governance, the indicator chosen results in the percentage of that cost compared to the company's revenue.

The innovation program was suggested by startup 1 and corroborated by startup 2 . The Innovation Pipeline Strength (IPS) is an indicator to preview the potential future revenue of the innovation projects and can be useful to incentive new profitable projects in startups. This program must be leaded by the accelerator bust startups should contribute with monthly reports of its innovative projects. 


\section{Chapter: Conclusion, Limitation and Future Research}

Chapter 6 consists of 3 sections. Section 6.1 shown conclusions of findings in this research, Section 6,.2 provides the limitations of the study, and Section 6.3 suggests future research approaches.

\subsection{Conclusions}

This thesis described a method for identifying KPIs used by accelerators and startups. It provided an empirical validation of the method using a scenario with one accelerator and two startups at different stages of growth. Given the small sample size, it is not possible to draw general conclusions about the KPIs accelerators and startups should use and how they can be aligned. However, the findings presented here allow us to conclude that a goal-oriented modelling approach is a helpful tool for documenting the KPIs used by an organization, the Balanced Scorecard approach due to its familiarity provides a useful template for starting the documentation of KPIs of accelerators and startups, and startups at different stages of growth appear to focus on different KPIs.

This study is delivering a method to be applied in goals and KPIs identification. So, the problem stated in Section 1 has been solved as shown in Sections 3 and 4. Some lessons learned from the literature review and the results of the research have been described below:

The success of an accelerator is intrinsically related of the performance of its startups. So, collaborate, measure and sharing information is crucial to accomplish the goals (Cohen, 2013) and by the accelerator side, aggregate information is a must. To get better insights and improve the relationship with startups, the accelerator should improve its 
performance indicators and periodically share it to affiliated startups. As in a consultancy firm, it takes time to develop but saves time after implemented.

In general terms, the startups will need the accelerator support to measure the performance indicators (Seens, 2015). And clearly, the startup in the commercialization stage need more attention from the accelerator because the number of goals to be achieved is higher than in the other actors. The accelerator should support the startup to open the market for innovative products. It is what the startups expected in this relationship.

All researched organizations are customer-oriented, but the startup in growth stage has a focused target in surpass the customer satisfaction and the one in commercialization stage has focus on sales and marketing.

Some improvements should be done in the relationship between accelerator and startups, specially the financial measurements. The cost control is not a major concern but, in my opinion, might be. Other authors share the same opinion (Vinaixa Vergés, 2017).

External stakeholders were rarely mentioned in the interviews. The attention with the business ecosystem should be improved. On accelerator side, quality assurance and project management are core. These good practices should be replicated to the associated startups.

Organizations' employees should be regularly trained to improve their competencies (Keogh et al., 2005), instead of the lack of budget in startups (Government of Canada, 2016). An evaluation after the training programs should be done to measure the real impact in the employees' performance. 


\subsection{Limitations}

The research had a small sample to validate the concepts and the proposed method. A largest sample would have helped to determine more interactions and visibility of the proposed variables. However, a great number of variables enriched the results, potentializing the findings and adding important details for this thesis.

Nevertheless, this study is trying to proof that a small company can develop its goals and measurements from scratch, with simple tools, for free, and in a fast pace has the results to drive their actions. Using the proposed method, the startup can identify the soft goals that must be improved, enclose the relationship with the accelerator to ask for support, and perhaps understand the barriers to growth.

\subsection{Future Research}

Using the method in new scenarios: This method should be used in other scenarios. Typical business relationships should be analyzed and then being compared. For example, a small company and a new business partner in a joint venture should compare the objectives and the business synergy between them. Another example is the relationship between accelerators and venture capitalists, understanding the needs, contributions and dependencies between the actors. It is recommended to check the performance indicator list and include or substitute the ones that are not fitted for future researches.

Extend Analysis using jUCNav: The scope of the analysis should be increased with the use of more features in jUCMNav. The GRL models may be analyzed automatically by the tool (Amyot et al., 2012) and the data exported to MS Excel files, allowing the user to 
create extra dimensions and apply other variables in the analysis.

Include variables: Other variables which are not presented in this study can be included in the proposed method, and for other researchers, the method adoption should be a starting point. The categorization proposed can save time and provide a base for further researches in the fields of KPI, goal-oriented models and balance scorecard implementation in small tech companies.

Replicate method: It is hoped that future research attempts to replicate this method, as well as it appears in this document. This would help to determine if the heuristics can be refined, or if the time required to generate the results should decrease. It would be worthwhile to compare the data when applying this method to a larger dataset. As the comparison was restricted to a relatively small data set, the effort is unclear.

Finally, a comprehensive review of the balanced scorecard adoption in startups, KPI selection and comparison between strategic objectives would generate interesting results. 


\section{Chapter: References}

Amyot, D., Ghanavati, S., Horkoff, J., Mussbacher, G., Peyton, L., et al. 2010. Evaluating goal models within the goal-oriented requirement language. International Journal of Intelligent Systems, 25(8): 841-877.

Amyot, D., Rashidi-Tabrizi, R., Mussbacher, G., Kealey, J., Tremblay, E., et al. 2013. Improved GRL Modeling and Analysis with jUCMNav 5. Proceedings of the 6th International $i^{*}$ Workshop (iStar 2013), CEUR Vol-978. Presented at the 6th International i* Workshop, Valencia, Spain.

Amyot, D., Shamsaei, A., Kealey, J., Tremblay, E., Miga, A., et al. 2012. Towards Advanced Goal Model Analysis with jUCMNav. Springer.

Andersen, H., Cobbold, I., \& Lawrie, G. 2009. Balanced Scorecard implementation in SMEs: reflection in literature and practice.

http://citeseerx.ist.psu.edu/viewdoc/download?doi=10.1.1.183.8335\&rep=rep1\&t ype $=$ pdf.

Ates, A., Garengo, P., Cocca, P., \& Bititci, U. 2013. The development of SME managerial practice for effective performance management. Journal of Small Business and Enterprise Development, 20(1): 28-54.

Bochman, G. V. 2010, Fall. Goal Modeling and GRL. University of Ottawa. http://www.site.uottawa.ca/ bochmann/SEG3101/Notes/SEG3101-ch3-5\%20\%20Goal\%20modeling\%20-\%20GRL.pdf.

Bøllingtoft, A., \& Ulhøi, J. P. 2005. The networked business incubator-leveraging entrepreneurial agency? Journal of Business Venturing, 20(2): 265-290.

Cabanillas, C., Resinas, M., \& Ruiz-Cortes, A. 2011. Mixing RASCI Matrices and BPMN Together for Responsibility Management?, 1: 167-180. Presented at the VII Jornadas en Ciencia e Ingeniería de Servicios (JCIS 2011), Spain: Universidad de Sevilla.

Cabanillas, C., Resinas, M., \& Ruiz-Cortés, A. 2012. Automated Resource Assignment in 
BPMN Models Using RACI Matrices. In R. Meersman, H. Panetto, T. Dillon, S. Rinderle-Ma, P. Dadam, et al. (Eds.), On the Move to Meaningful Internet Systems: OTM 2012, 56-73. Springer Berlin Heidelberg.

Camacho, C. M. 2015, February. Common Business Development Activities In Successful Technology Startups. Aalto University.

Carter, B. 2018, January 25. What is the definition of Customer Engagement? Access Development. https://blog.accessdevelopment.com/what-is-the-definition-ofcustomer-engagement.

Carvalho, A. C. C. C. de. 2016, September. Digital Startups Accelerators:

Characteristics and Evolution Trends. Universidade de Nova Lisboa. http://hdl.handle.net/10362/20023.

Castano, S., \& ER (Eds.). 2012. Advances in conceptual modeling: ER 2012 Workshops: CMS, ECDM-NoCoDA, MoDIC, MORE-BI, RIGiM, SeCoGIS, WISM, Florence, Italy, October 15 - 18, 2012: proceedings. Heidelberg: Springer.

Chris, A. n.d. What is the Difference Between SEO and SEM? reliablesoft.net. https://www.reliablesoft.net/what-is-the-difference-between-seo-and-sem/, August 21, 2018.

Christensson, P. 2006. CPL. Techterms.com. https://techterms.com/definition/cpl.

Cohen, S. 2013. What Do Accelerators Do Insights from Incubators and Angels.

Corporate Finance Institute. 2018. What is EBITDA? Corporate Finance Institute. https://corporatefinanceinstitute.com/resources/knowledge/finance/what-isebitda/.

Croll, A., \& Yoskovitz, B. 2013. Lean analytics: use data to build a better startup faster (1st ed). Sebastopol, CA: O’Reilly.

de Boer, J., Vandecasteele, J., \& Rau, K. 2001. Use of the Balanced Scorecard for ICT Performance Management. Compact, 6-19.

Dempwolf, S. C., Auer, J., \& D’Ippolito, M. 2014. Innovation Accelerators: Defining 
Characteristics Among Startup Assistance Organizations. Optimal Solutions Group, LLC.

Dorantes-Gonzalez, J. D. 2017. A Novel Business Model Frame for Innovative Startups, 4: 49-59. Presented at the 2nd World Conference on Technology, Innovation and Entrepreneurship, Istanbul, Turkey.

Ehrenberg, D. 2014, June 20. The Seven Startup Metrics You Must Track. Forbes.com. https://www.forbes.com/sites/theyec/2014/06/20/the-seven-startup-metrics-youmust-track/\#453146ea725e.

Feltus, C., Petit, M., \& Dubois, E. 2009. Strengthening employee's responsibility to enhance governance of IT: COBIT RACI chart case study. Proceedings of the first ACM workshop on Information security governance - WISG '09, 23. Presented at the the first ACM workshop, Chicago, Illinois, USA: ACM Press.

Feltus, C., Petit, M., \& Dubois, E. 2011. ReMoLa: Responsibility model language to align access rights with business process requirements. 2011 FIFTH INTERNATIONAL CONFERENCE ON RESEARCH CHALLENGES IN INFORMATION SCIENCE, 1-6. Presented at the 2011 IEEE Fifth International Conference on Research Challenges in Information Science (RCIS), Gosier, France: IEEE.

Financial Times. 2018. Definition of net profit. Financial Times. http://lexicon.ft.com/Term?term=net-profit.

Galetto, M. 2018, July 3. What is Customer Retention? NG Data. https://www.ngdata.com/what-is-customer-retention/.

Genroe Inc. n.d. Customer Satisfaction Score / Customer Satisfaction Index. Genroe. https://www.genroe.com/resources/glossary/customer-experience-managementdefinitions-and-glossary/customer-satisfaction-score-customer-satisfaction-index, August 5, 2018.

Gomes, R. C., \& Lírio, V. S. 2014. Strategic Planning in Brazilian Small-Scale Municipalities: is the Balanced Scorecard a feasible tool? Revista de 
Administração Da UFSM, 7(1). https://doi.org/10.5902/198346598143.

Government of Canada. 2016. Key Small Business Statistics. Inovatio, Science and Economic Development, Smal Business Branch. https://www.ic.gc.ca/eic/site/061.nsf/vwapj/KSBS-PSRPE_June-Juin_2016_engV2.pdf/\$file/KSBS-PSRPE_June-Juin_2016_eng-V2.pdf.

Government of Canada. 2017. BAI National Dialogue Summary. Government of Canada. https://www.ic.gc.ca/eic/site/061.nsf/eng/03051.html.

Government of Canada, I. 2016. Key Small Business Statistics - June 2016 - SME research and statistics. Reports;Statistical Reports. https://www.ic.gc.ca/eic/site/061.nsf/eng/h_03018.html.

Group I-Star. 2012. i-star - with tag _ industry-partnered [28 articles]. citeulike.org. http://www.citeulike.org/group/14571/tag/_industry-partnered.

Gumbus, A., \& Lussier, R. N. 2006. Entrepreneurs Use a Balanced Scorecard to Translate Strategy into Performance Measures. Journal of Small Business Management, 44(3): 407-425.

Hartman, F., \& Ashrafi, R. 2004. Development of the SMARTTM Project Planning framework. International Journal of Project Management, 22(6): 499-510.

Hoffman, D. L., \& Radojevich-Kelley, N. 2012. Analysis of Accelerator Companies: An Exploratory Case Study of Their Programs, Processes, and Early Results. Small Business Institute ${ }^{\circledR}$ Journal. https://www.sbij.org/index.php/SBIJ/article/view/136/93.

Hogg, S. 2016, October. Drowning in Seed Money - Congrats, you scored funding. Now what?

Hope, J., \& Fraser, R. 2003. Beyond budgeting: how managers can break free from the annual performance trap. Boston, Mass: Harvard Business School Press.

Horkoff, J., \& Yu, E. 2011. Analyzing goal models: different approaches and how to choose among them, 675. ACM Press. 
Horkoff, J., Yu, E., \& Ghose, A. 2010. Interactive Goal Model Analysis Applied Systematic Procedures versus Ad hoc Analysis. In P. van Bommel, S. Hoppenbrouwers, S. Overbeek, E. Proper, \& J. Barjis (Eds.), The Practice of Enterprise Modeling, vol. 68: 130-144. Berlin, Heidelberg: Springer Berlin Heidelberg.

Intrafocus. n.d. KPI Library - Customer Profitability. Intrafocus. https://www.intrafocus.com/kpi-library/customer-profitability-score/, August 5, 2018.

investinganswers. 2018. investinganswers.com. https://investinganswers.com/financialdictionary/financial-statement-analysis/operating-margin-370.

Investopedia. n.d. Net Income. Investopedia. https://www.investopedia.com/terms/n/netincome.asp, August 5, 2018a.

Investopedia. n.d. Gross Margin. Investopedia. https://www.investopedia.com/terms/g/grossmargin.asp, August 5, $2018 \mathrm{~b}$.

Investopedia. n.d. Operating Expense Ratio - OER. Investopedia. https://www.investopedia.com/terms/o/operating-expense-ratio.asp, August 5, 2018c.

Investopedia. n.d. Return On Capital Employed (ROCE). Investopedia. https://www.investopedia.com/terms/r/roce.asp, August 5, $2018 \mathrm{~d}$.

Investopedia. n.d. Price-Earnings Ratio - P/E Ratio. Investopedia. https://www.investopedia.com/terms/p/price-earningsratio.asp, August 5, $2018 \mathrm{e}$.

Investopedia. n.d. Capacity Utilization Rate. Investopedia. https://www.investopedia.com/terms/c/capacityutilizationrate.asp.

Isabelle, D. 2013. Key Factors Affecting a Technology Entrepreneur's Choice of Incubator or Accelerator. https://timreview.ca/sites/default/files/article_PDF/Isabelle_TIMReview_Februar y2013.pdf. 
I*Wiki. n.d. jUCMNav. I*Wiki. http://www.citeulike.org/group/14571/tag/_industrypartnered, August 27, 2018.

Juetten, M. 2016, June 15. Key Performance Metrics In The Innovation Department. Forbes.com. https://www.forbes.com/sites/maryjuetten/2016/06/15/keyperformance-metrics-in-the-innovation-department/\#22ef6ef54694.

Kaplan, R. S., \& Norton, D. P. 1993. Putting the Balanced Scorecard to Work. The Economic Impact of Knowledge. Elsevier. https://doi.org/10.1016/B978-0-75067009-8.50023-9.

Kaplan, R. S., \& Norton, D. P. 1996. Using the Balanced Scorecard as a Strategic Management System. Harvard Business Review Digital Articles. http://web.b.ebscohost.com/bsi/pdfviewer/pdfviewer?vid=0\&sid=adc8e640-1707477c-8000-a7789d811ac7\%40sessionmgr120.

Keogh, W., Mulvie, A., \& Cooper, S. 2005. The identification and application of knowledge capital within small firms. Journal of Small Business and Enterprise Development, 12(1): 76-91.

Kohler, T. 2016. Corporate accelerators: Building bridges between corporations and startups. Business Horizons, 59(3): 347-357.

KPI Institute. n.d. World's Largest Database of Documented Kpis. Smart KPIs. https://smartkpis.kpiinstitute.org/, July 10, 2018.

Lavinsky, D. 2014, March 18. How To Increase Conversion Rates. Forbes. https://www.forbes.com/sites/davelavinsky/2014/03/18/how-to-increaseconversion-rates/\#3784a20016d4.

Llorach, C., \& Ottosson, E. 2016. The Balanced Scorecard during the early stages of a tech firm - A multiple case study regarding performance management in Swedish tech startups. Master Thesis, Uppsala University, Uppsala, Sweden.

Lonbani, M., Sofian, S., \& Baroto, M. B. 2016. Balanced Scorecard Implementation in SMEs: Addressing the Moderating Role of Environmental Uncertainty. Global Business and Organizational Excellence, 35(3): 58-66. 
Marr, B. 2012. Key performance indicators: the 75 measures every manager needs to know (1st ed.). Harlow, England; New York: Pearson Financial Times Pub.

Marr, B. n.d. Quality Index. Bernard Marr. https://www.bernardmarr.com/default.asp?contentID=887, August 14, 2018a.

Marr, B. n.d. Innovation Pipeline Strenght. Bernardmarr.com. https://www.bernardmarr.com/default.asp?contentID=882, August 5, $2018 \mathrm{~b}$.

MaRS. 2015, June 16. Training programs: Evaluating ROI and training effectiveness. MaRS. https://www.marsdd.com/mars-library/training-programs-evaluating-roiand-training-effectiveness/.

Maurya, A. 2016. Scaling Lean. Penguin Publishing Group. http://www.myilibrary.com?id=928640.

Mussbacher, G., \& Amyot, D. 2009. Goal and Scenario Modeling, Analysis, and Transformation with jUCMNav. IEEE. https://www.researchgate.net/profile/Daniel_Amyot2/publication/224503839_Go al_and_Scenario_Modeling_Analysis_and_Transformation_with_jUCMNav/links /0c9605377aecd6aece000000.pdf.

NESTA Innovation Skills Team. 2014. Startup Accelerator Programmes - A Practice Guide. NESTA. https://www.nesta.org.uk/toolkit/startup-acceleratorprogrammes-a-practice-guide/.

Parmenter, D. 2007. Key performance indicators: developing, implementing, and using winning KPIs. Hoboken, N.J: John Wiley \& Sons.

Parmenter, D. 2015. Key performance indicators: developing, implementing, and using winning KPIs (Third edition). Hoboken, New Jersey: Wiley.

Partner Path. 2017. 5 Partner Program KPIs You're Measuring. Partner Path. https://www.partner-path.com/blog/5-partner-program-kpis-youre-measuring-andthe-5-you-should-be.

Pourshahid, A. 2013, December. A Framework for Monitoring and Adapting Business 
Processes Using Aspect-Oriented URN. University of Ottawa.

Pourshahid, A., Johari, I., Richards, G., Amyot, D., \& Akhigbe, O. S. 2014. A goaloriented, business intelligence-supported decision-making methodology. Decision Analytics, 1(1): 9.

Project Management Institute (Ed.). 2017. A guide to the project management body of knowledge / Project Management Institute (Sixth edition). Newtown Square, PA: Project Management Institute.

Rickards, R. C. 2007. BSC and benchmark development for an e-commerce SME. Benchmarking: An International Journal, 14(2): 222-250.

Roberts, P., \& Kempner, R. 2017. Startup Accelerators Have Become More Popular in Emerging Markets - and They're Working. Harvard Business Review Digital Articles.

Seens, D. 2015. SME operating performance. Government of Canada - Small Business Branch. http://epe.lac-bac.gc.ca/100/201/301/weekly_acquisition_lists/2015/w1536-F-E.html/collections/collection_2015/ic/Iu188-121-2015-eng.pdf.

Smith, M., \& Erwin, J. 2005. Role \& Responsibility Charting (RACI), 5. Presented at the Project Management Forum (PMForum).

Soffer, P., \& Wand, Y. 2005. On the notion of soft-goals in business process modeling. (I. Bider, Ed.)Business Process Management Journal, 11(6): 663-679.

Techopedia. n.d. Time to Market. Techopedia.com. https://www.techopedia.com/definition/23821/time-to-market, August 5, 2018.

Torun, M. 2016. Business Accelerators and Their Differences from Incubators. https://doi.org/10.13140/rg.2.2.25975.62884.

van Lamsweerde, A. 2000. Goal-oriented requirements engineering: a guided tour, 249262. IEEE Comput. Soc.

van Lamsweerde, A., \& Letier, E. 2004. From Object Orientation to Goal Orientation: A Paradigm Shift for Requirements Engineering. In M. Wirsing, A. Knapp, \& S. 
Balsamo (Eds.), Radical Innovations of Software and Systems Engineering in the Future, 325-340. Springer Berlin Heidelberg.

Vinaixa Vergés, A. 2017, June. Design of a Startup acceleration program. Escola

Tècnica Superior d'Enginyeria Industrial de Barcelona, Barcelona, Espanha. https://upcommons.upc.edu/bitstream/handle/2117/111812/Memory_Design_of_a _Startup_Acceleration_Programme_by_Albert_Vinaixa.pdf? sequence $=1 \&$ isAllo wed $=\mathrm{y}$.

Von Bueren, K. P. O. 2016. Accelerators, Startup Performance, and Crises. Massachusetts Institute of Technology.

WBDG. 2016. Earned Value Analysis - Introduction. WBDG.org. https://www.wbdg.org/resources/earned-value-analysis.

Weiss, M., \& Amyot, D. 2005a. Designing and Evolving Business Models with URN.

Weiss, M., \& Amyot, D. 2005b. Business Process Modeling with URN. International Journal of E-Business Research, 1(3). https://jucmnav.softwareengineering.ca/ucm/pub/UCM/VirLibIjebr05/IJEBR05.p df.

Wikipedia. n.d. Funding. Wikipedia. https://en.wikipedia.org/wiki/Funding, August 5, 2018. 


\title{
Appendices
}

\section{Appendix A - Performance Indicators Description}

\author{
1. Customer Performance Indicators
}

\begin{tabular}{|c|c|c|c|}
\hline $\begin{array}{l}\text { Customer } \\
\text { Soft Goals }\end{array}$ & $\begin{array}{l}\text { Performance } \\
\text { Indicators }\end{array}$ & Description & Source \\
\hline $\begin{array}{l}\text { Customer } \\
\text { retention }\end{array}$ & $\begin{array}{l}\text { Customer } \\
\text { Retention Rate }\end{array}$ & $\begin{array}{l}\text { (Galetto, 2018) Measure the organizations number of } \\
\text { customer defection. It begins with the customer first } \\
\text { approach and continues throughout the customer } \\
\text { lifetime relationship. }\end{array}$ & $\frac{\frac{\text { https://t }}{\text { inyurl.c }}}{\underline{\text { om/gsr }}}$ \\
\hline $\begin{array}{l}\text { Customer } \\
\text { satisfaction }\end{array}$ & $\begin{array}{l}\text { Customer } \\
\text { satisfaction index }\end{array}$ & $\begin{array}{l}\text { (Genroe Inc., n.d.) Customer satisfaction index is } \\
\text { attempting to measure how satisfied customers are } \\
\text { with company's performance, directly impacting in } \\
\text { the retention of customers. }\end{array}$ & $\frac{\underline{\text { https://t }}}{\underline{\text { inyurl.c }}} \frac{\text { om/y7r }}{\underline{\text { uwqd4 }}}$ \\
\hline $\begin{array}{l}\text { Customer } \\
\text { engagement }\end{array}$ & $\begin{array}{l}\text { Customer } \\
\text { engagement } \\
\text { Level }\end{array}$ & $\begin{array}{l}\text { (Carter, 2018) Customer engagement is characterized } \\
\text { when a customer has some of these feelings about the } \\
\text { company: (1) they purchased or continues paying for } \\
\text { company's products or services; ( } 2 \text { ) they refer the } \\
\text { brand for family, friends and in social media; (3) they } \\
\text { provide feedback about the product and brand } \\
\text { development; (4) they are loyal to the brand in a } \\
\text { particular category. }\end{array}$ & $\begin{array}{l}\frac{\text { https://t }}{\text { inyurl.c }} \\
\frac{\text { om/y7b }}{\text { zn3nm }}\end{array}$ \\
\hline $\begin{array}{l}\text { Customer } \\
\text { profitability }\end{array}$ & $\begin{array}{l}\text { Customer } \\
\text { profitability } \\
\text { score }(\mathrm{CP})\end{array}$ & $\begin{array}{l}\text { (Intrafocus, n.d.) This measure intends to inform and } \\
\text { prioritizes the customers regardless of their value to } \\
\text { the organization, understanding which customers } \\
\text { contribute positively to the organization's profit. }\end{array}$ & $\frac{\frac{\text { https://t }}{\text { inyurl.c }}}{\frac{\text { om/y9c }}{\text { bqc7u }}}$ \\
\hline $\begin{array}{l}\text { Revenue through } \\
\text { partners }\end{array}$ & $\begin{array}{l}\text { Revenue through } \\
\text { partners }\end{array}$ & $\begin{array}{l}\text { (Partner Path, 2017) It measures the revenue from } \\
\text { partners purchasing your company's products to } \\
\text { retailing it, or to track the revenue sourced by } \\
\text { partners. }\end{array}$ & $\begin{array}{l}\frac{\text { https://t }}{\text { inyurl.c }} \\
\underline{\text { om/ybe }} \\
\text { o5vwm }\end{array}$ \\
\hline
\end{tabular}

2. Financial Performance Indicators

\begin{tabular}{l|l|l|l|}
$\begin{array}{c}\text { Financial } \\
\text { Soft Goals }\end{array}$ & $\begin{array}{c}\text { Performance } \\
\text { Indicators }\end{array}$ & Description & Source \\
\hline $\begin{array}{l}\text { Revenue, profit } \\
\text { and margin }\end{array}$ & Net Income & $\begin{array}{l}\text { (Investopedia, n.d.) Net income is a calculus of the } \\
\text { income minus the cost of goods sold, expenses and }\end{array}$ & $\underline{\underline{\mathrm{https}: / / \mathrm{t}}}$ \\
$\underline{\mathrm{iny} / \mathrm{ub} / \mathrm{c}}$
\end{tabular}




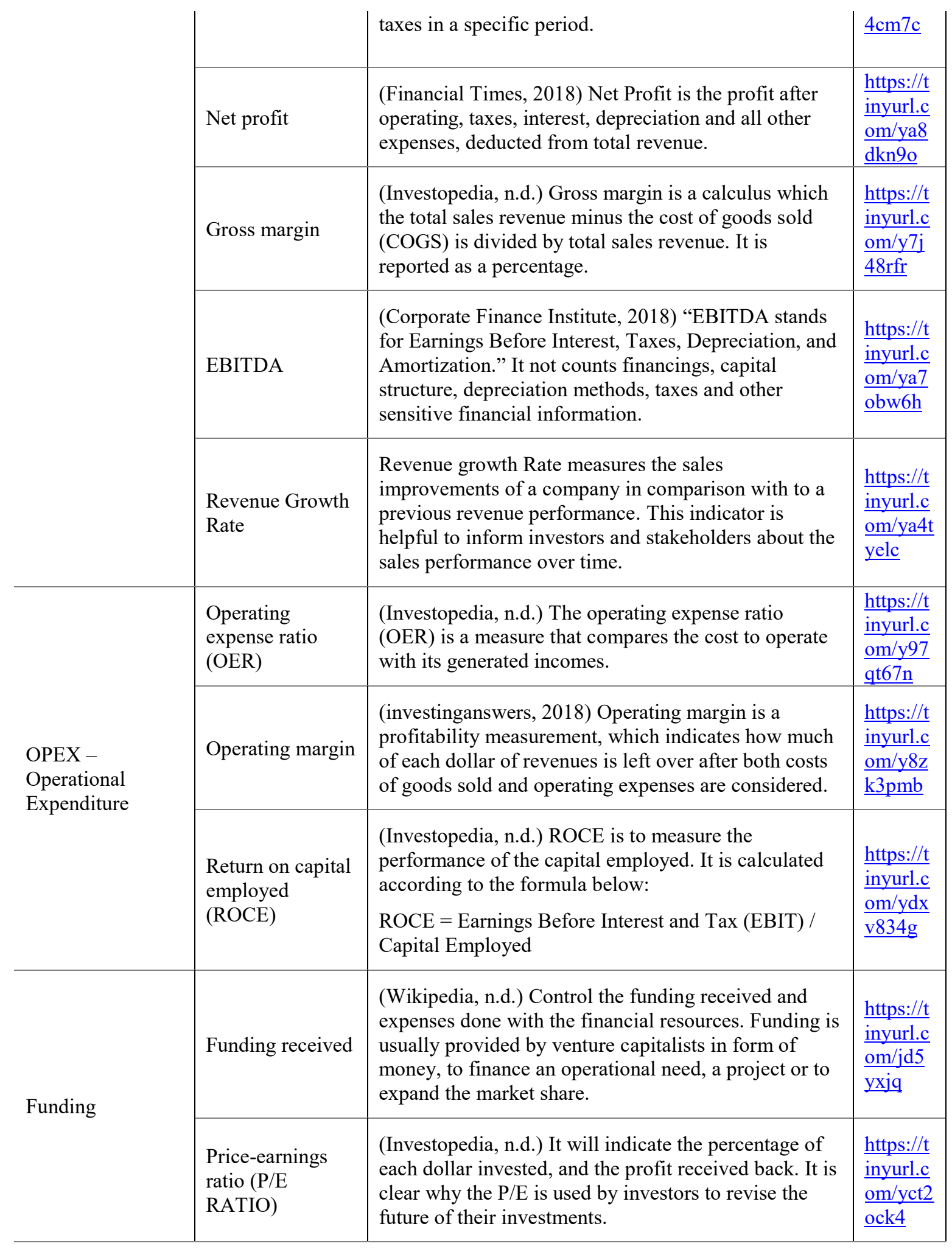

\section{Internal Business Process Performance Indicators}




\begin{tabular}{|c|c|c|c|}
\hline $\begin{array}{c}\text { Internal Business } \\
\text { Process } \\
\text { Soft Goals }\end{array}$ & $\begin{array}{l}\text { Performance } \\
\text { Indicators }\end{array}$ & Description & Source \\
\hline $\begin{array}{l}\text { Quality level } \\
\text { (e.g., Six Sigma) }\end{array}$ & Quality Index & $\begin{array}{l}\text { (Marr, n.d.) Quality Index is a combination of several } \\
\text { operational and service quality measurements, usually } \\
\text { including First Pass Yield, Defect rates, Delivery } \\
\text { Performance and more. }\end{array}$ & $\begin{array}{l}\frac{\text { https://t }}{\underline{\text { inyurl.c }}} \\
\underline{\underline{\text { om/yb4 }}} \\
\underline{\text { znh6s }}\end{array}$ \\
\hline $\begin{array}{l}\text { Project control } \\
\text { and monitoring }\end{array}$ & $\begin{array}{l}\text { Earned Value } \\
\text { Analysis (EVA) }\end{array}$ & $\begin{array}{l}\text { (WBDG, 2016) Earned Value Analysis (EVA) is a } \\
\text { project management standard method to measure and } \\
\text { control the project's performance time, budget, track } \\
\text { the completion date and cost, analyzing the variances } \\
\text { during the projects' time. }\end{array}$ & $\frac{\underline{\text { https: } / / \mathrm{t}}}{\underline{\underline{\text { inyurl.c }}}} \frac{\text { om/glv }}{\underline{\text { v7od }}}$ \\
\hline \multirow{3}{*}{$\begin{array}{l}\text { Marketing and } \\
\text { Online metrics }\end{array}$} & $\begin{array}{l}\text { Conversion } \\
\text { rating }\end{array}$ & $\begin{array}{l}\text { (Lavinsky, 2014) Measures the percentage of } \\
\text { prospective customers who take action previously } \\
\text { defined. For example, the rate of unique visitors that } \\
\text { had bought products from an e-commerce website. }\end{array}$ & $\frac{\frac{\text { https://t }}{\text { inyurl.c }}}{\frac{\text { om/yae }}{\text { yh8vq }}}$ \\
\hline & $\mathrm{SEO} / \mathrm{SEM}$ & $\begin{array}{l}\text { (Chris, n.d) Both processes aim at increasing visibility } \\
\text { in search engines. Search Engine Optimization (SEO) } \\
\text { is part of Search engine marketing, and it is free of } \\
\text { charge by search engines. In counter-part, Search } \\
\text { Engine Marketing (SEM) is a paid advertisement as in } \\
\text { Pay Per Click (PPC). }\end{array}$ & $\begin{array}{l}\frac{\text { https://t }}{\text { inyurl.c }} \\
\underline{\underline{\text { om/ycm }}} \\
\underline{5 \text { sx35 }}\end{array}$ \\
\hline & $\begin{array}{l}\text { Time to Market } \\
\text { index }\end{array}$ & $\begin{array}{l}\text { (Techopedia, n.d.) Time to market is a measurement } \\
\text { between the time the ideas flourished around a } \\
\text { product and when it is launching in the market. }\end{array}$ & $\begin{array}{l}\underline{\text { https://t }} \\
\underline{\underline{\text { inyurl.c }}} \\
\underline{\text { om/yb2 }} \\
\underline{\text { xpdqu }}\end{array}$ \\
\hline \multirow{2}{*}{$\begin{array}{l}\text { Products and } \\
\text { services } \\
\text { performance }\end{array}$} & $\begin{array}{l}\text { Cost per lead } \\
\text { (CPL) }\end{array}$ & $\begin{array}{l}\text { (Christensson, 2006) CPL defines how much revenue } \\
\text { a publisher receives when he creates a lead for an } \\
\text { advertiser. It is typically an online metric but can be } \\
\text { applied in sales leads as well. }\end{array}$ & $\begin{array}{l}\frac{\text { https://t }}{\text { inyurl.c }} \\
\underline{\text { om/yb2 }} \\
\underline{\text { bvn81 }}\end{array}$ \\
\hline & $\begin{array}{l}\text { Capacity } \\
\text { Utilization Rate } \\
\text { (CUR) }\end{array}$ & $\begin{array}{l}\text { (Investopedia, n.d.) The CUR measures the } \\
\text { percentage of production in comparison with the full } \\
\text { capacity of the company. The formula is: } \\
\text { (Actual Output / Potential Output ) x } 100\end{array}$ & $\begin{array}{l}\frac{\text { https://t }}{\text { inyurl.c }} \\
\frac{\text { om/yahj }}{9 \mathrm{wjy}}\end{array}$ \\
\hline
\end{tabular}

\section{Learning \& Growth Performance Indicators}

\begin{tabular}{|c|c|c|c|}
\hline $\begin{array}{l}\text { Learning \& } \\
\text { Growth } \\
\text { Soft Goals }\end{array}$ & $\begin{array}{l}\text { Performance } \\
\text { Indicators }\end{array}$ & Description & Source \\
\hline $\begin{array}{l}\text { Education and } \\
\text { Training }\end{array}$ & Training return & $\begin{array}{l}\text { (MaRS, 2015) To evaluates the effectiveness of the } \\
\text { training programs: (a) Participant feedback; (b) Tests }\end{array}$ & $\begin{array}{l}\underline{\text { https: } / / \mathrm{t}} \\
\underline{\text { inyurl.c }} \\
\underline{\text { om } / \mathrm{y} 9 \mathrm{o}}\end{array}$ \\
\hline
\end{tabular}




\begin{tabular}{|c|c|c|c|}
\hline & on investment & $\begin{array}{l}\text { and observation; (c) Qualitative and quantitative } \\
\text { results; (d) Focus the process on simplicity and } \\
\text { accountability. }\end{array}$ & qlqmb \\
\hline $\begin{array}{l}\text { Technology, } \\
\text { Equipment and } \\
\text { System } \\
\text { Development }\end{array}$ & $\begin{array}{l}\text { IT Costs as } \\
\text { Percentage of } \\
\text { Revenue }\end{array}$ & $\begin{array}{l}\text { (Marr, 2012) IT Cost as a Percentage of Revenue is a } \\
\text { comparison with the total cost of IT, including } \\
\text { outsourcing, with the company's revenue. }\end{array}$ & $\begin{array}{l}\underline{\text { https: } / / \mathrm{t}} \\
\underline{\text { inyurl.c }} \\
\underline{\underline{\text { om/ycx }}} \\
\underline{\text { ead9h }}\end{array}$ \\
\hline $\begin{array}{l}\text { Innovation } \\
\text { enhancement }\end{array}$ & $\begin{array}{l}\text { Innovation } \\
\text { pipeline strength } \\
\text { (IPS) }\end{array}$ & $\begin{array}{l}\text { (Marr, n.d.) Innovation Pipeline Strength (IPS) is an } \\
\text { indicator to preview the potential future revenue of the } \\
\text { innovation projects in a company. }\end{array}$ & $\begin{array}{l}\frac{\mathrm{https}: / / \mathrm{t}}{\text { inyurl.c }} \\
\underline{\text { om/y82 }} \\
\underline{\text { nenof }}\end{array}$ \\
\hline $\begin{array}{l}\text { Employee } \\
\text { satisfaction and } \\
\text { engagement }\end{array}$ & $\begin{array}{l}\text { Employee } \\
\text { satisfaction index }\end{array}$ & $\begin{array}{l}\text { (Marr, 2012) Employee Satisfaction Index can be } \\
\text { measured depending of the organizational priorities, } \\
\text { and it is nor restricted of one specific measurement. } \\
\text { To exemplify, the company can evaluate career } \\
\text { progression, company culture, work conditions, or } \\
\text { salary as an employee satisfaction factor. }\end{array}$ & $\frac{\underline{\text { https: } / / \mathrm{t}}}{\frac{\text { inyurl.c }}{\text { om/y9o }}}$ \\
\hline
\end{tabular}




\section{Appendix B - Data}

\section{Soft Goals - Importance}

\begin{tabular}{|c|c|c|c|c|c|c|}
\hline Importance Ratings & Acceler. & Startup 1 & Startup 2 & $\begin{array}{c}\text { Acceler. } \\
+ \\
\text { Startup } 1\end{array}$ & $\begin{array}{c}\text { Acceler. } \\
+ \\
\text { Startup } 2\end{array}$ & $\begin{array}{c}\text { Overall } \\
\text { rating }\end{array}$ \\
\hline CUSTOMER & High & High & Medium & High & High & High \\
\hline Customer engagement & High & High & High & Medium & Medium & High \\
\hline Customer lifetime value & High & Low & Medium & Medium & High & Medium \\
\hline Customer profitability & High & High & Medium & High & High & High \\
\hline Customer retention & High & High & Medium & High & High & High \\
\hline Customer satisfaction & High & High & High & High & High & High \\
\hline Partnerships and external relationships & Medium & High & Medium & Medium & Medium & Medium \\
\hline FINANCIAL & Medium & Low & Medium & Medium & Medium & Medium \\
\hline CAPEX and Capital Expenditure & Low & Low & Low & Low & Low & Low \\
\hline Company valuation & Low & Low & Low & Low & Low & Low \\
\hline Funding & High & Low & High & Medium & High & Medium \\
\hline OPEX and Operational Expenditure & Medium & Medium & High & Medium & Medium & Medium \\
\hline Portfolio evaluation & Low & Low & Low & Low & Low & Low \\
\hline Return on investment, capital, equity or assets & Medium & Medium & Low & Low & Low & Low \\
\hline Revenue, profit and margin & High & High & High & High & High & High \\
\hline INTERNAL BUSINESS PROCESS & Medium & Medium & Medium & High & Medium & Medium \\
\hline Consumables or recyclable & Low & Low & Low & Low & Low & Low \\
\hline Marketing and Online metrics & Medium & HIgh & High & Medium & Medium & High \\
\hline Operational setup and process & Low & High & Medium & Medium & Medium & Medium \\
\hline Patents & Low & Low & Low & Low & Low & Low \\
\hline Products and services performance & HIgh & HIgh & High & HIgh & HIgh & High \\
\hline Project control and monitoring & High & Medium & Low & High & Medium & Medium \\
\hline Quality level (e.g.: Six Sigma) & High & Low & Medium & Medium & High & Medium \\
\hline Supply chain/fulfillment & Low & Low & Low & Low & Low & Low \\
\hline LEARNING AND GROWTH & High & High & Medium & High & HIgh & High \\
\hline Actual jobs, new jobs and positions retained & Medium & Low & Low & Low & Low & Low \\
\hline Education and training & High & High & Medium & High & High & High \\
\hline Employee satisfaction and engagement & High & High & Medium & High & High & High \\
\hline Human capital value & Medium & Low & Low & Low & Low & Low \\
\hline Innovation enhancement & High & High & High & High & High & High \\
\hline
\end{tabular}




\section{a. Accelerator Point of View}

\begin{tabular}{|l|l|l|l|}
\hline Importance & Weight & Soft goals Range \\
\hline High & 1.00 & 2.00 & 1.51 \\
\hline Medium & 0.75 & 1.50 & 1.01 \\
\hline Low & 0.25 & 1.00 & 0.00 \\
\hline
\end{tabular}

\begin{tabular}{|c|c|c|c|c|c|}
\hline Accelerator & High & Medium & Low & Subtotals & Importance \\
\hline CUSTOMER & 8.00 & 1.50 & 0.50 & 10.00 & High \\
\hline Customer engagement & 1.00 & 0.00 & 0.25 & 1.25 & High \\
\hline Customer lifetime value & 1.00 & 0.75 & 0.00 & 1.75 & High \\
\hline Customer profitability & 2.00 & 0.00 & 0.00 & 2.00 & High \\
\hline Customer retention & 1.00 & 0.75 & 0.00 & 1.75 & High \\
\hline Customer satisfaction & 2.00 & 0.00 & 0.00 & 2.00 & High \\
\hline Partnerships and external relationships & 1.00 & 0.00 & 0.25 & 1.25 & Medium \\
\hline FINANCIAL & 5.00 & 2.25 & 1.50 & 8.75 & Medium \\
\hline CAPEX and Capital Expenditure & 0.00 & 0.75 & 0.25 & 1.00 & Low \\
\hline Company valuation & 0.00 & 0.00 & 0.50 & 0.50 & Low \\
\hline Funding & 1.00 & 0.75 & 0.00 & 1.75 & High \\
\hline OPEX and Operational Expenditure & 1.00 & 0.00 & 0.25 & 1.25 & Medium \\
\hline Portfolio evaluation & 0.00 & 0.75 & 0.25 & 1.00 & Low \\
\hline Return on investment, capital, equity or assets & 1.00 & 0.00 & 0.25 & 1.25 & Medium \\
\hline Revenue, profit and margin & 2.00 & 0.00 & 0.00 & 2.00 & High \\
\hline INTERNAL BUSINESS PROCESS & 7.00 & 1.50 & 1.75 & 10.25 & Medium \\
\hline Consumables or recyclable & 0.00 & 0.00 & 0.50 & 0.50 & Low \\
\hline Marketing and Online metrics & 1.00 & 0.00 & 0.25 & 1.25 & Medium \\
\hline Operational setup and process & 0.00 & 0.75 & 0.25 & 1.00 & Low \\
\hline Patents & 0.00 & 0.00 & 0.50 & 0.50 & Low \\
\hline Products and services performance & 2.00 & 0.00 & 0.00 & 2.00 & High \\
\hline Project control and monitoring & 2.00 & 0.00 & 0.00 & 2.00 & High \\
\hline Quality level (e.g.: Six Sigma) & 2.00 & 0.00 & 0.00 & 2.00 & High \\
\hline Supply chain/fulfillment & 0.00 & 0.75 & 0.25 & 1.00 & Low \\
\hline
\end{tabular}




\begin{tabular}{|l|l|l|l|l|l|}
\hline LEARNING AND GROWTH & 8.00 & 1.50 & 0.50 & 10.00 & High \\
\hline Actual jobs, new jobs and positions retained & 1.00 & 0.00 & 0.25 & 1.25 & Medium \\
\hline Education and training & 1.00 & 0.75 & 0.00 & 1.75 & High \\
\hline Employee satisfaction and engagement & 2.00 & 0.00 & 0.00 & 2.00 & High \\
\hline Human capital value & 1.00 & 0.00 & 0.25 & 1.25 & Medium \\
\hline Innovation enhancement & 2.00 & 0.00 & 0.00 & 2.00 & High \\
\hline Technology, equipment and systems development & 1.00 & 0.75 & 0.00 & 1.75 & High \\
\hline
\end{tabular}

\section{b. Startup 1 (Commercialization) Point of View}

\begin{tabular}{|l|l|l|l|}
\hline Importance & Weight & Soft goals Range \\
\hline High & 1.00 & 1.00 & 0.76 \\
\hline Medium & 0.75 & 0.75 & 0.51 \\
\hline Low & 0.25 & 0.50 & 0.00 \\
\hline
\end{tabular}

\begin{tabular}{|c|c|c|c|c|c|}
\hline Startup 1 & High & Medium & Low & Subtotals & Importance \\
\hline$\overline{\text { CUSTOMER }}$ & 5.00 & 0.00 & 0.25 & 5.25 & High \\
\hline Customer engagement & 1.00 & 0.00 & 0.00 & 1.00 & High \\
\hline Customer lifetime value & 0.00 & 0.00 & 0.25 & 0.25 & Low \\
\hline Customer profitability & 1.00 & 0.00 & 0.00 & 1.00 & High \\
\hline Customer retention & 1.00 & 0.00 & 0.00 & 1.00 & High \\
\hline Customer satisfaction & 1.00 & 0.00 & 0.00 & 1.00 & High \\
\hline Partnerships and external relationships & 1.00 & 0.00 & 0.00 & 1.00 & High \\
\hline FINANCIAL & 1.00 & 0.75 & 1.25 & 3.00 & Low \\
\hline CAPEX and Capital Expenditure & 0.00 & 0.00 & 0.25 & 0.25 & Low \\
\hline Company valuation & 0.00 & 0.00 & 0.25 & 0.25 & Low \\
\hline Funding & 0.00 & 0.00 & 0.25 & 0.25 & Low \\
\hline OPEX and Operational Expenditure & 0.00 & 0.75 & 0.00 & 0.75 & Medium \\
\hline Portfolio evaluation & 0.00 & 0.00 & 0.25 & 0.25 & Low \\
\hline Return on investment, capital, equity or assets & 0.00 & 0.00 & 0.25 & 0.25 & Medium \\
\hline Revenue, profit and margin & 1.00 & 0.00 & 0.00 & 1.00 & High \\
\hline INTERNAL BUSINESS PROCESS & 3.00 & 0.75 & 1.00 & 4.75 & Medium \\
\hline Consumables or recyclable & 0.00 & 0.00 & 0.25 & 0.25 & Low \\
\hline Marketing and Online metrics & 1.00 & 0.00 & 0.00 & 1.00 & High \\
\hline Operational setup and process & 1.00 & 0.00 & 0.00 & 1.00 & High \\
\hline Patents & 0.00 & 0.00 & 0.25 & 0.25 & Low \\
\hline
\end{tabular}




\begin{tabular}{|l|l|l|l|l|l|}
\hline Products and services performance & 1.00 & 0.00 & 0.00 & 1.00 & High \\
\hline Project control and monitoring & 0.00 & 0.75 & 0.00 & 0.75 & Medium \\
\hline Quality level (e.g.: Six Sigma) & 0.00 & 0.00 & 0.25 & 0.25 & Low \\
\hline Supply chain/fulfillment & 0.00 & 0.00 & 0.25 & 0.25 & Low \\
\hline LEARNING AND GROWTH & 4.00 & 0.00 & 0.50 & 4.50 & High \\
\hline Actual jobs, new jobs and positions retained & 0.00 & 0.00 & 0.25 & 0.25 & Low \\
\hline Education and training & 1.00 & 0.00 & 0.00 & 1.00 & High \\
\hline Employee satisfaction and engagement & 1.00 & 0.00 & 0.00 & 1.00 & High \\
\hline Human capital value & 0.00 & 0.00 & 0.25 & 0.25 & Low \\
\hline Innovation enhancement & 1.00 & 0.00 & 0.00 & 1.00 & High \\
\hline Technology, equipment and systems development & 1.00 & 0.00 & 0.00 & 1.00 & High \\
\hline
\end{tabular}

\section{c. Startup 2 (Growth) Point of View}

\begin{tabular}{|l|l|l|l|}
\hline Importance & Weight & \multicolumn{2}{|l|}{ Soft goals Range } \\
\hline High & 1.00 & 1.00 & 0.76 \\
\hline Medium & 0.75 & 0.75 & 0.51 \\
\hline Low & 0.25 & 0.50 & 0.00 \\
\hline
\end{tabular}

\begin{tabular}{|l|l|l|l|l|l|}
\hline Startup 2 & High & Medium & Low & Subtotals & Importance \\
\hline CUSTOMER & 2.00 & 3.00 & 0.00 & 5.00 & Medium \\
\hline Customer engagement & 1.00 & 0.00 & 0.00 & 1.00 & High \\
\hline Customer lifetime value & 0.00 & 0.75 & 0.00 & 0.75 & Medium \\
\hline Customer profitability & 0.00 & 0.75 & 0.00 & 0.75 & Medium \\
\hline Customer retention & 0.00 & 0.75 & 0.00 & 0.75 & Medium \\
\hline Customer satisfaction & 1.00 & 0.00 & 0.00 & 1.00 & High \\
\hline Partnerships and external relationships & 0.00 & 0.75 & 0.00 & 0.75 & Medium \\
\hline FINANCIAL & 3.00 & 0.00 & 1.00 & 4.00 & Medium \\
\hline CAPEX and Capital Expenditure & 0.00 & 0.00 & 0.25 & 0.25 & Low \\
\hline Company valuation & 0.00 & 0.00 & 0.25 & 0.25 & Low \\
\hline Funding & 1.00 & 0.00 & 0.00 & 1.00 & High \\
\hline OPEX and Operational Expenditure & 1.00 & 0.00 & 0.00 & 1.00 & High \\
\hline Portfolio evaluation & 0.00 & 0.00 & 0.25 & 0.25 & Low \\
\hline Return on investment, capital, equity or assets & 0.00 & 0.00 & 0.25 & 0.25 & Low \\
\hline Revenue, profit and margin & 1.00 & 0.00 & 0.00 & 1.00 & High \\
\hline INTERNAL BUSINESS PROCESS & 2.00 & 1.50 & 1.00 & 4.50 & Medium \\
\hline
\end{tabular}




\begin{tabular}{|l|l|l|l|l|l|}
\hline Consumables or recyclable & 0.00 & 0.00 & 0.25 & 0.25 & Low \\
\hline Marketing and Online metrics & 1.00 & 0.00 & 0.00 & 1.00 & High \\
\hline Operational setup and process & 0.00 & 0.75 & 0.00 & 0.75 & Medium \\
\hline Patents & 0.00 & 0.00 & 0.25 & 0.25 & Low \\
\hline Products and services performance & 1.00 & 0.00 & 0.00 & 1.00 & High \\
\hline Project control and monitoring & 0.00 & 0.00 & 0.25 & 0.25 & Low \\
\hline Quality level (e.g.: Six Sigma) & 0.00 & 0.75 & 0.00 & 0.75 & Medium \\
\hline Supply chain/fulfillment & 0.00 & 0.00 & 0.25 & 0.25 & Low \\
\hline LEARNING AND GROWTH & 1.00 & 2.25 & 0.50 & 3.75 & Medium \\
\hline Actual jobs, new jobs and positions retained & 0.00 & 0.00 & 0.25 & 0.25 & Low \\
\hline Education and training & 0.00 & 0.75 & 0.00 & 0.75 & Medium \\
\hline Employee satisfaction and engagement & 0.00 & 0.75 & 0.00 & 0.75 & Medium \\
\hline Human capital value & 0.00 & 0.00 & 0.25 & 0.25 & Low \\
\hline Innovation enhancement & 1.00 & 0.00 & 0.00 & 1.00 & High \\
\hline Technology, equipment and systems development & 0.00 & 0.75 & 0.00 & 0.75 & Medium \\
\hline
\end{tabular}

\section{d. Accelerator + Startup 1 (Commercialization) Point of View}

\begin{tabular}{|l|l|l|l|}
\hline Importance & Weight & \multicolumn{2}{|l|}{ Soft goals Range } \\
\hline High & 1.00 & 3.00 & 2.26 \\
\hline Medium & 0.75 & 2.25 & 1.51 \\
\hline Low & 0.25 & 1.50 & 0.00 \\
\hline
\end{tabular}

\begin{tabular}{|l|l|l|l|l|l|}
\hline Accelerator + Startup 1 & High & Medium & Low & Subtotals & Importance \\
\hline CUSTOMER & 13.00 & 1.50 & 0.75 & 15.25 & High \\
\hline Customer engagement & 2.00 & 0.00 & 0.25 & 2.25 & High \\
\hline Customer lifetime value & 1.00 & 0.75 & 0.25 & 2.00 & Medium \\
\hline Customer profitability & 3.00 & 0.00 & 0.00 & 3.00 & High \\
\hline Customer retention & 2.00 & 0.75 & 0.00 & 2.75 & High \\
\hline Customer satisfaction & 3.00 & 0.00 & 0.00 & 3.00 & High \\
\hline Partnerships and external relationships & 2.00 & 0.00 & 0.25 & 2.25 & Medium \\
\hline FINANCIAL & 6.00 & 3.00 & 2.75 & 11.75 & Medium \\
\hline CAPEX and Capital Expenditure & 0.00 & 0.75 & 0.50 & 1.25 & Low \\
\hline Company valuation & 0.00 & 0.00 & 0.75 & 0.75 & Low \\
\hline
\end{tabular}




\begin{tabular}{|c|c|c|c|c|c|}
\hline Funding & 1.00 & 0.75 & 0.25 & 2.00 & Medium \\
\hline OPEX and Operational Expenditure & 1.00 & 0.75 & 0.25 & 2.00 & Medium \\
\hline Portfolio evaluation & 0.00 & 0.75 & 0.50 & 1.25 & Low \\
\hline Return on investment, capital, equity or assets & 1.00 & 0.00 & 0.50 & 1.50 & Low \\
\hline Revenue, profit and margin & 3.00 & 0.00 & 0.00 & 3.00 & High \\
\hline INTERNAL BUSINESS PROCESS & 10.00 & 2.25 & 2.75 & 15.00 & High \\
\hline Consumables or recyclable & 0.00 & 0.00 & 0.75 & 0.75 & Low \\
\hline Marketing and Online metrics & 2.00 & 0.00 & 0.25 & 2.25 & Medium \\
\hline Operational setup and process & 1.00 & 0.75 & 0.25 & 2.00 & Medium \\
\hline Patents & 0.00 & 0.00 & 0.75 & 0.75 & Low \\
\hline Products and services performance & 3.00 & 0.00 & 0.00 & 3.00 & High \\
\hline Project control and monitoring & 2.00 & 0.75 & 0.00 & 2.75 & High \\
\hline Quality level (e.g.: Six Sigma) & 2.00 & 0.00 & 0.25 & 2.25 & Medium \\
\hline Supply chain/fulfillment & 0.00 & 0.75 & 0.50 & 1.25 & Low \\
\hline LEARNING AND GROWTH & 12.00 & 1.50 & 1.00 & 14.50 & High \\
\hline Actual jobs, new jobs and positions retained & 1.00 & 0.00 & 0.50 & 1.50 & Low \\
\hline Education and training & 2.00 & 0.75 & 0.00 & 2.75 & High \\
\hline Employee satisfaction and engagement & 3.00 & 0.00 & 0.00 & 3.00 & High \\
\hline Human capital value & 1.00 & 0.00 & 0.50 & 1.50 & Low \\
\hline Innovation enhancement & 3.00 & 0.00 & 0.00 & 3.00 & High \\
\hline Technology, equipment and systems development & 2.00 & 0.75 & 0.00 & 2.75 & High \\
\hline
\end{tabular}

\section{e. Accelerator + Startup 2 (Growth) Point of View}

\begin{tabular}{|l|l|l|l|}
\hline Importance & Weight & Soft goals Range \\
\hline High & 1.00 & 3.00 & 2.26 \\
\hline Medium & 0.75 & 2.25 & 1.51 \\
\hline Low & 0.25 & 1.50 & 0.00 \\
\hline
\end{tabular}

\begin{tabular}{|l|l|l|l|l|l|}
\hline Accelerator + Startup 2 & High & Medium & Low & Subtotals & Importance \\
\hline CUSTOMER & 10.00 & 4.50 & 0.50 & 15.00 & High \\
\hline Customer engagement & 2.00 & 0.00 & 0.25 & 2.25 & Medium \\
\hline Customer lifetime value & 1.00 & 1.50 & 0.00 & 2.50 & High \\
\hline Customer profitability & 2.00 & 0.75 & 0.00 & 2.75 & High \\
\hline
\end{tabular}




\begin{tabular}{|c|c|c|c|c|c|}
\hline Customer retention & 1.00 & 1.50 & 0.00 & 2.50 & High \\
\hline Customer satisfaction & 3.00 & 0.00 & 0.00 & 3.00 & High \\
\hline Partnerships and external relationships & 1.00 & 0.75 & 0.25 & 2.00 & Medium \\
\hline FINANCIAL & 8.00 & 2.25 & 2.50 & 12.75 & Medium \\
\hline CAPEX and Capital Expenditure & 0.00 & 0.75 & 0.50 & 1.25 & Low \\
\hline Company valuation & 0.00 & 0.00 & 0.75 & 0.75 & Low \\
\hline Funding & 2.00 & 0.75 & 0.00 & 2.75 & High \\
\hline OPEX and Operational Expenditure & 2.00 & 0.00 & 0.25 & 2.25 & Medium \\
\hline Portfolio evaluation & 0.00 & 0.75 & 0.50 & 1.25 & Low \\
\hline Return on investment, capital, equity or assets & 1.00 & 0.00 & 0.50 & 1.50 & Low \\
\hline Revenue, profit and margin & 3.00 & 0.00 & 0.00 & 3.00 & High \\
\hline INTERNAL BUSINESS PROCESS & 9.00 & 3.00 & 2.75 & 14.75 & Medium \\
\hline Consumables or recyclable & 0.00 & 0.00 & 0.75 & 0.75 & Low \\
\hline Marketing and Online metrics & 2.00 & 0.00 & 0.25 & 2.25 & Medium \\
\hline Operational setup and process & 0.00 & 1.50 & 0.25 & 1.75 & Medium \\
\hline Patents & 0.00 & 0.00 & 0.75 & 0.75 & Low \\
\hline Products and services performance & 3.00 & 0.00 & 0.00 & 3.00 & HIgh \\
\hline Project control and monitoring & 2.00 & 0.00 & 0.25 & 2.25 & Medium \\
\hline Quality level (e.g.: Six Sigma) & 2.00 & 0.75 & 0.00 & 2.75 & High \\
\hline Supply chain/fulfillment & 0.00 & 0.75 & 0.50 & 1.25 & Low \\
\hline LEARNING AND GROWTH & 9.00 & 3.75 & 1.00 & 13.75 & HIgh \\
\hline Actual jobs, new jobs and positions retained & 1.00 & 0.00 & 0.50 & 1.50 & Low \\
\hline Education and training & 1.00 & 1.50 & 0.00 & 2.50 & High \\
\hline Employee satisfaction and engagement & 2.00 & 0.75 & 0.00 & 2.75 & High \\
\hline Human capital value & 1.00 & 0.00 & 0.50 & 1.50 & Low \\
\hline Innovation enhancement & 3.00 & 0.00 & 0.00 & 3.00 & High \\
\hline Technology, equipment and systems development & 1.00 & 1.50 & 0.00 & 2.50 & High \\
\hline
\end{tabular}

\section{f. Accelerator + Startup 1 (Commercialization) + Startup 2 (Growth) Point}

\section{of View}

\begin{tabular}{|l|l|l|l|}
\hline Importance & Weight & \multicolumn{2}{|l|}{ Soft goals Range } \\
\hline High & 1.00 & 3.00 & 2.26 \\
\hline Medium & 0.75 & 2.25 & 1.51 \\
\hline Low & 0.25 & 1.50 & 0.00 \\
\hline
\end{tabular}




\begin{tabular}{|c|c|c|c|c|c|}
\hline Accelerator + Startup $1+$ Startup 2 & High & Medium & Low & Subtotals & Importance \\
\hline CUSTOMER & 15.00 & 4.50 & 0.75 & 20.25 & High \\
\hline Customer engagement & 3.00 & 0.00 & 0.25 & 3.25 & High \\
\hline Customer lifetime value & 1.00 & 1.50 & 0.25 & 2.75 & Medium \\
\hline Customer profitability & 3.00 & 0.75 & 0.00 & 3.75 & High \\
\hline Customer retention & 2.00 & 1.50 & 0.00 & 3.50 & High \\
\hline Customer satisfaction & 4.00 & 0.00 & 0.00 & 4.00 & High \\
\hline Partnerships and external relationships & 2.00 & 0.75 & 0.25 & 3.00 & Medium \\
\hline FINANCIAL & 9.00 & 3.00 & 3.75 & 15.75 & Medium \\
\hline CAPEX and Capital Expenditure & 0.00 & 0.75 & 0.75 & 1.50 & Low \\
\hline Company valuation & 0.00 & 0.00 & 1.00 & 1.00 & Low \\
\hline Funding & 2.00 & 0.75 & 0.25 & 3.00 & Medium \\
\hline OPEX and Operational Expenditure & 2.00 & 0.75 & 0.25 & 3.00 & Medium \\
\hline Portfolio evaluation & 0.00 & 0.75 & 0.75 & 1.50 & Low \\
\hline Return on investment, capital, equity or assets & 1.00 & 0.00 & 0.75 & 1.75 & Low \\
\hline Revenue, profit and margin & 4.00 & 0.00 & 0.00 & 4.00 & High \\
\hline INTERNAL BUSINESS PROCESS & 12.00 & 3.75 & 3.75 & 19.50 & Medium \\
\hline Consumables or recyclable & 0.00 & 0.00 & 1.00 & 1.00 & Low \\
\hline Marketing and Online metrics & 3.00 & 0.00 & 0.25 & 3.25 & High \\
\hline Operational setup and process & 1.00 & 1.50 & 0.25 & 2.75 & Medium \\
\hline Patents & 0.00 & 0.00 & 1.00 & 1.00 & Low \\
\hline Products and services performance & 4.00 & 0.00 & 0.00 & 4.00 & High \\
\hline Project control and monitoring & 2.00 & 0.75 & 0.25 & 3.00 & Medium \\
\hline Quality level (e.g.: Six Sigma) & 2.00 & 0.75 & 0.25 & 3.00 & Medium \\
\hline Supply chain/fulfillment & 0.00 & 0.75 & 0.75 & 1.50 & Low \\
\hline LEARNING AND GROWTH & 13.00 & 3.75 & 1.50 & 18.25 & High \\
\hline Actual jobs, new jobs and positions retained & 1.00 & 0.00 & 0.75 & 1.75 & Low \\
\hline Education and training & 2.00 & 1.50 & 0.00 & 3.50 & High \\
\hline Employee satisfaction and engagement & 3.00 & 0.75 & 0.00 & 3.75 & High \\
\hline Human capital value & 1.00 & 0.00 & 0.75 & 1.75 & Low \\
\hline Innovation enhancement & 4.00 & 0.00 & 0.00 & 4.00 & High \\
\hline Technology, equipment and systems development & 2.00 & 1.50 & 0.00 & 3.50 & High \\
\hline
\end{tabular}

\section{Soft Goals - Responsibility}




\section{a. Accelerator Point of View}

Legend: A - Accelerator; S - Startup; SH - Stakeholder

\begin{tabular}{|c|c|c|c|c|c|c|c|c|c|c|c|c|}
\hline \multirow{2}{*}{$\begin{array}{l}\text { Point of view } \\
\text { ACCELERATOR }\end{array}$} & \multicolumn{3}{|c|}{ Responsible } & \multicolumn{3}{|c|}{ Accountable } & \multicolumn{3}{|c|}{ Consulted } & \multicolumn{3}{|c|}{ Informed } \\
\hline & $\mathrm{A}$ & $\mathrm{S}$ & $\mathrm{SH}$ & $\bar{A}$ & $\mathrm{~S}$ & $\mathrm{SH}$ & $\bar{A}$ & $\mathrm{~S}$ & $\mathrm{SH}$ & $\mathrm{A}$ & $\overline{\mathrm{S}}$ & $\overline{\mathrm{SH}}$ \\
\hline CUSTOMER & 12 & 6 & & & & & & & & 2 & & \\
\hline Customer engagement & 2 & 1 & & & & & & & & & & \\
\hline Customer lifetime value & 2 & 1 & & & & & & & & & & \\
\hline Customer profitability & 2 & 1 & & & & & & & & 1 & & \\
\hline Customer retention & 2 & 1 & & & & & & & & & & \\
\hline Customer satisfaction & 2 & 1 & & & & & & & & 1 & & \\
\hline Partnerships and external relationships & 2 & 1 & & & & & & & & & & \\
\hline FINANCIAL & 7 & 4 & & 1 & 1 & & 2 & & & 2 & & \\
\hline CAPEX and Capital Expenditure & 1 & 1 & & & & & & & & & & \\
\hline Company valuation & 1 & & & & & & 1 & & & & & \\
\hline Funding & 1 & 1 & & & & & & & & 1 & & \\
\hline OPEX and Operational Expenditure & 1 & 1 & & & & & & & & & & \\
\hline Portfolio evaluation & 1 & & & & & & 1 & & & & & \\
\hline Return on investment, capital, equity or assets & 1 & & & 1 & & & & & & & & \\
\hline Revenue, profit and margin & 1 & 1 & & & 1 & & & & & 1 & & \\
\hline INTERNAL BUSINESS PROCESS & 11 & 3 & & 2 & 1 & & 1 & & & 2 & 2 & \\
\hline Consumables or recyclable & 1 & 1 & & & 1 & & 1 & & & & 1 & \\
\hline Marketing and Online metrics & 1 & & & 1 & 1 & & & & & & 1 & \\
\hline Operational setup and process & 2 & 1 & & & 1 & & & & & & & \\
\hline Patents & 1 & 1 & & & 1 & & & & & 1 & & \\
\hline Products and services performance & 1 & & & & 2 & & & & & 1 & & \\
\hline Project control and monitoring & 1 & & & 1 & 1 & & & & & & & \\
\hline Quality level (e.g.: Six Sigma) & 2 & & & & 1 & & & & & & & \\
\hline Supply chain/fulfillment & 2 & & & & 2 & & & & & & & \\
\hline LEARNING AND GROWTH & 6 & 2 & & & 4 & 1 & 3 & & & 3 & $\overline{6}$ & 1 \\
\hline Actual jobs, new jobs and positions retained & 1 & & & & 1 & & & & & 1 & 1 & \\
\hline Education and training & 1 & 1 & & & & 1 & 1 & & & & 1 & 1 \\
\hline Employee satisfaction and engagement & 1 & 1 & & & & & 1 & & & & 1 & \\
\hline Human capital value & 1 & & & & 1 & & & & & 1 & 1 & \\
\hline Innovation enhancement & 1 & & & & 1 & & & & & 1 & 1 & \\
\hline Technology, equipment and systems development & 1 & & & & 1 & & 1 & & & & 1 & \\
\hline
\end{tabular}

\section{b. Startup 1 (Commercialization) Point of View}


Legend: A - Accelerator; S - Startup; SH - Stakeholder

\begin{tabular}{|c|c|c|c|c|c|c|c|c|c|c|c|c|}
\hline \multirow{2}{*}{$\begin{array}{l}\text { Point of view } \\
\text { Startup } 1\end{array}$} & \multicolumn{3}{|c|}{ Responsible } & \multicolumn{3}{|c|}{ Accountable } & \multicolumn{3}{|c|}{ Consulted } & \multicolumn{3}{|c|}{ Informed } \\
\hline & $\mathrm{A}$ & $\mathrm{S}$ & $\overline{\mathrm{SH}}$ & $\mathrm{A}$ & $\mathrm{S}$ & $\mathrm{SH}$ & $\mathrm{A}$ & $\mathrm{S}$ & $\mathrm{SH}$ & $\bar{A}$ & $\mathrm{~S}$ & $\overline{\mathrm{SH}}$ \\
\hline CUSTOMER & & 1 & & & 5 & 1 & & & & 1 & & \\
\hline Customer engagement & & & & & 1 & & & & & & & \\
\hline Customer lifetime value & & & & & 1 & & & & & & & \\
\hline Customer profitability & & & & & 1 & & & & & 1 & & \\
\hline Customer retention & & & & & 1 & & & & & & & \\
\hline Customer satisfaction & & & & & 1 & & & & & & & \\
\hline Partnerships and external relationships & & 1 & & & & 1 & & & & & & \\
\hline FINANCIAL & & 6 & & & 1 & & & & & 6 & & 1 \\
\hline CAPEX and Capital Expenditure & & 1 & & & & & & & & 1 & & \\
\hline Company valuation & & 1 & & & & & & & & 1 & & \\
\hline Funding & & 1 & & & & & & & & 1 & & \\
\hline OPEX and Operational Expenditure & & 1 & & & & & & & & 1 & & \\
\hline Portfolio evaluation & & 1 & & & & & & & & & & 1 \\
\hline Return on investment, capital, equity or assets & & 1 & & & & & & & & 1 & & \\
\hline Revenue, profit and margin & & & & & 1 & & & & & 1 & & \\
\hline INTERNAL BUSINESS PROCESS & & & & & 8 & & & & & 2 & & \\
\hline Consumables or recyclable & & & & & 1 & & & & & & & \\
\hline Marketing and Online metrics & & & & & 1 & & & & & & & \\
\hline Operational setup and process & & & & & 1 & & & & & & & \\
\hline Patents & & & & & 1 & & & & & 1 & & \\
\hline Products and services performance & & & & & 1 & & & & & 1 & & \\
\hline Project control and monitoring & & & & & 1 & & & & & & & \\
\hline Quality level (e.g.: Six Sigma) & & & & & 1 & & & & & & & \\
\hline Supply chain/fulfillment & & & & & 1 & & & & & & & \\
\hline LEARNING AND GROWTH & & 3 & & & 3 & & 3 & & 3 & 2 & & \\
\hline Actual jobs, new jobs and positions retained & & & & & 1 & & & & & & & \\
\hline Education and training & & 1 & & & & & 1 & & 1 & & & \\
\hline Employee satisfaction and engagement & & & & & 1 & & & & & 1 & & \\
\hline Human capital value & & & & & 1 & & & & & 1 & & \\
\hline Innovation enhancement & & 1 & & & & & 1 & & 1 & & & \\
\hline Technology, equipment and systems development & & 1 & & & & & 1 & & 1 & & & \\
\hline
\end{tabular}

\section{c. Startup 2 (Growth) Point of View}

Legend: A - Accelerator; S - Startup; SH - Stakeholder

\begin{tabular}{|l|l|l|l|l|}
\hline Point of view & Responsible & Accountable & Consulted & Informed \\
\hline
\end{tabular}




\begin{tabular}{|c|c|c|c|c|c|c|c|c|c|c|c|c|}
\hline Startup 2 & $\mathrm{~A}$ & $\bar{S}$ & $\mathrm{SH}$ & $\bar{A}$ & $\mathrm{~S}$ & $\overline{\mathrm{SH}}$ & $\bar{A}$ & $\bar{S}$ & $\mathrm{SH}$ & $\mathrm{A}$ & $\mathrm{S}$ & $\mathrm{SH}$ \\
\hline CUSTOMER & & 6 & & & & & 3 & & & 3 & & \\
\hline Customer engagement & & 1 & & & & & & & & 1 & & \\
\hline Customer lifetime value & & 1 & & & & & 1 & & & & & \\
\hline Customer profitability & & 1 & & & & & & & & 1 & & \\
\hline Customer retention & & 1 & & & & & 1 & & & & & \\
\hline Customer satisfaction & & 1 & & & & & & & & 1 & & \\
\hline Partnerships and external relationships & & 1 & & & & & 1 & & & & & \\
\hline FINANCIAL & 2 & 3 & & & 3 & & & 1 & & 2 & & \\
\hline CAPEX and Capital Expenditure & & & & & 1 & & & & & & & \\
\hline Company valuation & & & & & 1 & & & & & 1 & & \\
\hline Funding & & 1 & & & & & & & & 1 & & \\
\hline OPEX and Operational Expenditure & & 1 & & & & & & & & & & \\
\hline Portfolio evaluation & 1 & & & & & & & 1 & & & & \\
\hline Return on investment, capital, equity or assets & 1 & & & & 1 & & & & & & & \\
\hline Revenue, profit and margin & & 1 & & & & & & & & & & \\
\hline INTERNAL BUSINESS PROCESS & & 8 & & & & & 3 & & & 1 & & \\
\hline Consumables or recyclable & & 1 & & & & & & & & & & \\
\hline Marketing and Online metrics & & 1 & & & & & 1 & & & & & \\
\hline Operational setup and process & & 1 & & & & & & & & & & \\
\hline Patents & & 1 & & & & & 1 & & & & & \\
\hline Products and services performance & & 1 & & & & & & & & 1 & & \\
\hline Project control and monitoring & & 1 & & & & & & & & & & \\
\hline Quality level (e.g.: Six Sigma) & & 1 & & & & & 1 & & & & & \\
\hline Supply chain/fulfillment & & 1 & & & & & & & & & & \\
\hline LEARNING AND GROWTH & & 6 & & & & & 1 & & 1 & 5 & & \\
\hline Actual jobs, new jobs and positions retained & & $\overline{1}$ & & & & & & & & 1 & & \\
\hline Education and training & & 1 & & & & & 1 & & & & & \\
\hline Employee satisfaction and engagement & & 1 & & & & & & & & 1 & & \\
\hline Human capital value & & 1 & & & & & & & & 1 & & \\
\hline Innovation enhancement & & 1 & & & & & & & & 1 & & \\
\hline Technology, equipment and systems development & & 1 & & & & & & & 1 & 1 & & \\
\hline
\end{tabular}

\section{d. Accelerator + Startup 1 (Commercialization) Point of View}

Legend: A - Accelerator; S - Startup; SH - Stakeholder

\begin{tabular}{|l|c|c|c|c|c|c|c|c|c|c|c|c|}
\hline Point of view & \multicolumn{3}{|c|}{ Responsible } & \multicolumn{3}{|c|}{ Accountable } & \multicolumn{3}{|c|}{ Consulted } & \multicolumn{3}{|c|}{ Informed } \\
\hline Accelerator + Startup 1 & A & S & SH & A & S & SH & A & S & SH & A & S & SH \\
\hline CUSTOMER & 12 & 7 & & & 5 & 1 & & & & 3 & & \\
\hline
\end{tabular}






\section{e. Accelerator + Startup 2 (Commercialization) Point of View}

Legend: A - Accelerator; S - Startup; SH - Stakeholder

\begin{tabular}{|l|c|c|c|c|c|c|c|c|c|c|c|c|}
\hline Point of view & \multicolumn{3}{|c|}{ Responsible } & \multicolumn{3}{|c|}{ Accountable } & \multicolumn{3}{|c|}{ Consulted } & \multicolumn{3}{c|}{ Informed } \\
\hline Startup 1 & A & S & SH & A & S & SH & A & S & SH & A & S & SH \\
\hline CUSTOMER & 12 & 12 & & & & & 3 & & & 5 & & \\
\hline Customer engagement & 2 & 2 & & & & & & & & 1 & & \\
\hline
\end{tabular}




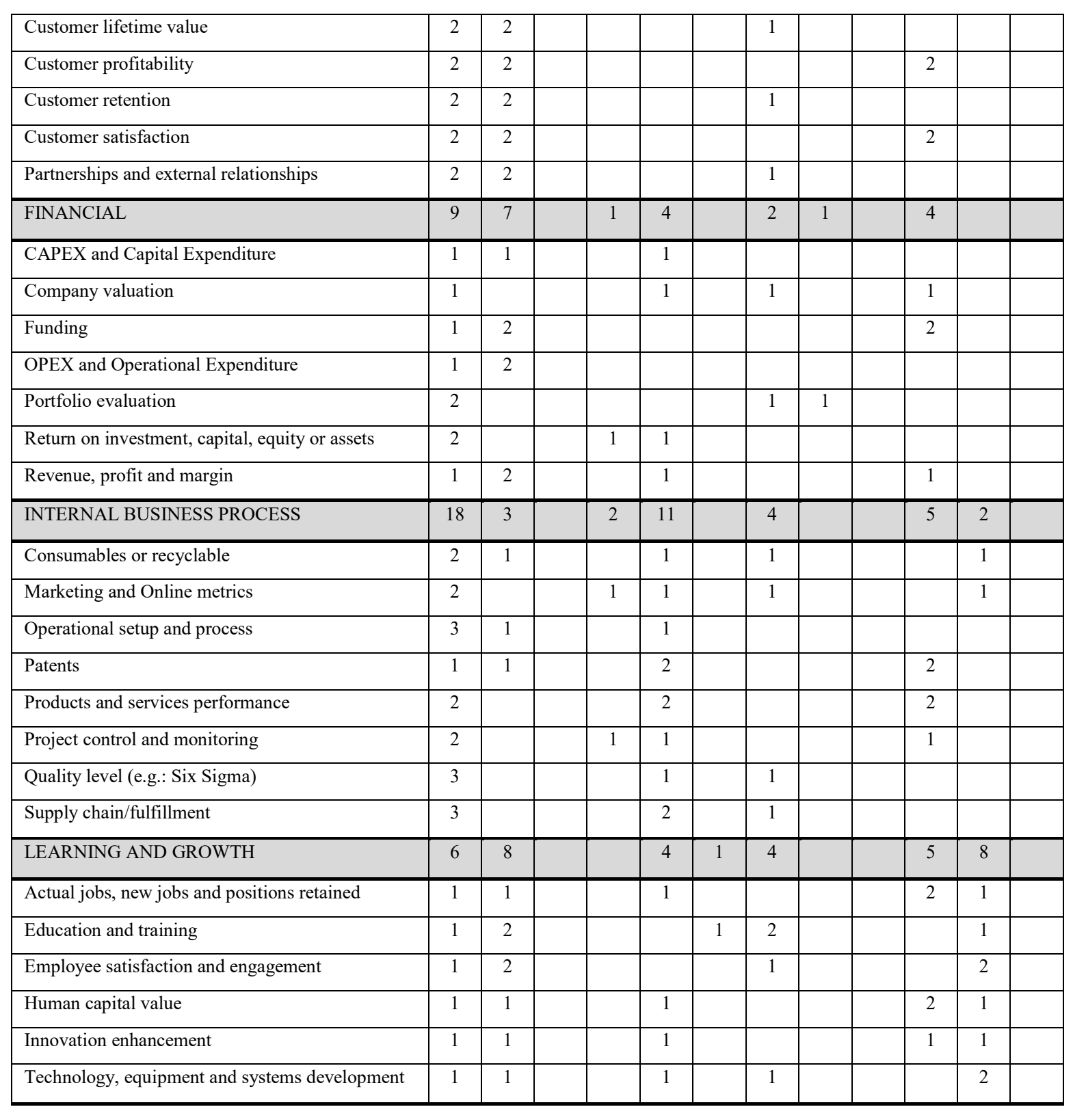




\section{Appendix C - Interview design}

1. Interview Design

The table below includes the main steps of the interview process that should be followed by the researcher.

\begin{tabular}{ll}
\hline Opening: & $\begin{array}{l}\text { Stablish rapport, shake hands, and introduce myself. } \\
\text { "Hello! My name is "xxxx", and I would like to ask you } \\
\text { some questions today about your company goals, } \\
\text { metrics and KPIs." }\end{array}$ \\
\hline Introduce the research & $\begin{array}{l}\text { Clarify the research objective, the research method and } \\
\text { which deliverables are expected with the thesis. }\end{array}$
\end{tabular}

Sign in the Consent Form The researcher must ask the interviewee signature in the Consent Form document before starting the interview.

Fill "ID" and "Date"
$\begin{aligned} & \text { The researcher must fill the interviewee's "ID Code" and } \\ & \text { "Dields } \\ & \text { should take about one hour. }\end{aligned}$
Explain the logical As in a brainstorm, the interview should be used to sequence of the interview identify Soft Goals, Goals, Tasks and KPIs for each balanced scorecard perspective researched.
The body of the interview Put the Goal to KPI Canvas, sticky notes, the KPI reference card, and pens on the table and start the interview. The interviewer would drive the interviewee in the construction of the model for each BSC perspective.

KPI Reference List - As examples, a short list of KPIs was provided for the interviewee.

During the interview, the interviewer might take notes using pen and paper, and a summary of the notes are going to be stored in the Qualtrics software after the interview meeting. The paper notes will be destroyed instantly after the summary was done.

After had passed for all perspectives, the researcher shall double-check the responses, and insert the collected information in Qualtrics for further analysis.

After finishing the interview questions, the researcher might check if the interviewee needs to clarify any topic, 
or perhaps if he/she has any question or doubt.

\section{Close the interview}

Finally, the researcher shall say how useful the interview was to his thesis and briefly summarize the information that he has collected during our interview.

The information collected in the interviews was organized and stored in Qualtrics. The questionnaire below was developed to promote flexibility in the author's analysis:

ID Code:

Date $(\mathrm{mm} / \mathrm{dd} / \mathrm{yy})$

Type of the company

Accelerator

Startup 1 - COMMERCIALIZATION stage

Startup 2 GROWTH stage

What is your role in the accelerator or startup company?

C-Level

Director

Manager

SOFT GOALS in the CUSTOMER Perspective 


\begin{tabular}{|c|c|c|c|c|c|c|}
\hline & & & & Responsibility & Responsibility & Stakeholder \\
\hline & High & Medium & Low & & & \\
\hline $\begin{array}{c}\text { Customer } \\
\text { profitability (1) }\end{array}$ & & & & $\begin{array}{c}\boldsymbol{\nabla} \\
\text { Responsible; } \\
\text { Accountable; } \\
\text { Consulted; } \\
\text { Informed }\end{array}$ & $\begin{array}{c}\boldsymbol{\nabla} \\
\text { Responsible; } \\
\text { Accountable; } \\
\text { Consulted; } \\
\text { Informed }\end{array}$ & $\begin{array}{c}\boldsymbol{\nabla} \\
\text { Responsible; } \\
\text { Accountable; } \\
\text { Consulted; } \\
\text { Informed }\end{array}$ \\
\hline $\begin{array}{c}\text { Customer } \\
\text { lifetime value } \\
\text { (2) }\end{array}$ & & & & $\begin{array}{c}\boldsymbol{\nabla} \\
\text { Responsible; } \\
\text { Accountable; } \\
\text { Consulted; } \\
\text { Informed }\end{array}$ & $\begin{array}{c}\boldsymbol{\nabla} \\
\text { Responsible; } \\
\text { Accountable; } \\
\text { Consulted; } \\
\text { Informed }\end{array}$ & $\begin{array}{c}\boldsymbol{\nabla} \\
\text { Responsible; } \\
\text { Accountable; } \\
\text { Consulted; } \\
\text { Informed }\end{array}$ \\
\hline $\begin{array}{c}\text { Customer } \\
\text { retention (3) }\end{array}$ & & & & $\begin{array}{c}\boldsymbol{\nabla} \\
\text { Responsible; } \\
\text { Accountable; } \\
\text { Consulted; } \\
\text { Informed }\end{array}$ & $\begin{array}{c}\boldsymbol{\nabla} \\
\text { Responsible; } \\
\text { Accountable; } \\
\text { Consulted; } \\
\text { Informed }\end{array}$ & $\begin{array}{c}\boldsymbol{\nabla} \\
\text { Responsible; } \\
\text { Accountable; } \\
\text { Consulted; } \\
\text { Informed }\end{array}$ \\
\hline $\begin{array}{c}\text { Customer } \\
\text { engagement (4) }\end{array}$ & & & & $\begin{array}{c}\boldsymbol{\nabla} \\
\text { Responsible; } \\
\text { Accountable; } \\
\text { Consulted; } \\
\text { Informed }\end{array}$ & $\begin{array}{c}\boldsymbol{\nabla} \\
\text { Responsible; } \\
\text { Accountable; } \\
\text { Consulted; } \\
\text { Informed }\end{array}$ & $\begin{array}{c}\boldsymbol{\nabla} \\
\text { Responsible; } \\
\text { Accountable; } \\
\text { Consulted; } \\
\text { Informed }\end{array}$ \\
\hline $\begin{array}{c}\text { Customer } \\
\text { satisfaction (5) }\end{array}$ & & & & $\begin{array}{c}\boldsymbol{\nabla} \\
\text { Responsible; } \\
\text { Accountable; } \\
\text { Consulted; } \\
\text { Informed }\end{array}$ & $\begin{array}{c}\boldsymbol{\nabla} \\
\text { Responsible; } \\
\text { Accountable; } \\
\text { Consulted; } \\
\text { Informed }\end{array}$ & $\begin{array}{c}\boldsymbol{\nabla} \\
\text { Responsible; } \\
\text { Accountable; } \\
\text { Consulted; } \\
\text { Informed }\end{array}$ \\
\hline $\begin{array}{c}\text { Partnerships } \\
\text { and external } \\
\text { relationships } \\
\text { (6) }\end{array}$ & & & & $\begin{array}{c}\boldsymbol{\nabla} \\
\text { Responsible; } \\
\text { Accountable; } \\
\text { Consulted; } \\
\text { Informed }\end{array}$ & $\begin{array}{c}\boldsymbol{\nabla} \\
\text { Responsible; } \\
\text { Accountable; } \\
\text { Consulted; } \\
\text { Informed }\end{array}$ & $\begin{array}{c}\boldsymbol{\nabla} \\
\text { Responsible; } \\
\text { Accountable; } \\
\text { Consulted; } \\
\text { Informed }\end{array}$ \\
\hline
\end{tabular}

GOALs identified in the CUSTOMER Perspective

SOFT GOALS in the FINANCIAL Perspective

\begin{tabular}{|c|c|c|c|c|c|c|}
\hline & \multicolumn{3}{|c|}{ Importance } & $\begin{array}{c}\text { Accelerator } \\
\text { Responsibility }\end{array}$ & $\begin{array}{c}\text { Startup } \\
\text { Responsibility }\end{array}$ & $\begin{array}{c}\text { Another } \\
\text { Stakeholder }\end{array}$ \\
\hline & High & Medium & Low & & & \\
\hline $\begin{array}{l}\text { Revenue, profit } \\
\text { and margin ( } 7 \text { ) }\end{array}$ & & & & $\begin{array}{c}\boldsymbol{\nabla} \\
\text { Responsible; } \\
\text { Accountable; } \\
\text { Consulted; } \\
\text { Informed }\end{array}$ & $\begin{array}{c}\boldsymbol{\nabla} \\
\text { Responsible; } \\
\text { Accountable; } \\
\text { Consulted; } \\
\text { Informed }\end{array}$ & $\begin{array}{c}\boldsymbol{\nabla} \\
\text { Responsible; } \\
\text { Accountable; } \\
\text { Consulted; } \\
\text { Informed }\end{array}$ \\
\hline $\begin{array}{c}\text { Return on } \\
\text { investment, } \\
\text { capital, equity }\end{array}$ & & & & $\begin{array}{c}\boldsymbol{\nabla} \\
\text { Responsible; } \\
\text { Accountable; }\end{array}$ & $\begin{array}{c}\quad \boldsymbol{\nabla} \\
\text { Responsible; } \\
\text { Accountable; }\end{array}$ & $\begin{array}{c}\boldsymbol{\nabla} \\
\text { Responsible; } \\
\text { Accountable; }\end{array}$ \\
\hline
\end{tabular}




\begin{tabular}{|c|c|c|c|}
\hline or assets (8) & $\begin{array}{l}\text { Consulted; } \\
\text { Informed }\end{array}$ & $\begin{array}{l}\text { Consulted; } \\
\text { Informed }\end{array}$ & $\begin{array}{l}\text { Consulted; } \\
\text { Informed }\end{array}$ \\
\hline $\begin{array}{c}\text { CAPEX - } \\
\text { Capital } \\
\text { Expenditure (9) }\end{array}$ & $\begin{array}{c}\boldsymbol{\nabla} \\
\text { Responsible; } \\
\text { Accountable; } \\
\text { Consulted; } \\
\text { Informed }\end{array}$ & $\begin{array}{c}\boldsymbol{\nabla} \\
\text { Responsible; } \\
\text { Accountable; } \\
\text { Consulted; } \\
\text { Informed }\end{array}$ & $\begin{array}{c}\boldsymbol{\nabla} \\
\text { Responsible; } \\
\text { Accountable; } \\
\text { Consulted; } \\
\text { Informed }\end{array}$ \\
\hline $\begin{array}{c}\text { OPEX - } \\
\text { Operational } \\
\text { Expenditure } \\
(10)\end{array}$ & $\begin{array}{c}\boldsymbol{\nabla} \\
\text { Responsible; } \\
\text { Accountable; } \\
\text { Consulted; } \\
\text { Informed }\end{array}$ & $\begin{array}{c}\boldsymbol{\nabla} \\
\text { Responsible; } \\
\text { Accountable; } \\
\text { Consulted; } \\
\text { Informed }\end{array}$ & $\begin{array}{c}\boldsymbol{\nabla} \\
\text { Responsible; } \\
\text { Accountable; } \\
\text { Consulted; } \\
\text { Informed }\end{array}$ \\
\hline Funding (11) & $\begin{array}{c}\boldsymbol{\nabla} \\
\text { Responsible; } \\
\text { Accountable; } \\
\text { Consulted; } \\
\text { Informed }\end{array}$ & $\begin{array}{c}\boldsymbol{\nabla} \\
\text { Responsible; } \\
\text { Accountable; } \\
\text { Consulted; } \\
\text { Informed }\end{array}$ & $\begin{array}{c}\boldsymbol{\nabla} \\
\text { Responsible; } \\
\text { Accountable; } \\
\text { Consulted; } \\
\text { Informed }\end{array}$ \\
\hline $\begin{array}{c}\text { Company } \\
\text { valuation (12) }\end{array}$ & $\begin{array}{c}\boldsymbol{\nabla} \\
\text { Responsible; } \\
\text { Accountable; } \\
\text { Consulted; } \\
\text { Informed }\end{array}$ & $\begin{array}{c}\boldsymbol{\nabla} \\
\text { Responsible; } \\
\text { Accountable; } \\
\text { Consulted; } \\
\text { Informed }\end{array}$ & $\begin{array}{c}\boldsymbol{\nabla} \\
\text { Responsible; } \\
\text { Accountable; } \\
\text { Consulted; } \\
\text { Informed }\end{array}$ \\
\hline $\begin{array}{c}\text { Portfolio } \\
\text { evaluation (13) }\end{array}$ & $\begin{array}{c}\boldsymbol{\nabla} \\
\text { Responsible; } \\
\text { Accountable; } \\
\text { Consulted; } \\
\text { Informed }\end{array}$ & $\begin{array}{c}\boldsymbol{\nabla} \\
\text { Responsible; } \\
\text { Accountable; } \\
\text { Consulted; } \\
\text { Informed }\end{array}$ & $\begin{array}{c}\boldsymbol{\nabla} \\
\text { Responsible; } \\
\text { Accountable; } \\
\text { Consulted; } \\
\text { Informed }\end{array}$ \\
\hline
\end{tabular}

GOALs identified in the FINANCIAL Perspective

SOFT GOALS in the INTERNAL BUSINESS PROCESS Perspective

\begin{tabular}{|c|c|c|c|c|c|c|}
\hline & \multicolumn{3}{|c|}{ Importance } & $\begin{array}{l}\text { Accelerator } \\
\text { Responsibility }\end{array}$ & $\begin{array}{c}\text { Startup } \\
\text { Responsibility }\end{array}$ & $\begin{array}{c}\text { Another } \\
\text { Stakeholder }\end{array}$ \\
\hline & High & Medium & Low & & & \\
\hline $\begin{array}{l}\text { Quality level } \\
\text { (e.g.: Six } \\
\text { Sigma) (14) }\end{array}$ & & & & $\begin{array}{c}\boldsymbol{\nabla} \\
\text { Responsible; } \\
\text { Accountable; } \\
\text { Consulted; } \\
\text { Informed }\end{array}$ & $\begin{array}{c}\boldsymbol{\nabla} \\
\text { Responsible; } \\
\text { Accountable; } \\
\text { Consulted; } \\
\text { Informed }\end{array}$ & $\begin{array}{c}\boldsymbol{\nabla} \\
\text { Responsible; } \\
\text { Accountable; } \\
\text { Consulted; } \\
\text { Informed }\end{array}$ \\
\hline $\begin{array}{c}\text { Supply } \\
\text { chain/fulfillment } \\
\text { (15) }\end{array}$ & & & & $\begin{array}{c}\boldsymbol{\nabla} \\
\text { Responsible; } \\
\text { Accountable; } \\
\text { Consulted; } \\
\text { Informed }\end{array}$ & $\begin{array}{c}\boldsymbol{\nabla} \\
\text { Responsible; } \\
\text { Accountable; } \\
\text { Consulted; } \\
\text { Informed }\end{array}$ & $\begin{array}{c}\boldsymbol{\nabla} \\
\text { Responsible; } \\
\text { Accountable; } \\
\text { Consulted; } \\
\text { Informed }\end{array}$ \\
\hline $\begin{array}{l}\text { Project control } \\
\text { and monitoring } \\
\text { (16) }\end{array}$ & & & & $\begin{array}{c}\boldsymbol{\nabla} \\
\text { Responsible; } \\
\text { Accountable; }\end{array}$ & $\begin{array}{l}\quad \boldsymbol{\nabla} \\
\text { Responsible; } \\
\text { Accountable; }\end{array}$ & $\begin{array}{c}\boldsymbol{\nabla} \\
\text { Responsible; } \\
\text { Accountable; }\end{array}$ \\
\hline
\end{tabular}






GOALs identified in the INTERNAL BUSINESS PROCESS Perspective

SOFT GOALS in the LEARNING AND GROWTH Perspective

\begin{tabular}{|c|c|c|c|c|c|c|}
\hline & \multicolumn{3}{|c|}{ Importance } & $\begin{array}{c}\text { Accelerator } \\
\text { Responsibility }\end{array}$ & $\begin{array}{c}\text { Startup } \\
\text { Responsibility }\end{array}$ & $\begin{array}{c}\text { Another } \\
\text { Stakeholder }\end{array}$ \\
\hline & High & Medium & Low & & & \\
\hline $\begin{array}{l}\text { Education and } \\
\text { training (22) }\end{array}$ & & & & $\begin{array}{c}\boldsymbol{\nabla} \\
\text { Responsible; } \\
\text { Accountable; } \\
\text { Consulted; } \\
\text { Informed }\end{array}$ & $\begin{array}{c}\boldsymbol{\nabla} \\
\text { Responsible; } \\
\text { Accountable; } \\
\text { Consulted; } \\
\text { Informed }\end{array}$ & $\begin{array}{c}\boldsymbol{\nabla} \\
\text { Responsible; } \\
\text { Accountable; } \\
\text { Consulted; } \\
\text { Informed }\end{array}$ \\
\hline $\begin{array}{l}\text { Technology, } \\
\text { equipment and } \\
\text { systems } \\
\text { development } \\
\text { (23) }\end{array}$ & & & & $\begin{array}{c}\boldsymbol{\nabla} \\
\text { Responsible; } \\
\text { Accountable; } \\
\text { Consulted; } \\
\text { Informed }\end{array}$ & $\begin{array}{c}\boldsymbol{\nabla} \\
\text { Responsible; } \\
\text { Accountable; } \\
\text { Consulted; } \\
\text { Informed }\end{array}$ & $\begin{array}{c}\boldsymbol{\nabla} \\
\text { Responsible; } \\
\text { Accountable; } \\
\text { Consulted; } \\
\text { Informed }\end{array}$ \\
\hline
\end{tabular}






GOALs identified in the LEARNING AND GROWTH Perspective 